$$
\text { DR. } 1145: 2
$$

\title{
CHARACTERIZATION OF RETENTION PROCESSES AND THEIR EFFECT ON THE ANALYSIS OF TRACER TESTS IN FRACTURED RESERVOIRS
}

Gardner W. Walkup, Jr.

$$
\begin{aligned}
& \text { NOT MICROFILM } \\
& \text { COVER }
\end{aligned}
$$$$
\text { June } 1984
$$

Stanford Geothermal Program INTERDISCIPLINARY RESEARCH IN ENGINEERING AND EARTH SCIENCES Stanford University, Stanford, California 


\section{DISCLAIMER}

This report was prepared as an account of work sponsored by an agency of the United States Government. Neither the United States Government nor any agency Thereof, nor any of their employees, makes any warranty, express or implied, or assumes any legal liability or responsibility for the accuracy, completeness, or usefulness of any information, apparatus, product, or process disclosed, or represents that its use would not infringe privately owned rights. Reference herein to any specific commercial product, process, or service by trade name, trademark, manufacturer, or otherwise does not necessarily constitute or imply its endorsement, recommendation, or favoring by the United States Government or any agency thereof. The views and opinions of authors expressed herein do not necessarily state or reflect those of the United States Government or any agency thereof. 


\section{DISCLAIMER}

Portions of this document may be illegible in electronic image products. Images are produced from the best available original document. 


\section{ACKNOWLEDGEMENTS}

The United States Department of Energy provided funds for this study under contract number DE-ATO3-80SF-11459. The data used in this work was made available by the Institute of Nuclear Sciences, Department of Industrial and Scientific Research New Zealand. 


\section{TABLE OF CONTENTS}

ACKNOWLEDGEMENTS ..................................................ii

ABSTRACT .........................................................................

LIST OF FIGURES............................................................vii

LIST OF TABLES..............................................................viii

INTRODUCTION .............................................................. 1

WTERATURE REVIEW .......................................................

EXPERIMENTAL WORK...........................................................

RESULTS OF EXPERIMENTAL STUDY ......................................10

DISCUSSION OF EXPERIMENTAL STUDY ..................................11

THEORETICAL DEVELOPMENT OF TWO-DIMENSIONAL MODEL...............14

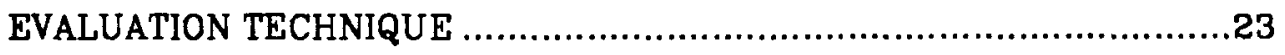

RESULTS OF TWO-DIMENSIONAL MODEL ...................................26

TRACER TEST ANALYSIS TECHNIQUE: NUMERICAL CURVE FTTTING .....33

APPLICATION OF TRACER TEST ANALYSIS TECHNIQUE..................40

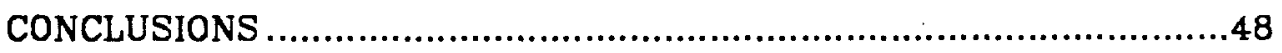

SUGGESTIONS FOR FURTHER WORK ....................................49

REFERENCES ............................................................... 51

Appendix A: DERIVATION OF SOLUTION .................................53

Appendix B: LISTING OF GENERATE.STEP ..............................56

Appendix C: LISTING OF MAIN OF GENERATE.STEP .....................65

Appendix D: LISTING OF SFUNCTION FOR GENERATE.SPIKE ............68

Appendix E: CALCULATION OF THE DERIVATIVES ........................69

Appendix F: LISTING OF CURVEFIT ......................................72 
$\therefore$

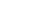




\section{ABSTRACT}

Retention processes such as adsorption and diffusion into an immobile region can effect tracer movement through a fractured reservoir. This study has conducted experimental work and has developed a two-dimensional model to characterize retention processes. A method to directly determine some important flow parameters, such as the fracture aperture, from the analysis of tracer tests has been developed as a result of the new two-dimensional model.

The experimental work consisted of batch experiments designed to both reproduce earlier work and to determine the magnitude of the retention effects. Negligible retention was observed from which it was concluded that the batch experiments were not sensitive enough and that more sensitive flowing tests were needed.

A two-dimensional model that represents a fractured medium by a mobile region, in which convection, diffusion, and adsorption are allowed, and an immobile region in which only diffusion and adsorption are allowed has been developed. It was possible to demonstrate how each of the mass-transfer processes included in the model affect tracer return curves by producing return curves for any set of the defining variables.

Field data from the New Zealand was numerically fit with the model. The optimum values of the parameters determined from curve fitting provided a direct estimate of the fracture width and could be used to estimate other important flow parameters if experimentally determinable values were known. 
,

$\because$ 


\section{LIST OF FIGURES}

1. View of Apparatus .......................................................5

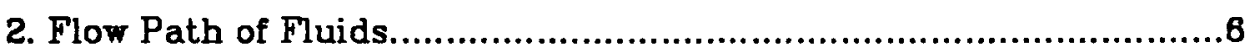

3. New Core Sleeve................................................................6

4. New Upstream Core End-plug ...............................................7

5. New Downstream Core End-plug .....................................7

6. Schematic of Two-dimensional Model .......................................14

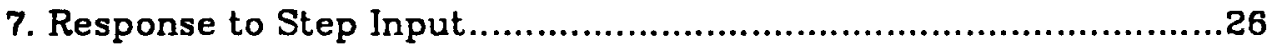

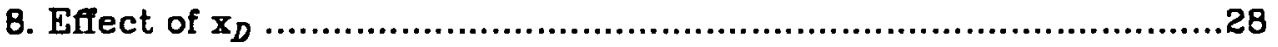

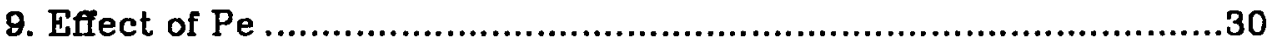

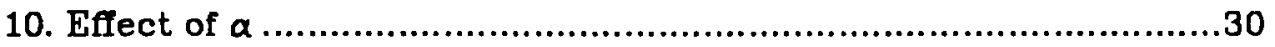

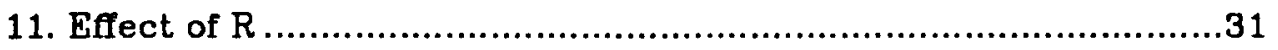

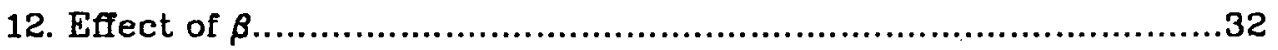

13. Flow Chart of Curve Fitting Procedure ...............................4 4

14. Well 24 Fit with Two-dimensional Model ...............................42

15. Well 103 Fit with Two-dimensional Model .................................42

16. Well 121 Fit with Two-dimensional Model .................................43

17. Well 24 Fit with Fossum's Model...........................................43

18. Well 24 Fit with Jensen's Model .........................................44

19. Well 103 Fit with Fossum's Model ..........................................44

20. Well 103 Fit with Jensen's Model .........................................45

21. Well 121 Fit with Fossums's Model ...................................45

22. Well 121 Fit with Jensens's Model......................................46 


\section{LIST OF TABLES}

1. Sieve Analysis of Core Material ............................................8

2. Experimental Results ....................................................... 10

3. Results from Breitenbach Study ........................................11

4. Base Values used in Sensitivity Study .....................................27

5. Best Fit Values of Dimensionless Variables..............................46

6. Calculated Fracture Widths .................................................47 


\section{Section 1: INTRODUCTION}

Tracers have long been used by petroleum reservoir engineers to gain information on reservoir heterogeneities, but have recently gained importance to geothermal engineers because of the problem of waste water reinjection. In most geothermal utilizations, only steam is used to drive the turbines and any produced water as well as a smaller amount of steam condensate must be disposed of. This waste water is at high temperature and has environmentally hazardous levels of dissolved materials and is usually reinjected since surface disposal of these waters is no longer an acceptable procedure in most places.

The reinjection of waste water can serve a second purpose other than disposal by maintaining reservoir pressure and mass of fluid in place. However these possible benefits must be related to the potentially damaging effects that the cooler (than reservoir fluids) injected water will have on the reservoir. If the injected water travels to the production well so quickly that it does not heat up to the original reservoir temperature, it will reduce the enthalpy of the produced water. This results in a smaller steam fraction in the produced fluid, and a smaller flow rate for a given wellhead pressure since the flow of the wells is strongly governed by the hydrostatic pressure of the fluid column. Thus less energy can be produced. Such "short-circuiting" has been observed in several geothermal fields. 1

It is the task of the reservoir engineer to determine how the waste water should be reinjected so that the harmful effects of the cooler water is minimized. Tracers have proven useful for this task. By injecting tracers and observing their returns at production wells, one can get an idea how the injected water travels through the reservoir. Such tests have shown some unexpected results. In Japan, tracer tests have recorded mean displacement of tracers at a rate as 
high as $78 \mathrm{~m} / \mathrm{hr}$. and as low as $0.5 \mathrm{~m} / \mathrm{hr}$. ${ }^{1}$ Similar flow rates were observed in New Zealand. 2 It has been demonstrated that there is a correspondence between fast tracer return rates and wells that show enthalpy declines upon reinjection. ${ }^{1}$

While tracer testing has proven useful, the analysis of these tests has been mostly qualitative. In order to predict thermal breakthroughs and enthalpy declines, quantitative data on reservoir flow parameters are needed. Currently there are no methods to directly determine these parameters from tracer tests in geothermal reservoirs. There are two main problems that make the analysis of tracer tests in geothermal reservoirs difficult.

The first problem is that most geothermal reservoirs are highly fractured. Thus the quantitative analysis of tracer testing in porous media, developed for the oil and gas industry, does not apply to geothermal reservoirs.

The second problem is modeling all the processes that can occur to a tracer as it moves through the reservoir. Besides the macroscopic processes of convection and dispersion, such microscopic processes as diffusion, chemical reaction, ion exchange, adsorption and decay can occur which effect the analysis of tracer tests. Quantitative analysis of tracer tests depends on the ability to describe accurately all processes that occur to the tracer as it travels through the reservoir.

In this study, experimental work was conducted to examine transport properties and a two-dimensional model was developed to describe those processes which can effect the analysis of tracer return curves. A method to directly determine some important flow parameters from the analysis of tracer test has been developed as a result of the new two-dimensional model. 


\section{Section 2: ITTERATURE REVIET}

Strom and Johnson (1950) demonstrated the importance of tracer tests to reservoir engineers by verifying the existence of directional permeability with the use of brine and fluorescein dyes. 'Many other uses for tracer test were soon found. A fairly complete list of information obtainable from tracer tests has been given by Wagner (1974). 4

Early analysis of tracer tests tended to ignore the microscopic processes such as diffusion, ion exchange, and adsorption. These early studies only considered convection and dispersion. 5 The corresponding dispersion-convection governing differential equations has been solved for several boundary conditions by Carslaw and Jagger (1959). ${ }^{8}$ A summary of the use of such equations and the empirical correlations used to determine the parameters in those equations is given by Perkins and Johnson (1963). ${ }^{7}$

In order to increase correspondence between theoretical and experimental results, other flow processes were considered. Coats and Smith (1964) included diffusion into a stagnant pore volume. ${ }^{8} \mathrm{~A}$ correction to the boundary conditions used in this study was given by Brigham (1974). 8

The above references do not necessarily assume a porous media but rather develop general flow models. Most further developments in the petroleum literature are limited to porous media and as such are of limited value to understanding tracer flow in highly fractured geothermal reservoirs.

Many additional refinements to the basic dispersion-convection model are found in the ground-water hydrology and soil chemistry literature. The inclusion of adsorption into the model with stagnant pore volume was shown by van Genuchten and Wierenga (1976). ${ }^{10}$ Cleary and van Genuchten (1979) showed how also to include decay and chemical reaction in the model. ${ }^{11}$ 
Recent fleld experience as described by Horne (1982) and Tester, Bivins, and Potter (1982) demonstrate the need to apply a detailed model to the analysis of tracer tests. ${ }^{1.12}$ An experimental study by Breitenbach (1982) showed that considerable retention of chemical tracer possibly occurs with geothermal material (unconsolidated). ${ }^{13}$

Horne and Rodriguez (1983) presented a one-dimensional model for flow in a fracture. ${ }^{14}$ This model included convection and diffusion (Taylor Dispersion) within the fracture. Fossum and Horne (1982) applied this model to field data from Wairakei with some success. ${ }^{15}$

Jensen (1983) extended this model by allowing the fracture to communicate by diffusion with a porous matrix. ${ }^{18}$ Adsorption was also allowed in both the fracture and the matrix. Jensen applied this model to the same Wairakei data with greater success. While Jensen's model fitted well with the data it revealed only partial information about flow characteristics or reservoir parameters because of the lack of direct measurements of some of the process parameters. 


\section{Section 3: EXPERIMENTAL FORK}

The goals of the experimental phase of this study were:

(1) To locate the mechanisms of the retention seen in Breitenbach's study. 13

(2) To determine the magnitude of the retention processes under batch conditions.

A $60^{\circ}$ axonometrix view of the apparatus used for this experiment is shown in Figure (1). A schematic of the flow paths is shown in Figure (2). This equipment was designed by A. Sageev ${ }^{17}$ and was later modified by Breitenbach. ${ }^{13} \mathrm{De}-$ tailed discussions of the apparatus and of the subsequent modifications to the apparatus used in this study are given in these earlier studies.

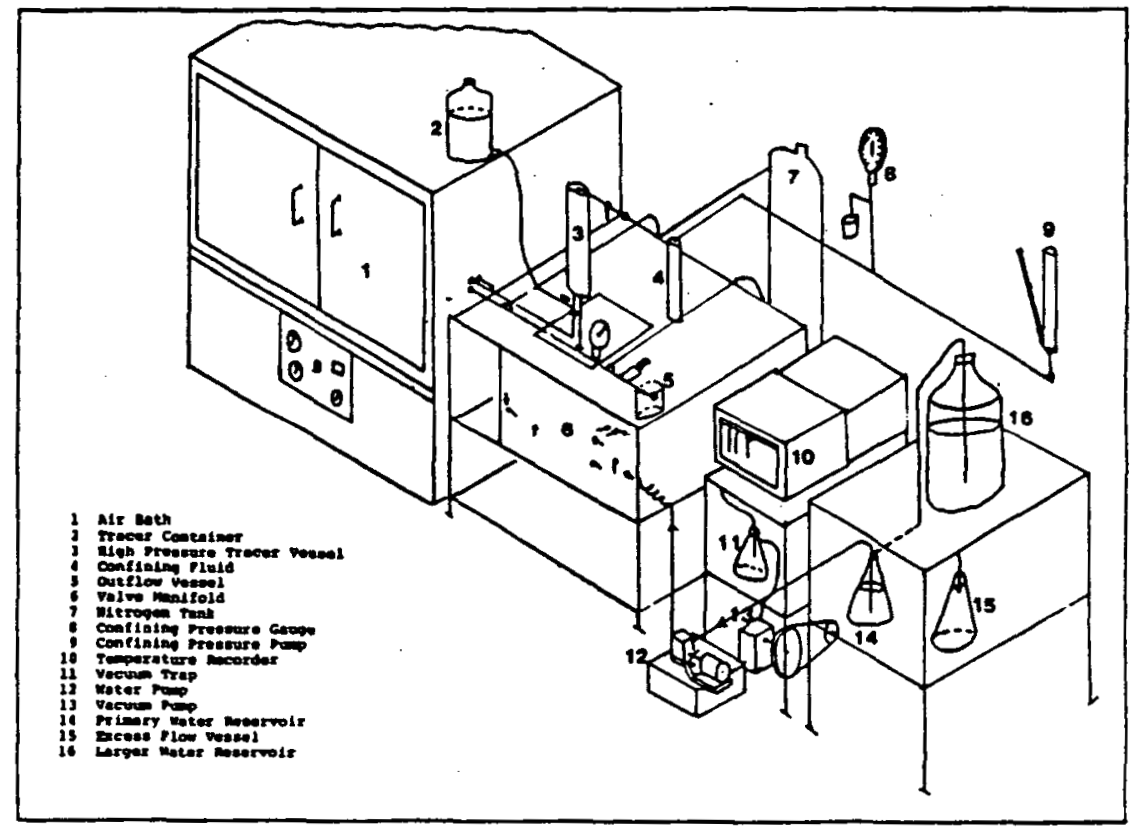

Figure 1 - VIEW OF APPARATUS ${ }^{17}$

An additional modification for this study was the alteration of the core sleeve. Previous experiments used a viton sleeve to support the unconsolidated core but because of possible interaction between the viton and the chemical 


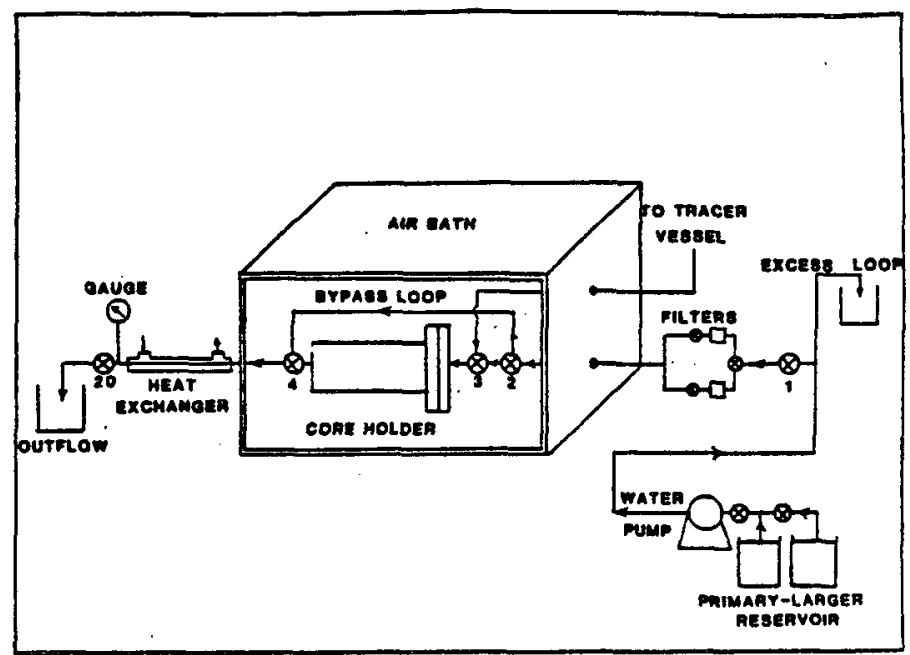

Figure 2 - FLOW PATH OF FLUIDS ${ }^{17}$

tracer, the viton sleeve was replaced by a stainless steel sleeve. The stainless steel sleeve also allowed the apparatus to operate at higher temperatures. It was also necessary to modify the endplugs to hold the new sleeve. The new sleeve and the modified end plugs are shown in Figure (3) through (5).

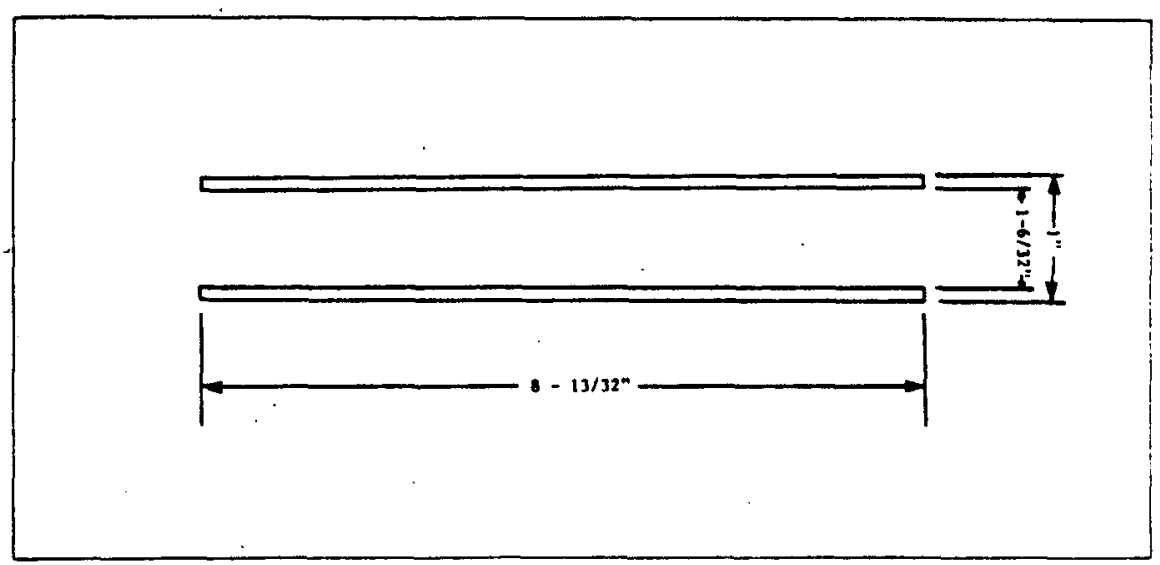

Figure 3 - NEW CORE SLEEVE ${ }^{19}$ 


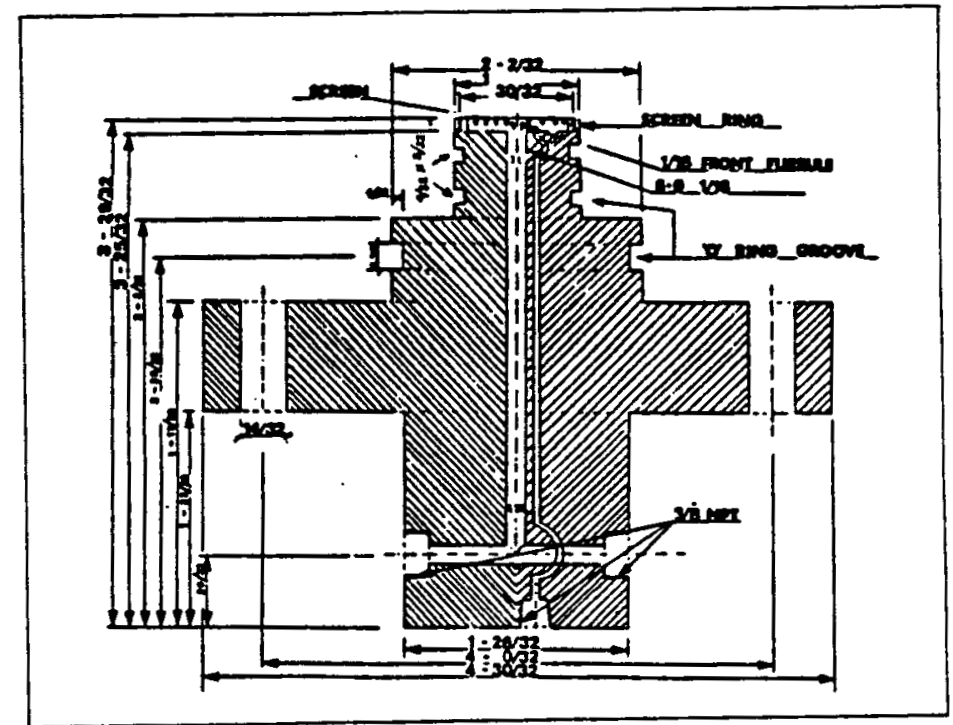

Figure 4 - NEW UPSTREAM CORE END-PLUG ${ }^{10}$

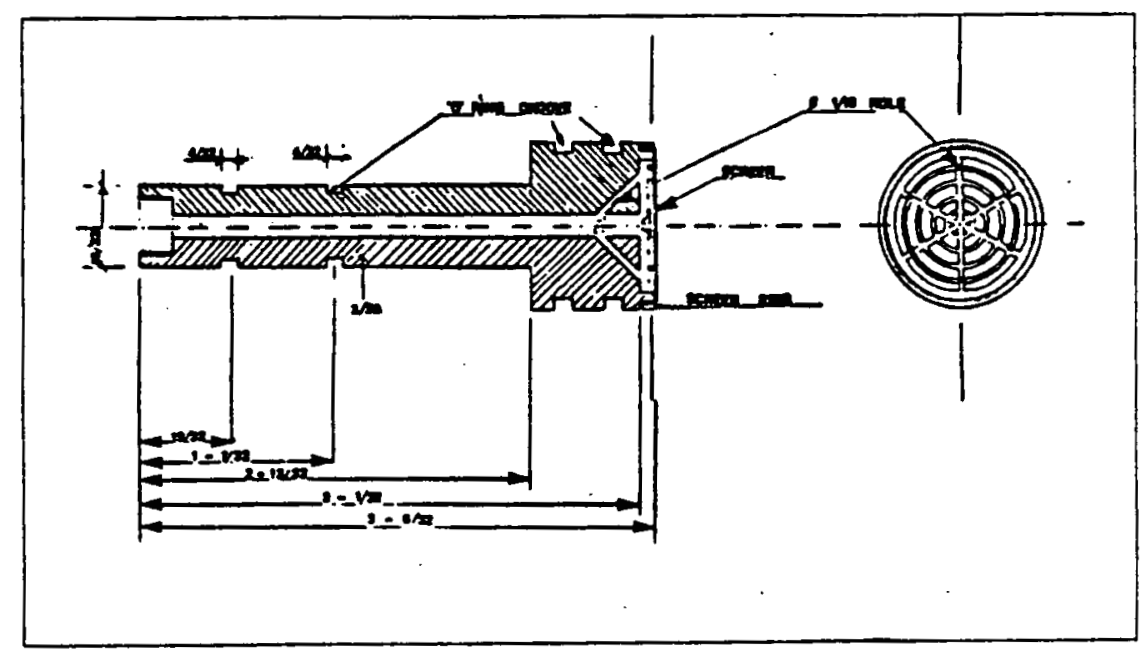

Figure 5 - NEW DOWNSTREAM CORE END-PLUG ${ }^{19}$

The core material used was unconsolidated reservoir rock. The first material used was reservoir rock from Klamath Falls, Oregon and the second was from Los Azufres, Mexico.

The core material from Klamath Falls was comprised of drill cuttings col- 
lected from the producing zone (600-660 ft) of a well near the location of a tracer test conducted in May 1983 by the Stanford Geothermal Program ${ }^{10}$. This material was described by the driller as "black lava". A geological report of the cuttings was done and described the cuttings as fine-grained andesite or basalt with a minimum of alteration. Before the cuttings were loaded into the core holder, they were cleaned, dried, and sieved. A review of the sieve analysis is shown in Table (1).

\begin{tabular}{|c|c|c|c|c|c|c|}
\hline \multicolumn{7}{|c|}{ Table 1-SIEVE ANALYSIS BY PERCENT OF TOTAL MASS } \\
\hline \hline \multirow{2}{*}{ MATERIAL } & \multicolumn{7}{|c|}{ MESH SIZE } \\
\cline { 2 - 7 } & $<100$ & $100-120$ & $120-140$ & $140-170$ & $170-200$ & $>200$ \\
\hline KLAMATH FALLS & 77.3 & 6.1 & 3.9 & 3.5 & 2.6 & 6.6 \\
LOS AZUFRES & 93.6 & $\ldots$ & $1.1^{*}$ & 0.3 & 0.6 & 4.4 \\
\hline
\end{tabular}

$*(100-140)$ mesh

The core material from the Los Azufres field was collected from an outcrop in the field and is described as a typical andesite of the reservoir. In this case the material was crushed, cleaned, dried, and sieved before loading into the core holder. Table (1) also summarizes the sieve analysis for the Los Azufres material.

A detailed step-by-step procedure for this experiment with this equipment is given by Breitenbach. ${ }^{13}$

The general procedure was to first load the core holder with reservoir material. The core holder was then put into the pressure cell and connected with all the flow lines. A vacuum was then applied to the downstream end of the core to remove any air. The core was then brought up to the desired pressure and temperature. After completely fushing the core with distilled water, the core 
was flooded with approximately three pore volumes of tracer. The tracer used was sodium iodide where the iodide ion was the chemical species traced. The effluent was collected. The cell was then isolated and allowed to sit for the desired residence time. The core was then flushed with six pore volumes of distilled water, and the effluent was again collected.

Determination of the amount of tracer retained in the core was achieved by mass balance calculation. The concentrations of the input and effluents were measured by specific ion electrode analysis, using a Fisher "Accument", Model 750 Selective Ion Analyzer. Description of this analyzer and its use is given by Jackson. 20 
Section 4: RESULTS OF EXPERIMENTAL STUDY

Seven different runs were made. Five runs with the Klamath Falls (KF) core material and two runs with the Los Azufres (LA) core material.

Tracer concentration for all runs was approximately 20ppm. Temperature was varied from room temperature to $300 \mathrm{~F}$. Confining pressure was 1500 psi. Residence times were varied from two hours to 72 hours. Table (2) summarizes all the runs and gives the calculated percent mass of tracer retained.

\begin{tabular}{|c|c|c|c|c|c|}
\hline \multicolumn{6}{|c|}{ Table 2 - EXPERIMENTAL RESULTS } \\
\hline \hline RUN & MATERIAL & $\begin{array}{c}\text { CONC. } \\
(\text { PPM })\end{array}$ & TEMP. & RESIDENCE & PERCENT \\
& & TIME(HR) & RETAINED \\
\hline 1 & KF & 18.0 & 194 & 2 & -2.23 \\
2 & KF & 10.1 & 194 & 24 & 6.71 \\
3 & KF & 15.0 & 210 & 60 & 1.76 \\
4 & KF & 21.0 & 300 & 72 & 9.09 \\
5 & KF & 17.2 & 300 & 24 & -4.65 \\
6 & LA & 23.2 & 300 & 72 & -4.76 \\
7 & LA & 22.6 & 300 & 44 & 4.81 \\
\hline
\end{tabular}




\section{Section 5: DISCUSSION OF EXPERIMENTAL STUDY}

Table (2) shows that the calculated percent tracer retained ranged from 9.1 to $\mathbf{- 4 . 8}$ percent. The negative retention values mean that more tracer was calculated coming out than was injected.

An error analysis shows an experimental error to be about $5.0 \%$. The values of percent retained all (but one) fall within $5.0 \%$ of no retention at all.

The present results are considerably different from those of Breitenbach ${ }^{18}$ study. Results are summarized in Table(3). showing values of percent retained ranging from a low of 17 percent to a high of about 70 percent.

\begin{tabular}{|c|c|c|c|c|}
\hline \multicolumn{5}{|c|}{ Table 3 - RESULTS FROM BRETTENBACH } \\
\hline \hline \multirow{2}{*}{ RUN } & $\begin{array}{c}\text { CONC. } \\
\text { (PPM) }\end{array}$ & $\begin{array}{c}\text { TEMP. } \\
\text { (F) }\end{array}$ & $\begin{array}{c}\text { RESIDENCE TIME } \\
\text { (HR) }\end{array}$ & $\begin{array}{c}\text { PERCENT } \\
\text { RETAINED }\end{array}$ \\
\hline 4 & 10 & 300 & 72 & 30.6 \\
5 & 20 & 300 & 72 & 68.6 \\
6 & 50 & 300 & 72 & 67.5 \\
7 & 100 & 300 & 72 & 69.4 \\
8 & 500 & 300 & 72 & 61.6 \\
10 & 10 & 300 & 24 & 25.9 \\
12 & 10 & 300 & 2 & 16.9 \\
\hline
\end{tabular}

It is possible to explain the fact that the present study sees little if any retention, and it is also possible to postulate some explanations for the different results between this and Breitenbach's study.

Since Breitenbach also used outcroppings from the Los Azufres field the difference between the two studies cannot be explained on the basis of different core material. However, Breitenbach used a viton sleeve to hold the core material while the present study used a stainless steel sleeve. The sleeve was changed because it was supposed that the viton might possibly adsorb the iodide tracer. This is the most likely explanation for the differences between the two studies. 
Another possible reason for the difference is that the previous study did not use high temperature valves while the present study did. It is not possible to determine if the earlier valves did leak but if they did the differences in results could be explained.

A close examination of the procedure used in these batch experiments suggests some reasons why negligible retention was seen. Using unconsolidated material as designed, the number of mass transfer processes that could result in retention of the chemical tracer are limited. In particular the loss of tracer from a mobile region to an immobile region due to diffusion is not allowed. This is because the entire core must be considered a mobile region.

Other processes which are allowed are those that can be classified as surface retention processes. An example of a surface retention process is adsorption. By isolating this one type of retention process these batch experiments demonstrate that surface retention processes are negligible.

This can be explained by examining the important parameters for surface processes. The first important parameter is surface area. Obviously the more surface available the more surface processes will occur. The unconsolidated material used in this experiment gives more surface area per weight than would be expected under reservoir conditions if flow were occurring in a fracture. Surface retention processes would therefore be be magnified under these experimental conditions. However another effect needs to be considered and that is the relative volume of tracer injected. Three pore volumes of tracer were injected in this experiment while in a field tracer test orders of magnitude less than three pore volumes of tracer are injected. The result is that in the experimental case the number of surface sites available for surface retention processes are overloaded in comparison to that in a realistic case. So even if all surface sites were active in retention the retention seen, using the adopted procedures, would 
be small.

An obvious solution to this problem would be to inject less tracer. Unfortunately, experimental constraints such as the sensitivity of the analysis technique and the error in the mass balance calculation will not allow for less tracer to be injected.

Another method for experimentally analyzing those mass transfer processes whose net effect is the retention of a tracer is to run flowing experiments. Previous studies have shown that flowing experiments are more sensitive than batch experiments. ${ }^{21}$ These earlier studies have been for porous media and thus the analysis of the tracer return curves from these studies is not directly applicable to a fractured media.

While there are models that have attempted to fit field data for a fractured reservoir, these models are not useful in examining the retention processes. ${ }^{12,15.18}$ Before an experiment could be designed to run flowing studies, a model was needed in order to examine the magnitudes of various retention processes, be they surface processes or bulk processes (diffusion from mobile to an immobile phase).

This study has developed such a model, the derivation of which is now discussed. 


\section{Section 6: THEORETICAL DEVEIOPMENT OF TTO-DIMENSTONAL MODEI}

The two dimensional, two control volume model used for this development is shown in Figure (6). The first control volume represents the mobile region where convection, diffusion, and adsorption are allowed. The second control volume represents the immobile region where only diffusion and adsorption are allowed.

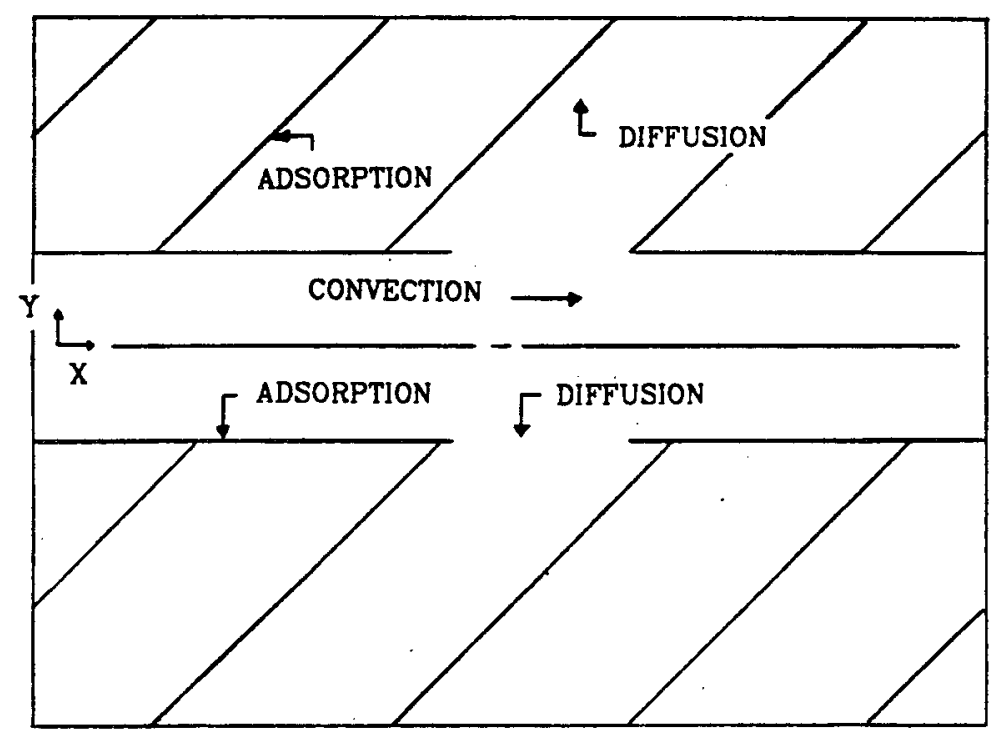

Figure 6 - SCHEMATIC OF TWO-DIMENSIONAL MODEL

A general mass balance on control volume (1) is

(rate change of mass of species in control volume) =.

(net mass rate of species into contral volume) +

(production of species in control volume)

Assuming:

(1) Production of species is negligible

(2) Density of species is constant

allows Equation (6.1) to be simplified. Thus Equation (6.1) becomes

$$
\frac{\partial A_{k}}{\partial t}=-\operatorname{div}\left(j_{k}^{T}\right)
$$


where

$$
\begin{aligned}
& \mathrm{A}_{k}=\text { Mass of species per total volume } \\
& \mathrm{j}_{k}^{T}=\text { Total mass flux of species }
\end{aligned}
$$

The mass per volume $\left(A_{k}\right)$ can be expressed as

$$
A_{k}=q_{a, m}+\varphi_{m} C_{m}
$$

where

$$
\begin{aligned}
& q_{a, m}=\text { Total mass adsorbed per total volume } \\
& C_{m}=\text { Concentration of species in mobile phase } \\
& \varphi_{m}=\text { Portion of porosity due to mobile region }
\end{aligned}
$$

The adsorption term in Equation (6.3) can be expressed as

$$
q_{a, m}=\rho_{b} P q_{m}
$$

where

$$
\begin{aligned}
& \rho_{b}=\text { Bulk density } \\
& P=\text { Fraction of total adsorption sites in the mobile region } \\
& q_{m}=\text { Adsorbed concentration in the mobile region per bulk } \\
& \quad \text { volume }
\end{aligned}
$$

Substitution of equations (6.3) and (6.4) into Equation (6.2) gives

$$
\frac{\partial A_{k}}{\partial t}=\frac{\partial\left[\rho_{b} P q_{m}+\varphi_{m} C_{m}\right]}{\partial t}
$$

Substitution of Equation (6.5) into Equation (6.1) gives

$$
\frac{\partial\left[\rho_{b} P q_{m}+\varphi_{m} C_{m}\right]}{\partial t}=-\operatorname{div}\left(j_{k}^{T}\right)
$$

The right hand side of Equation (6.6) can be expanded to

$$
j_{k}^{T}=J_{c} C_{m}+j_{k}^{d}
$$

where

$$
\begin{aligned}
& \mathrm{J}_{c}=\text { Convective flux density } \\
& \mathrm{j}_{k}^{d}=\text { Diffusive flux }
\end{aligned}
$$


Substituting Equation (6.7) into Equation (6.6) and differentiating gives

$-\operatorname{div}\left(j_{k}^{\lambda}\right)=J_{c}^{x} \frac{\partial C_{m}}{\partial x}+C_{m} \frac{\partial J_{c}^{x}}{\partial x}+J y \frac{\partial C_{m}}{\partial y}+C_{m} \frac{\partial J_{c}^{y}}{\partial y}+\frac{\partial j_{k}^{d, x}}{\partial x}+\frac{\partial j_{k}^{d, y}}{\partial y}(6.8)$ Assuming

(3) J $y=0$, convective flow in the $x$-direction only

(4) steady flow, $\frac{\partial J_{c}^{x}}{\partial x}=0$

gives

$$
-\operatorname{div}\left(j_{k}^{T}\right)=\left[J_{c}^{x} \frac{\partial C_{m}}{\partial x}+\frac{\partial j_{k}^{d, z}}{\partial x}+\frac{\partial j_{k}^{d, y}}{\partial y}\right]
$$

Assuming

$$
\text { (5) } \frac{\partial j_{k}^{z, d}}{\partial x} \text { is negligible }
$$

gives

$$
-\operatorname{div}\left(j_{k}^{T}\right)=J_{c}^{x} \frac{\partial C_{m}}{\partial x}+\frac{\partial j_{k_{y, D}}}{\partial y}
$$

Substitution of Equation (6.10) into Equation (6.6) gives

$$
\frac{\partial\left[\rho_{b} P q_{m}+\varphi_{m} C_{m}\right]}{\partial t}=-\left[J_{c}^{x} \frac{\partial C_{m}}{\partial x}-\frac{\partial j y, d}{\partial y}\right]
$$

Because steady flow has been assumed, the convective term can be expressed as

$$
J_{c}^{z}=V_{m} \varphi_{m}
$$

The diffusion term can be expanded using Fick's Law of diffusion, as

$$
j k^{y \cdot d}=-\varphi_{m} D_{m}^{y} \frac{\partial C_{m}}{\partial y}
$$

where

$$
\begin{aligned}
& D y=\text { Diffusion coefficient in the mobile phase in the } y \text { - } \\
& \text { direction }
\end{aligned}
$$

Substituting Equation (6.13) and Equation (6.12) into Equation (6.11) gives

$$
\frac{\partial\left[\rho_{b} P q_{m}+\varphi_{m} C_{m}\right]}{\partial t}=\varphi_{m} D_{m}^{y} \frac{\partial^{2} C_{m}}{\partial y^{2}}-\varphi_{m} V_{m} \frac{\partial C_{m}}{\partial x}
$$


Differentiating gives

$$
\rho_{b} P \frac{\partial q_{m}}{\partial t}+\varphi_{m} \frac{\partial C_{m}}{\partial t}=\varphi_{m} D \frac{\partial^{2} C_{m}}{\partial y_{2}}-\varphi_{m} V_{m} \frac{\partial C_{m}}{\partial x}
$$

Equation (6.15) has two time dependent variables, the flowing concentration $\left(C_{m}\right)$ and the adsorbed concentration $\left(q_{m}\right)$. To reduce the number of variables to one, the adsorbed concentration is expressed as a function of the flowing concentration. There are many choices for such a relationship, but this study has used the simple Freundlich linear isotherm. This isotherm assumes equilibrium and instantaneous adsorption. The adsorbed concentration is related to the flowing concentration by

$$
q_{m}=k C_{m}
$$

where

$$
\begin{aligned}
& \mathbf{k}=\text { adsorption constant which is a function of temperature } \\
& \text { only }
\end{aligned}
$$

Applying this relationship to Equation (6.15) gives

$$
\left[\varphi_{m}+\rho_{b} P k_{m}\right] \frac{\partial C_{m}}{\partial t}=\varphi_{m} D \frac{\partial^{2} C_{m}}{\partial y^{2}}-\varphi_{m} V_{m} \frac{\partial C_{m}}{\partial x}
$$

Applying the same mass balance on control volume (2) as was applied on control volume (1) gives

$$
\frac{\partial A_{t}}{\partial t}=-d i v\left(j_{k}^{T}\right)
$$

For control volume (2) only diffusion and adsorption are allowed so $\left(A_{k}\right)$ becomes

$$
A_{k}=\rho_{b}(1-P) q_{i m}+\varphi_{i n} C_{i m}
$$

The flux term becomes

$$
j_{k}^{T}=J_{c} C_{i m}+j_{k}^{d}
$$

The first term on the right hand side of Equation (6.20) is equal to zero because no convection is allowed in this control volume. Differentiating Equation (6.20) 
gives

$$
\operatorname{div}\left(j_{k}^{T}\right)=\frac{\partial j_{k}^{x \cdot d}}{\partial x}+\frac{\partial j_{k}^{\prime d}}{\partial y}
$$

As in the mobile region the diffusion in the $x$-direction is assumed to be negligible. The diffusion term is expressed using Fick's Law to give

$$
j z \cdot D=-\varphi_{i m} D_{z m}^{y} \frac{\partial C_{i m}}{\partial y}
$$

Substituting equations (6.22),(6.21), and (6.19) into Equation (6.18) gives

$$
\rho_{b}(1-P) \frac{\partial q_{i m}}{\partial t}+\varphi_{i m} \frac{\partial C_{i m}}{\partial t}=\varphi_{i m} D_{i m}^{y} \frac{\partial^{2} C_{i m}}{\partial y^{2}}
$$

Again using the Freundlich linear isotherm to relate the adsorbed concentration to the fluid concentration gives

$$
\left[\varphi_{i m}+\rho_{b}(1-P) k\right] \frac{\partial C_{i m}}{\partial t}=D_{i m}^{y} \varphi_{i m} \frac{\partial^{2} C_{i m}}{\partial y^{2}}
$$

Equations (6.17) and (6.24) are the governing partial differential equations for the two-dimensional model. The initial condition used for this model is one of uniform concentration. This is given by

$$
C_{m}(x, y, 0)=C_{i m}(x, y, 0)=C_{i}
$$

Symmetry is invoked at the centerline of the mobile region, so

$$
\left.\frac{\partial C_{m}}{\partial y}\right]_{y=0}=0
$$

At the interface of the two control volumes, concentration is forced to be continuous, thus

$$
\left.\left.C_{m}\right]_{y=w}=C_{i m}\right]_{y=w}
$$

where

$$
w=\text { half width of the mobile region }
$$

The flux across the interface is also continuous, giving

$$
\left.\left.\varphi_{m} D_{m} \frac{\partial C_{m}}{\partial y}\right]_{y=w}=\varphi_{i m} D_{i m} \frac{\partial C_{i m}}{\partial y}\right]_{y=w}
$$


The outer boundary condition in the $y$-direction is

$$
\left.\frac{\partial C_{i n}}{\partial y}\right]_{y=-=}=0
$$

The inlet condition in the $\mathrm{x}$-direction is

$$
\left.C_{m}\right]_{x=0}=C_{0}
$$

In order to simplify the governing differential equations and the associated boundary conditions a set of "dimensionless" variables are introduced.

$$
\begin{gathered}
C_{1}=\frac{C_{m}-C_{i}}{C_{0}-C_{i}} \\
C_{2}=\frac{C_{i m}-C_{i}}{C_{0}-C_{i}} \\
y_{D}=\frac{y}{w} \\
x_{D}=\frac{x}{w} \\
P_{\varepsilon}=\frac{V_{m} w}{D_{m}} \\
\beta=\frac{\varphi_{m}+\rho P k}{\varphi_{T}+\rho k} \\
R=\left[\frac{\varphi_{T}+\rho k}{\varphi_{m}} V_{m}\right. \\
a=\left(\frac{\varphi_{i m}}{\varphi_{m}}\right)\left(\frac{D_{i m}}{D_{m}}\right)
\end{gathered}
$$

It should be noted that all the variables are dimensionless except (R) which has units of reciprocal time. Using these dimensionless variables the partial differential equations become

$$
\beta R \frac{\partial C_{1}}{\partial t}=\left(\frac{1}{P_{e}}\right) \frac{\partial^{2} C_{1}}{\partial y_{D}^{2}}-\frac{\partial C_{1}}{\partial x_{D}}
$$

and

$$
(1-\beta) R \frac{\partial C_{2}}{\partial t}=\left(\frac{\alpha}{P e}\right) \frac{\partial^{2} C_{2}}{\partial y_{D}^{2}}
$$

where

$$
\begin{aligned}
& 1=\text { mobile region } \\
& 2=\text { immobile region }
\end{aligned}
$$


The initial and boundary conditions become

$$
\begin{gathered}
C_{1}\left(x_{D}, y_{D}, 0\right)=C_{2}\left(x_{D, y_{D}} 0\right)=0 \\
\left.\frac{\partial C_{1}}{\partial y_{D}}\right]_{y_{D}=1}=0 \\
\left.\left.C_{1}\right]_{y_{D}=1}=C_{2}\right]_{y_{D}=1} \\
\left.\left.\frac{\partial C_{1}}{\partial y_{D}}\right]_{y_{D}=1}=\alpha \frac{\partial C_{2}}{\partial y_{D}}\right]_{y_{D}=1} \\
\left.\frac{\partial C_{2}}{\partial y_{D}}\right]_{y_{D}=-}=0 \\
C_{1}\left(0, y_{D}, t_{D}\right)=1
\end{gathered}
$$

The complete solution of the simultaneous partial differential Equations (6.39) and (6.40) with boundary conditions (6.41)-(6.46) is given in Appendix (A).

The general method of solution was to transform the equations with the Laplace transform with respect to time $(t)$ and then again with respect to $(x)$. With the equations in the transformed space ( $p$-space), the solution could be solved for directly. Unfortunately, the resulting analytic solution cannot be analytically inverted. Thus to express the solution in real space required use of the Stehfest numerical inversion algorithm. ${ }^{22}$ The details of this evaluation process will be discussed later.

The analytical solution for the concentration in the mobile phase in p-space is

$$
C P=\frac{C_{0}}{s(p+s \beta R)}-\left[\frac{z \alpha C_{0}}{s(p+s \beta R)}\right] \frac{e^{m y_{D}}+e^{-m y_{D}}}{(1-\alpha) M\left(e^{m}-e^{-m}\right)+z \alpha\left(e^{m}+e^{-m}\right)}
$$

where

$$
\begin{aligned}
& \mathrm{s}=\text { Laplace operator for transforming } \mathrm{t} \\
& \mathrm{p}=\text { Laplace operator for transforming } \mathrm{x} \\
& \mathrm{z}=\left[\frac{P e(1-\beta) R s}{\alpha}\right]^{\frac{1}{2}} \\
& \mathrm{~m}=\left[\frac{\boldsymbol{P}+s \beta R}{P e}\right]^{\frac{1}{2}}
\end{aligned}
$$


No mention of a fractured or a matrix is made in the above development, rather the only distinction is that between a mobile and an immobile region. Thus the model is general.

The general nature of this model is best seen by considering the variables $\left(\varphi_{m}\right),\left(\varphi_{i m}\right)$, and $\left(\varphi_{m}\right)$ where

$$
\begin{aligned}
& \left(\varphi_{m}\right)=\text { Portion of total porosity due to the mobile region } \\
& \left(\varphi_{i m}\right)=\text { Portion of total porosity due to the immobile region } \\
& \left(\varphi_{T}\right)=\text { Total porosity }
\end{aligned}
$$

When considering the case of a completely saturated (single phase) porous medium, essentially the entire volume should be considered as mobile, thus

$$
\varphi_{m}>\varphi_{i m}
$$

This is true no matter what fraction of the entire reservoir is considered.

With regard to the fraction of mobile to immobile region, the completely saturated porous media is at one end of the spectrum with essentially everything being mobile while a fractured media is at the other end. In a fractured medium all but a small portion of the entire reservoir is immobile, thus over the entire reservoir

$$
\varphi_{i m}>\varphi_{m}
$$

The model is able to consider both porous and fractured media as well as intermediate cases. Such intermediate cases would include only partially saturated single phase reservoirs and could possibly include multi-phase systems if the loss of the traced material from the sampled fluid depended upon the concentration difference of the traced material between the sampled fluid and the other fluids. While this model has other applications, this study has concentrated on applying the model to fractured systems.

When considering fractured systems the nature the testing procedure is important in the understanding of the different variables. As discussed above, the 
portion of the total porosity due to the mobile phase is given by $\left(\varphi_{m}\right)$. When tracer testing in a fractured medium, only a finite amount of tracer is injected, thus not the entire reservoir is examined. In this case $\left(\varphi_{m}\right)$ is more accurately the portion of the encountered porosity due to the mobile phase rather than the portion of the total porosity due to the mobile phase. This is not necessarily a handicap to tracer analysis as will be discussed later. 


\section{Section 7: EVALUATION TECHNIQUE}

The solution to the two dimensional model is for a step input and is analytic only in $\mathrm{p}$-space, where $\mathrm{p}$-space is two Laplace transformations away from real space. Any investigation of how the different parameters that were included in the physical model effect tracer movement in a reservoir requires expressing the solution in real space for any value of the dimensionless variables. Furthermore, since most tracer tests are not step inputs, the solution for a step input of finite duration (a finite-step) and the solution for a spike input (infinitesimally short duration) are needed.

A computer program GENERATE.STEP was developed to evaluate the solution for a step input in real space. A listing of GENERATE.STEP is given in Appen$\operatorname{dix}(B)$

GENERATE.STEP is made up of five parts; the main program (MAIN), the function INVERSE1; the subroutine SFUNCTION, the function INVERSE2, and the subroutine PFUNCTION.

The main program (MAIN) reads and writes the values of the dimensionless variables and the time steps at which the solution is to be evaluated. MAIN then evaluates the solution by calling the function INVERSE1.

INVERSE1 is the Stehfest numerical inversion algorithm used to invert from $(x, y, s)$-space to $(x, y, t)$-space (real space). This algorithm requires an evaluation of the solution in $(x, y, s)$-space and gets this by calling the subroutine SFUNCTION.

Since the solution is not analytic in $(x, y, s)$-space. SFUNCTION gives an evaluation of the solution in $(x, y, s)$-space by calling the function INVERSE2.

INVERSE2 is again the Stehfest algorithm which is used here to invert from 
$(p, y, s)$-space to $(x, y, s)$-space. The expression of the solution in $(p, y, s)$-space which is needed by INVERSE2 is evaluated by calling PFUNCTION.

PFUNCTION evaluates the value of the solution in $(p, y, s)$-space from the analytic expression of the solution.

The program then returns control to MAIN which writes the value of the solution for all the time steps. Examples of input and output files are also given in Appendix (B).

The use of the Stehfest algorithm to invert the solution results in "noise" or error caused by the numerical technique. This error is greatest where the function to be inverted is not smooth. A consequence of this error in the calculation procedure is that negative concentrations are sometimes calculated in region where noise dominates. Since negative concentrations are clearly not allowed, the program sets all negative values to zero.

The evaluation of the solution for a step input is given by GENERATE.STEP, but the evaluation for a finite-step and a spike-step input required modifications to the above procedure.

To evaluate the solution for a finite-step the program GENERATE.FINSTEP was developed. This program is very similar to GENERATE.STEP and has used the concept of superpositon in time to generate the results for a finite-step. Using superpositon, the concentration after the step input has ended is given by

$$
c_{f s}\left(t, \alpha_{i}\right)=C_{s}\left(t+\Delta t, \alpha_{i}\right)-C_{S}\left(t, \alpha_{i}\right)
$$

where

$$
\begin{aligned}
& C_{s s}=\text { Concentration for finite step } t \\
& C_{s}=\text { Concentration for step input } \\
& \Delta t=\text { Duration of finite step } \\
& t=\text { Time since the end of the step input }
\end{aligned}
$$


The only part of GENERATE.STEP that needed to be modified was the main program MAIN. The modified MAIN that was used in GENERATE.FINSTEP is given in Appendix (C). All other programs in GENERATE.FINSTEP are exactly those already given in GENERATE.STEP. Since MAIN is changed in GENERATE.FINSTEP, the input fle is different than that used in GENERATE.STEP. An example input fle is also given in Appendix (C).

The evaluation of the solution for a spike-input is greatly simplified by the solution technique used. It can be shown that the response of a spike-input is merely the time derivative of a step input. Using the Laplace property

$$
\frac{\partial F}{\partial t}=L^{-1}[s f(s)]
$$

it is easy to see that all that is needed to do to get the spike-input from the step input is to multiply the expression for the step input in $(x, y, s)$-space by $(s)$ before it is inverted to $(x, y, t)$-space. This is easily done by modifying SFUNCTION . Thus the program to calculate the results for a spike-input, GENERATE.SPIKE, is exactly like GENERATE.STEP except for a slight modification in SFUNCTION. A listing of the SFUNCTION used in GENERATE.STEP is given in Appendix (D). Since the main program is not changed in GENERATE.SPIKE it requires the same input as GENERATE.STEP. 
Section 8: RESULIS OF TTO-DIMENSIONAL YODEI

It was possible to examine how each of the variables in the two-dimensional model affects tracer movement through a reservoir by examining the return curves that were generated by the procedure described above. While one could look at all three type of tests (step, finite-step, spike), only the finite-step and spike are practically applicable. Since most field tests are more like a spikeinput, this study examines how each of the dimensionless variables effect tracer return curves for a spike-input of tracer.

The step-input program (GENERATE.STEP) was used to check the analysis procedure. One would expect that if a system were subjected to a step-input of unit concentration then the response of this system would have an initial delay followed by an asymptotic approach to unity. Entering base values of the variables and evaluating the solution gave a curve similar to what was expected. Figure (7) shows a response for a typical step-input.

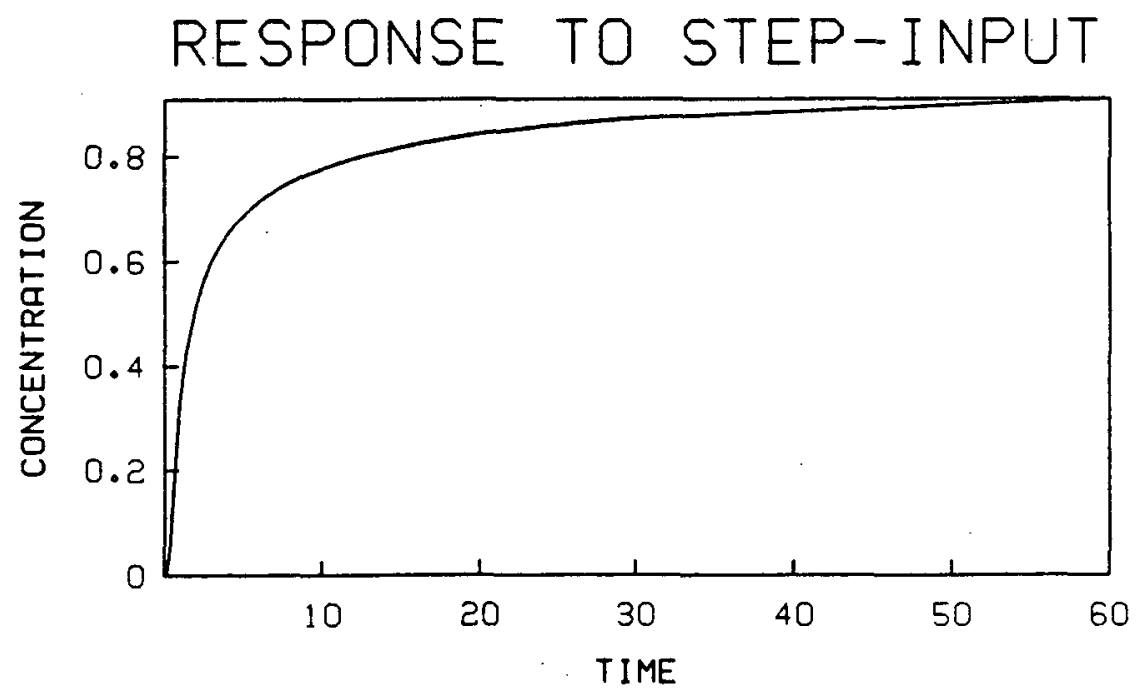

Figure 7 - RESPONSE TO STEP INPUT 
In the generation of any return curve, the value of all six dimensionless variables need to be entered. A simplifying assumption was made when a value of $\left(y_{D}\right)$ was entered. The concentration profle at a given distance $\left(x_{D}\right)$ should be the area average of the calculated values for all $\left(y_{D}\right)$ values, where $\left(y_{D}\right)$ ranges from zero to one. This averaging procedure was not done, instead the value of the concentration calculated at $\left(y_{D}\right)=0.5$ was used as the average value. This assumption was made to simplify an already complicated procedure and to prevent an already long running (cpu time) computer program from becoming prohibitively long. The basis for this assumption was a series of calculations of the concentration profle across a fracture. These profiles showed an essentially flat profile with little variation in concentration across the fracture. This flat profile is to be expected because in the solution of the two-dimensional model it was assumed that the velocity proflle was not a function of $(y)$.

The sensitivity of the model to the five dimensionless variables; $\left(\mathrm{x}_{D}\right),(\mathrm{Pe})$, $(\beta),(R)$, and $(\alpha)$ was studied by examining how a typical return curve was affected by varying each of the variables independently. The base values of the dimensionless variables used were determined by "eye" fitting the model to real data. The base values used in the sensitivity studies are shown in Table (4). The sensitivity study showed large differences in sensitivity among the five variables.

Table 4 - BASE VALUES USED IN SENSITTVITY STUDY

\begin{tabular}{|c|c|c|c|c|}
\hline \hline $\mathrm{Pe}$ & $\beta$ & $\mathrm{R}$ & $\alpha$ & $x_{D}$ \\
\hline 0.02 & 0.50 & .002 & .10 & 10000 \\
\hline
\end{tabular}

The dimensionless variable $\left(\mathbf{x}_{D}\right)$ is the dimensionless distance between wells. The two-dimensional model was more sensitive to $\left(x_{D}\right)$ than any of the 
other variables. In order to be able to graph the results of varying $\left(x_{D}\right)$ on a single plot the value of $\left(x_{D}\right)$ could only be increased and decreased by a factor of two. The base case $\left(x_{D}=10000\right)$ and the higher and lower cases are shown in Figure (B).

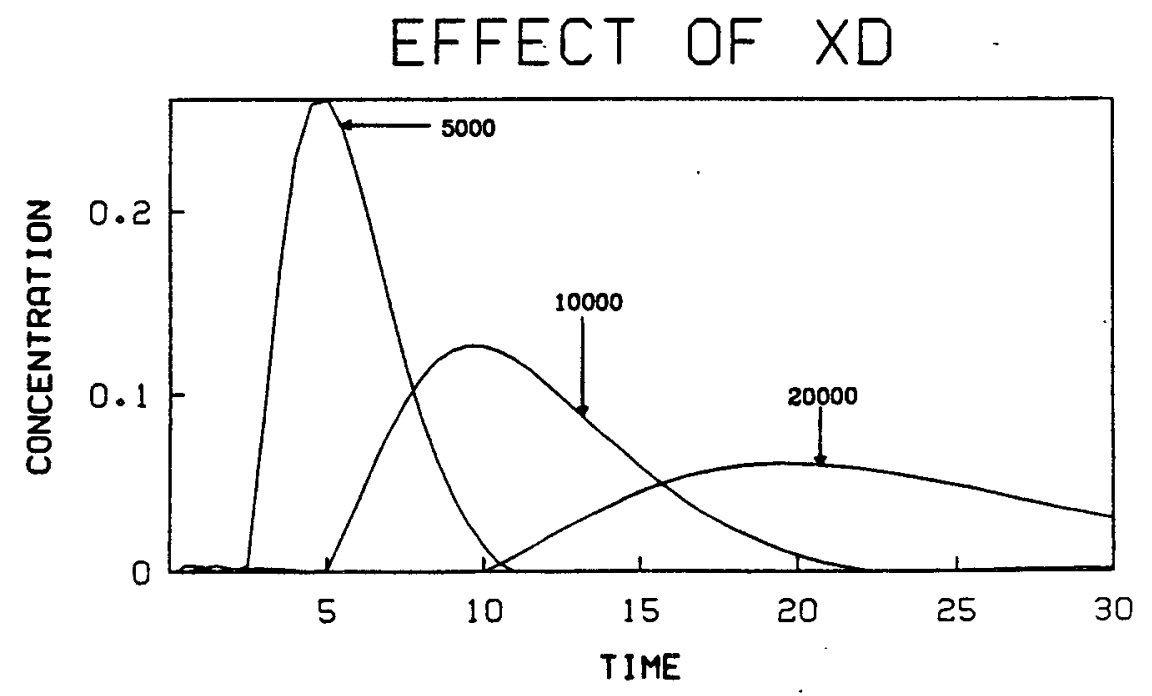

Figure 8 - EFFECT OF $X_{D}$

As would be expected when the dimensionless distance is decreased the tracer both breaks through earlier and has a higher peak concentration than the base case. When $\left(x_{D}\right)$ is increased, equivalent to a greater distance between wells, the breakthrough occurs later and the peak concentration is less. Not only breakthrough times and peak concentration are changed, but the shape of the curve is changed as well. In particular the backside of the return curves are quite different depending on the value of $\left(x_{D}\right)$. The backside of the return curves is where retention effects are visible and as would be expected the greater the distance between wells the more retention occurs and thus the longer the tailing effects.

The dimensionless variable $(\mathrm{Pe})$ is given by 


$$
P e=\frac{V_{m} w}{D_{m}}
$$

and is a modified form of the Peclet number, an important variable in many mass transport systems. Usually the characteristic length that would have been used to make this group dimensionless would have been the actual distance between the wells, but this study has used the fracture half-width (w). The result is that the values of the Peclet number here are orders of magnitude less than commonly seen.

Despite its frequent use as a group to define many systems, the twodimensional model showed small sensitivity to the Peclet number. Other recent studies have seen similar effects. ${ }^{21}$ Figure (9) shows the effect of decreasing the Peclet number by a factor of ten and increasing the Peclet number by a factor of five. The most apparent effect of changing the Peclet number is to change the amount of retention or equivalently the amount of tailing of the return curve. Figure (9) shows that the larger the Peclet number the more the tailing effect. Figure (9) also shows that relatively large changes in the Peclet number cause small changes in the breakthrough times. Another important observation is that the changes in the Peclet number do not create symmetric changes in the return curve.

The sensitivity of the model to $(\alpha)$, where

$$
\alpha=\left(\frac{\varphi_{i m}}{\varphi_{m}}\right)\left(\frac{D_{i m}}{D_{m}}\right)
$$

is shown in Figure (10). Like the Peclet number the relative sensitivity of the model to $(\alpha)$ is small. A decrease in $(\alpha)$ by a factor of ten results in a higher peak concentration, less tailing effects and a similar shape when compared to the base case. An increase by a factor of eight results in much more tailing and a lower peak concentration. Breakthrough times on all the curves are similar.

The effect of changing the variable $(R)$ where 


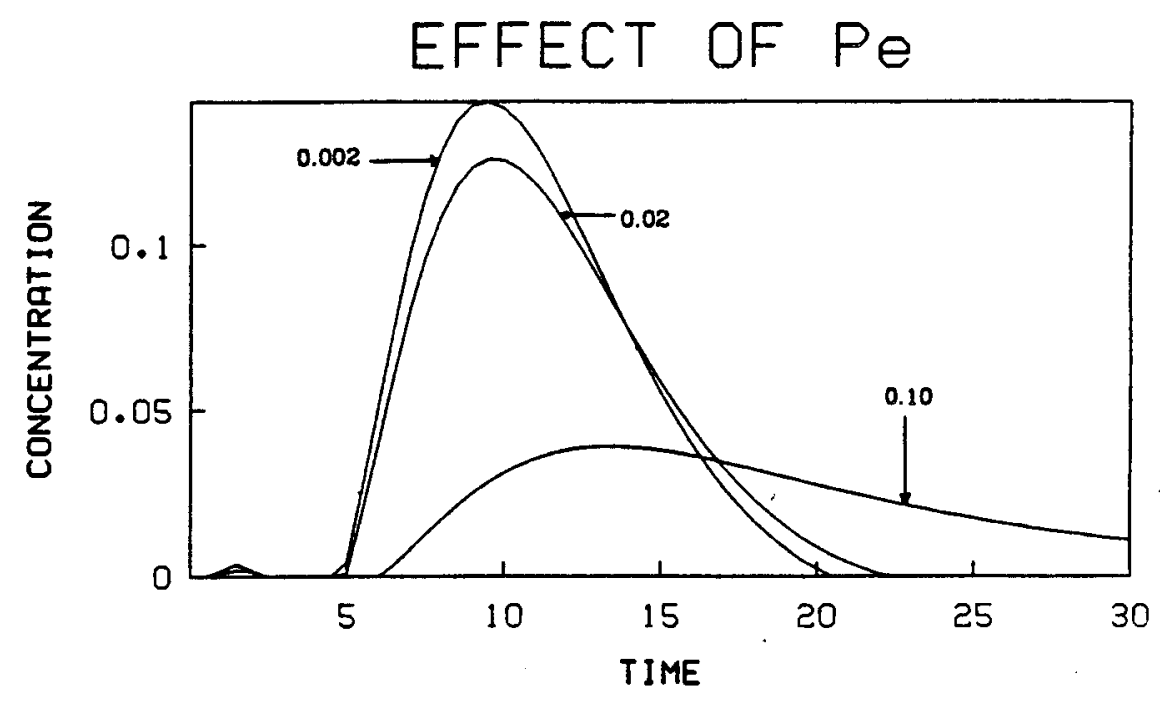

Figure 9 - EFFECT OF Pe

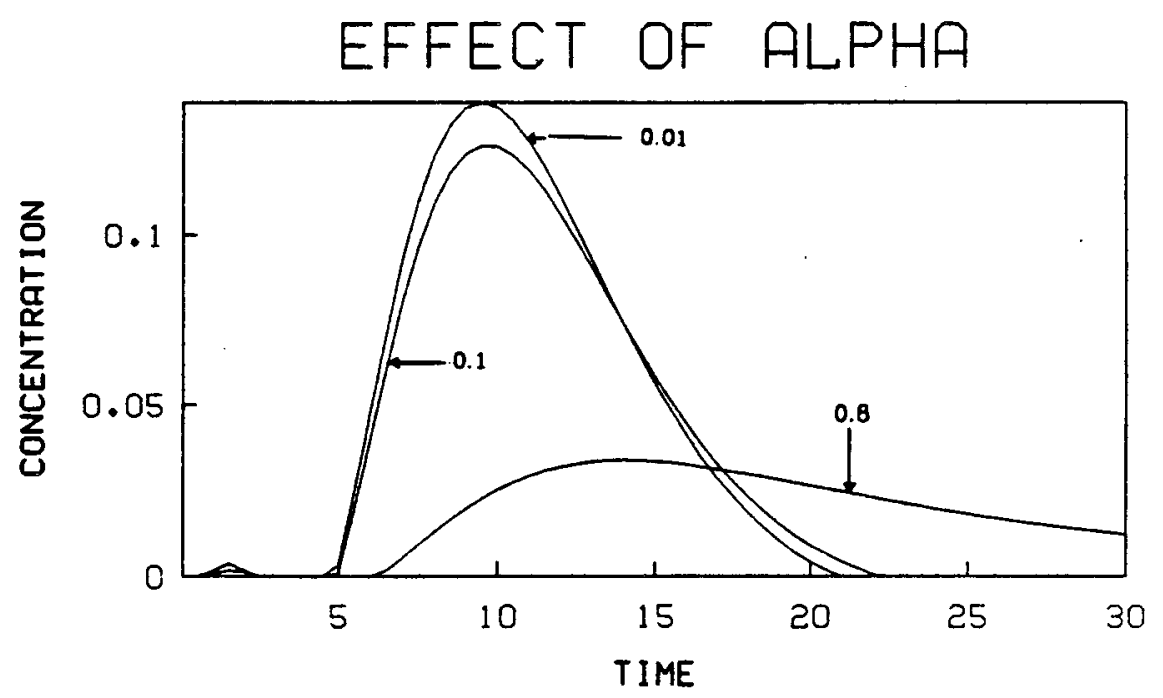

Figure 10 - EFFECT OF $\alpha$

$$
R=\left[\frac{\varphi_{T}+\rho k}{\varphi_{m} V_{m}}\right] w
$$

is similar to the effect of changing $\left(x_{D}\right)$. Doubling the base value of $(R)$ results in more tailing and a slower breakthrough. Decreasing the base value by a factor of two gives a profile with a higher peak concentration and a earlier break- 
through. These results can be seen in Figure (11).

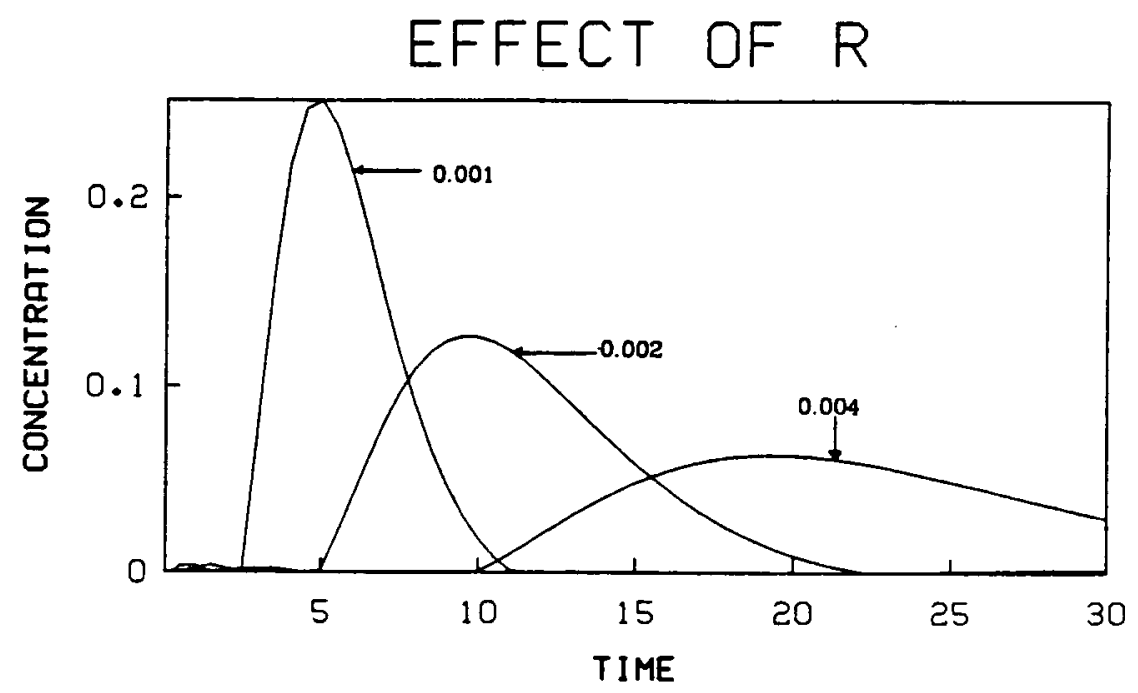

Figure 11 - EFFECT OF R

The sensitivity of the two-dimensional model to $(\beta)$ is intermediate between the high sensitivity of the model to $\left(x_{D}\right)$ and $(R)$ and the low sensitivity of the model to $(\mathrm{Pe})$ and $(\alpha)$. The variable $(\beta)$ is defined as

$$
\beta=\frac{\varphi_{m}+\rho P k}{\varphi_{T}+\rho k}
$$

and gives the fraction of the total retardation due to the fractured region. By deflnition $(\beta)$ is constrained to lie between zero and one. As can be seen in Figure (11) decreasing $(\beta)$ from $(0.5)$ to $(0.1)$ resulted in an increase in the peak concentration, a decrease in the breakthrough time and a decrease in the amount of tailing. An increase in $(\beta)$ gave opposite results.

The above sensitivity study shows that the two-dimensional model is affected differently by the five dimensionless variables that define the model. Within the five dimensionless variables there are at least eight unknown physical parameters $\left(w, \varphi_{m}, \varphi_{T}, P, k, V_{m}, D_{m}, D_{i m}\right)$, thus there is no unique combination of physical parameters that can be determined from or can determine the five 


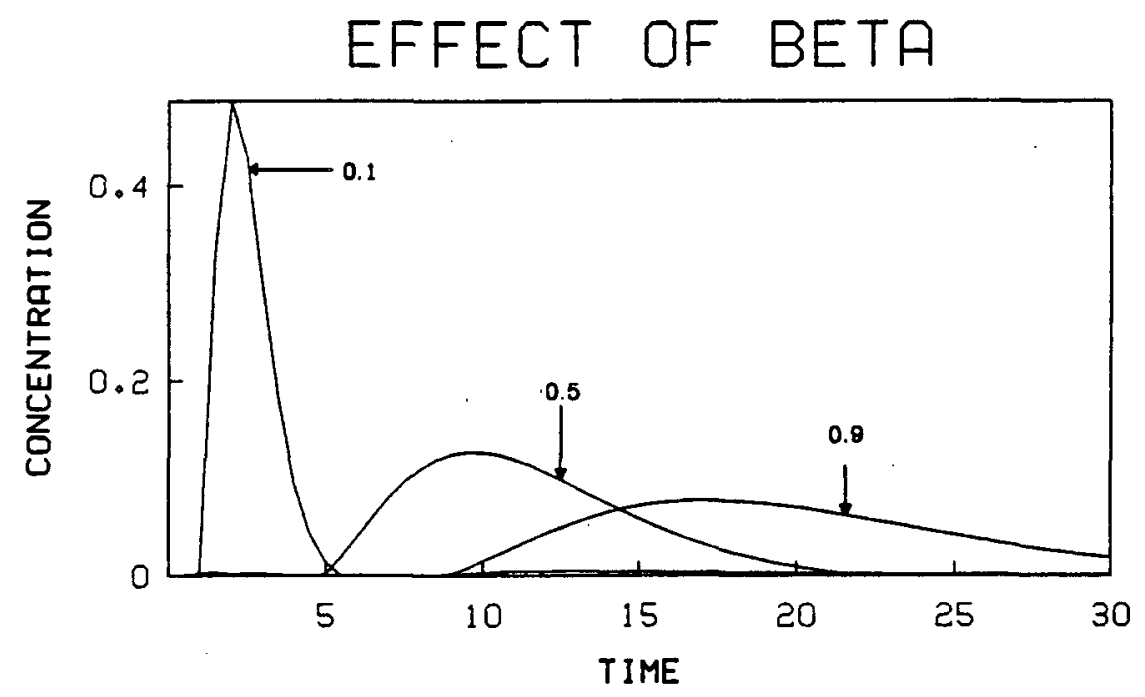

Figure 12 - EFFECT OF $\beta$

dimensionless variables. This two-dimensional model makes possible the production of tracer return curves for any given set of physical parameters and the associated dimensionless variables. 


\section{Section 9: TRACER TBST ANALYSIS TECHNIQUE; NULERICAL CURVE FITTING}

The initial goal of this study was to model and quantify those processes that affect the movement of a tracer as it moves through a reservoir. The twodimensional model described above allows this by producing tracer return curves for any given set of dimensional variables that define the system. This forward type of problem, a problem where the input and system are known and the output from the system is desired, may be used to study the effects of different processes on the model-but it is not helpful for the inverse problem. The inverse problem, frequently encountered in reservoir engineering, is where both the input and the output are known while the system is the unknown. This is the type of problem that must be dealt with in the interpretation of an actual field tracer test. In a field case the details of how the tracer was injected are known (the input), and the tracer return curves are known (the output), what is desired is an interpretation of the reservoir (the system).

The general procedure to solve the inverse problem is to statistically fit a model to the real data. From this fit the optimum values of the variables that define the model may be determined. Hopefully from the values of the defining variables it may be possible to say something about the reservoir. Since the two-dimensional model developed in this study is very general and the variables that define this model give information about the reservoir, it was hoped that this model could be applied in the interpretation of tracer tests. It should be noted that previous studies, in particular Jensen's ${ }^{16}$ study, have attempted to fit models to real data with considerable success. Unfortunately the variables that were determined from the fitting process did not reveal much about the reservoir. The advantage of the present model is that the variables involved are more directly associated with reservoir properties.

Before the two-dimensional model can be applied to a fitting process the 
solution must be put in a form that is open to statistical analysis. The solution for a step input in terms of the dimensionless variables can be written as

$$
C_{8}\left(t ; \alpha_{i}\right)=C_{0} F\left(t, \alpha_{i}\right)
$$

where

$$
\begin{gathered}
C_{s}\left(t ; \alpha_{i}\right)=\text { Concentration at time } t \text { for a step input. } \\
C_{0}=\text { Concentration at inlet } \\
F\left(t ; \alpha_{i}\right)=\text { Solution for unit-step input at time } t \\
\alpha_{i}=\text { Dimensionless variables }(i=1,5) \\
\alpha_{1}=\mathrm{Pe} \\
\alpha_{2}=\beta \\
\alpha_{3}=\mathrm{R} \\
\alpha_{4}=\alpha \\
\alpha_{5}=\mathrm{X}_{D}
\end{gathered}
$$

Using superpositon, the solution for a finite-step $\left(\mathrm{C}_{f s}\right)$ can be written as

$$
C_{f 8}=C_{0}[F(t+\Delta t)-F(t)] \quad \text { for } t>\Delta t
$$

The inlet condition $\left(C_{0}\right)$ can be expressed as

$$
C_{0}=\frac{M}{Q \Delta t}
$$

where

$$
\begin{aligned}
& M=\text { Total mass input } \\
& Q=\text { Total volume flowrate } \\
& \Delta t=\text { Duration of input }
\end{aligned}
$$

Substituting the expression for the inlet concentration into the Equation (9.2) gives

$$
C_{f s}=\frac{M}{Q}\left[\frac{F(t+\Delta t)-F(t)}{\Delta t}\right]
$$

Allowing $(\Delta t)$ to approach zero is equivalent to having a spike-input. Thus a spike input is given by 


$$
\begin{aligned}
C_{\Delta p} & =\frac{M}{Q} \lim _{\Delta t \rightarrow 0}\left[\frac{F(t+\Delta t)-F(t)}{\Delta t}\right] \\
& =\frac{M \partial F}{Q \partial t}
\end{aligned}
$$

This solution can be written in a generalized form as

$$
C_{s p}=E f\left(t ; \alpha_{i}\right)
$$

The term (E) is a normalization factor that normalizes the function to one. Since there is no detailed knowledge of the inlet conditions at the entrance to the fracture, a normalization of the solution is needed. This normalization of the solution has no effect on the shape of return curves it only changes the size of the curve.

The parameters in Equation (9.6) were optimized by using a non-linear least squares method of curve fitting. This curve fitting was done by using VARPRO23, a computer program developed by the Computer Science Department of Stanford University. VARPRO optimizes both the non-linear and the linear parameters of a given function.

The method of curve fitting used in VARPRO is based on a paper by Golub and Pereya. ${ }^{24}$ It is shown that a non-linear model of the form

$$
\eta(\alpha, \beta ; T)=\sum_{j=1}^{L} \beta_{j} \varphi_{j}(\alpha ; T)+\varphi_{L+1}\left(\alpha_{i} T\right)
$$

Where

$$
\begin{aligned}
& \eta=\text { Model to be fit } \\
& \alpha=\text { Non-linear parameters } \\
& \beta=\text { Linear parameters } \\
& \mathrm{T}=\text { Independent variable } \\
& \mathrm{L}=\text { Number of linear parameters } \\
& \varphi=\text { Nonlinear function }
\end{aligned}
$$

can be fitted by a non-linear least squares method by separately optimizing the linear parameters and the non-linear parameters. 
In the present case there is only one linear parameter (E) and five nonlinear parameters $\left(\alpha_{i}\right)$. The objective function (0) which is minimized by the least squares fit is given by

$$
O\left(E, \alpha_{i}\right)=\left[C_{i}-C\left(t ; E, \alpha_{i}\right)\right]^{2}
$$

where

$$
\begin{aligned}
& C_{i}=\text { Observed concentrations } \\
& \mathrm{C}=\text { Calculated concentrations }
\end{aligned}
$$

This function is minimized by using initial estimates of the non-linear parameters and then iterating to determine the optimum values of the non-linear parameters. The optimum linear parameter is then determined.

The details of how VARPRO works are discussed elsewhere. ${ }^{15,29}$ It is important to note that since a Taylor expansion of the objective function (0) with respect to the non-linear parameters $\left(\alpha_{i}\right)$ is used, an expression of the derivative of the two-dimensional solution with respect to the non-linear parameters was needed.

A summary of the input requirements of VARPRO is

(1) N observed concentrations $\left(C_{i}\right)$

(2) Value of the independent variable ( $T$ ) at each data point

(3) Estimate of the non-linear parameters

(4) Evaluation of the solution at any given $(T)$ and for any set of dimensionless variables $\left(\alpha_{i}\right)$

(5) Evaluation of the derivative of the solution with respect to the non-linear parameters at any given (T) for any set of $\left(\alpha_{i}\right)$.

The subroutine that calculated the solution and the derivative of the solution with respect to the non-linear parameters was called ADA. ADA needed to include the double Stehfest numerical inversion techniques used in the different GENERATE programs (see Section 7). Since the analytic solution is available 
only in $(p, y, s)$-space, the calculation of the derivatives was of necessity in ( $p, y, s)$-space also. Thus ADA needed to doubly invert both the solution and the derivatives. The calculation of the derivatives is discussed in Appendix (E).

A main program (MAIN) was also needed to; read in the data and the initial estimates of the non-dimensional variables, to call VARPRO, and to print the final results. A listing of CURVE.FIT, which is the program that incorporates VARPRO and all required subroutines, is given in Appendix (F).

The goal of CURVE.FIT is to determine the optimum values of the five dimensionless variables for a given set of real data. The goal of the entire tracer analysis is to determine something of the nature of the reservoir. This is done by relating the dimensionless variables to the reservoir parameters. There can be no unique determination of all of the different reservoir parameters because there are more unknown reservoir parameters than dimensionless variables. However it is possible to uniquely determine some of the physical parameters from the dimensionless variables.

The most important parameter that can be determined is the fracture half-width (w), which can be obtained directly. Using the definition of $\left(x_{D}\right)$, the fracture half-width is given by

$$
w=\frac{x}{x_{D}}
$$

where

$$
\mathbf{x}=\text { distance between wells }
$$

The fracture aperture is important not only to the flow model, as was shown in the sensitivity study, but also to any subsequent heat-transfer model that would be used to forecast thermal breakthrough. This ability to solve directly for the fracture width is a major advantage over preceding methods of curve fitting.

The other reservoir parameters cannot be directly determined but could be 
approximated if some additional information were available. From the definition of the Peclet number

$$
P_{B}=\frac{V_{m} w}{D_{m}}
$$

it can be seen that if the value for the velocity in the mobile phase $\left(V_{m}\right)$ were known then the diffusion coefficient in the mobile phase could be calculated. The velocity term can be approximated by using the breakthrough time $\left(t_{b t}\right)$ and the distance between the wells as

$$
V_{m}=\frac{x}{t_{b t}}
$$

This approximation ignores retardation effects. Using Equation $(9.10),\left(D_{m}\right)$ can be approximated by

$$
D_{m}=\frac{x w}{t_{b t} P e}
$$

Combining the definitions for $(\beta)$ and $(R)$, equations (6.36) and (6.37) respectively, gives $\left(\varphi_{m}\right)$ as

$$
\varphi_{m}=\frac{\rho P k}{\left[1-\frac{V_{m} R k}{w}\right]}
$$

The values of $(R)$, and $(\beta)$ are determined from the curve fitting procedure, (w) can be calculated and $\left(\mathrm{V}_{m}\right)$ can be approximated as discussed. It may be possible to determine $(k)$ experimentally and $(\rho)$ can be estimated. Values for $(P)$ cannot be determined, but since $(P)$ by definition ranges from zero to one only, equation (9.12) can give a range for $\left(\varphi_{m}\right)$.

A range for $\left(\varphi_{i m}\right)$ can be determined if a value for $\left(D_{i m}\right)$ can be experimentally determined since

$$
\varphi_{i m}=\varphi_{m}\left(\frac{D_{m}}{D_{i m}}\right)
$$

As shown above, the two-dimensional model developed in this study can be posed in the form necessary to apply a numerical curve fitting procedure. From 
this curve fitting technique it is possible to determine the optimum values of the dimensionless variables, and from the values of these variables it is possible to directly calculated the fracture width and to indirectly determine some of the other physical parameters used to develop the model. The application of this technique to real data is now discussed. 


\section{Section 10: APPLICATION OF TRACER TEST ANALYSIS TECHNIQUE}

The analysis technique discussed in the previous section was tested by applying it to data from tracer tests in the Wairakei geothermal field in New Zealand. This data was collected by the Institute of Nuclear Sciences of the Department of Scientific and Industrial Research. New Zealand, and made available to the Stanford Geothermal Program for this study. No attempt was made to interpret to results on a field wide basis, rather the purpose was only to test the curve fitting procedure.

The first important result found from attempting to fit the model to real data was that the initial values of the non-linear variables enter into the curve fitting process had to be "good guesses". If the initial values were not good choices the matching process would fail altogether. Good choices were determined by first generating return curves with the GENERATE.SPIKE program given in Section 6 that were similar to the real data.

The second important result was that the curve fitting procedure had very slow convergence with the flve parameter model. The consequence of this was that more than one combination of initial guesses of the non-linear parameters and subsequent numerical curve fitting was necessary to produce an acceptable fit. It was found that it usually took at least three series of guesses and numerical curve fittings to create a final fit. A flow chart of the procedure is shown in Figure (13). The most important step in the overall procedure was the intermediate step where the best fit values determined after numerically curve fitting were changed before re-entering the numerical curve fitting procedure. This step required a knowledge of how the variables affect the shape of the return curves. The sensitivity study discussed in Section (7) provided this information. 
The third general result found when using this curve fitting procedure with real data is that the procedure requires a large amount of computing time. An example case of twenty iterations on a data set of forty points took about 200 minutes of c.p.u. time on a DEC VAX \#750. Since any final match required many such fits the computing time became a constraint.

The result of the curve fitting procedure for wells \#24, \#103, and \#121 are shown in Figures (14), (15), and (16) respectively. In these figures the data are shown as crosses and the generated curves using the optimum values for the variables are shown as solid lines.

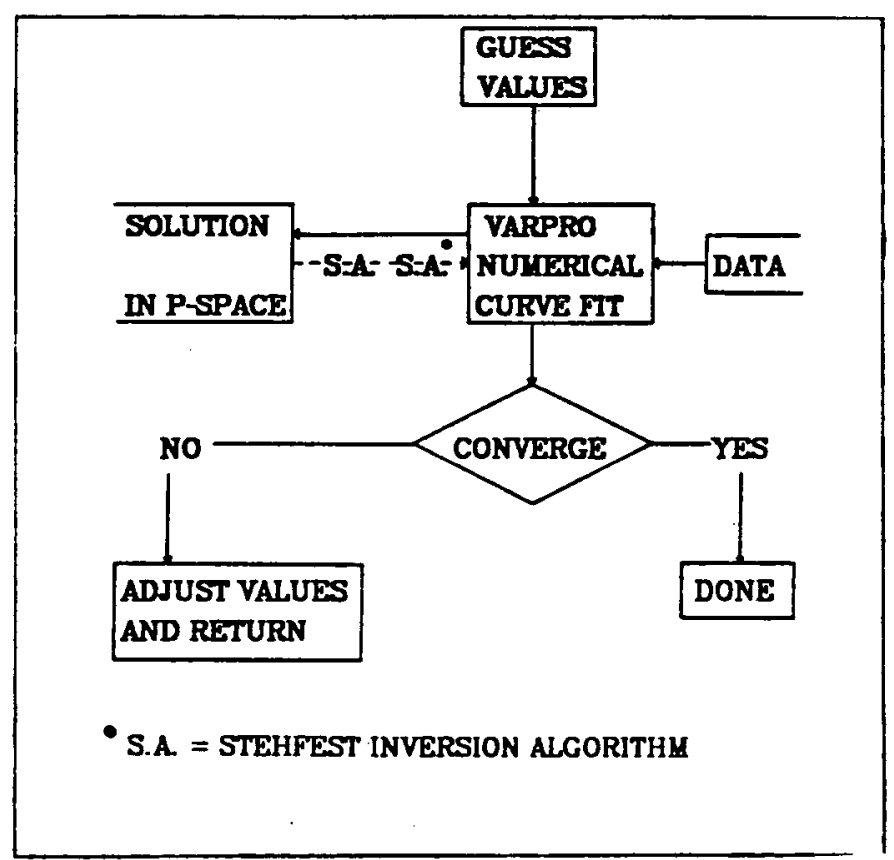

Figure 13 - CURVE FITTING PROCEDURE

In order to compare with other models, the results from the Fossum ${ }^{15}$ and Jensen ${ }^{16}$ models for the same wells using a single fracture fit are shown in Figures (17)-(22). The fits from the present study are better than those from Fossum's model and are comparable to those from Jensen's model.

The values of the dimensionless variables used to generate the curves shown in Figures (14)-(16) are given in Table (5). The only reservoir parameter that can be directly determined from the dimensionless variables is the fracture 


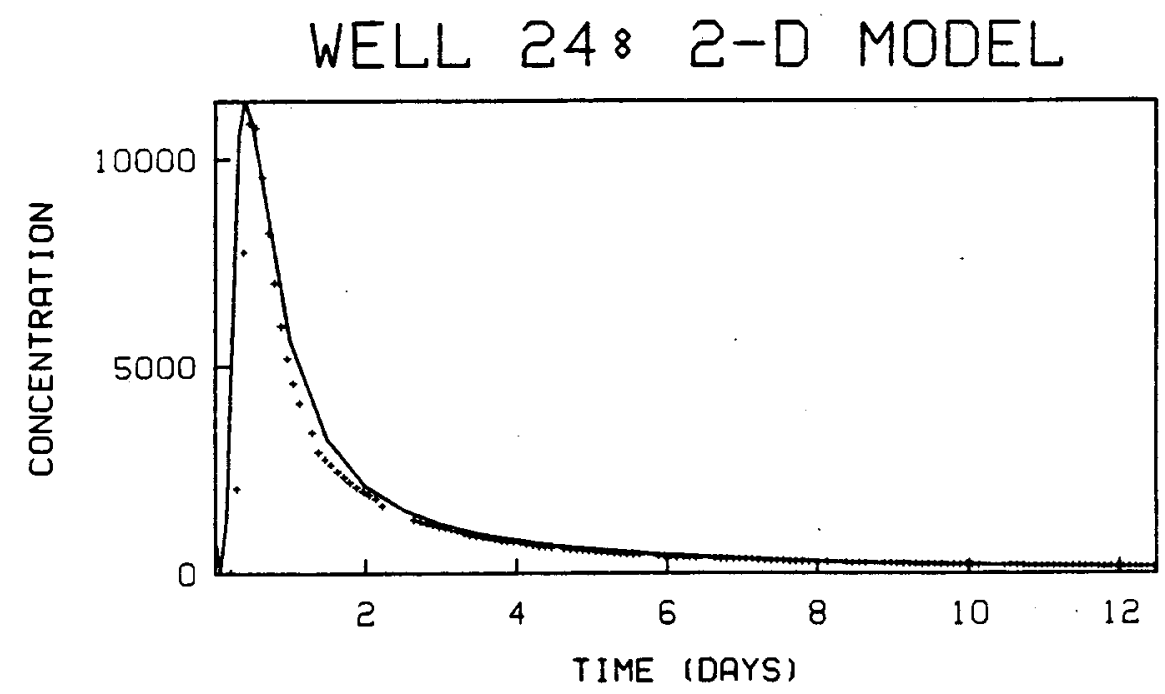

Figure 14 - WELL \#24 FIT WITH TWO-DIMENSIONAL MODEL

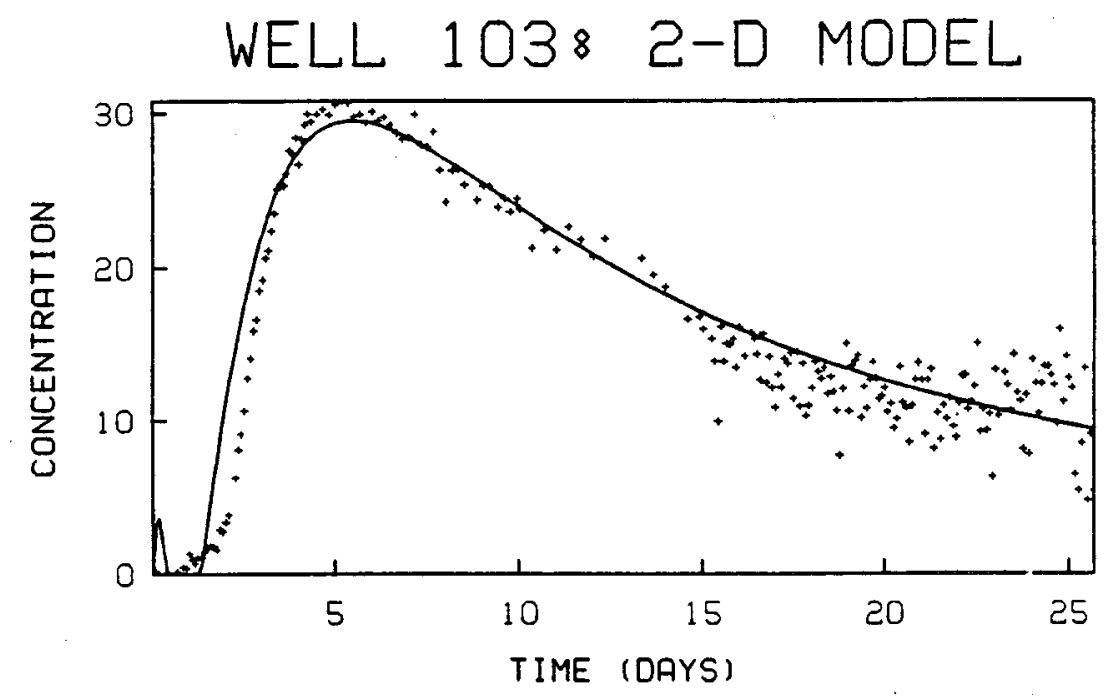

Figure 15 - WELL \#103 FIT WITH TWO-DIMENSIONAL MODEL

width. The value of the fracture width for each case is given in Table (6). The fracture widths shown in Table (6) range from a low of $2.7 \mathrm{~mm}$ to a high of $10.1 \mathrm{~mm}$. 


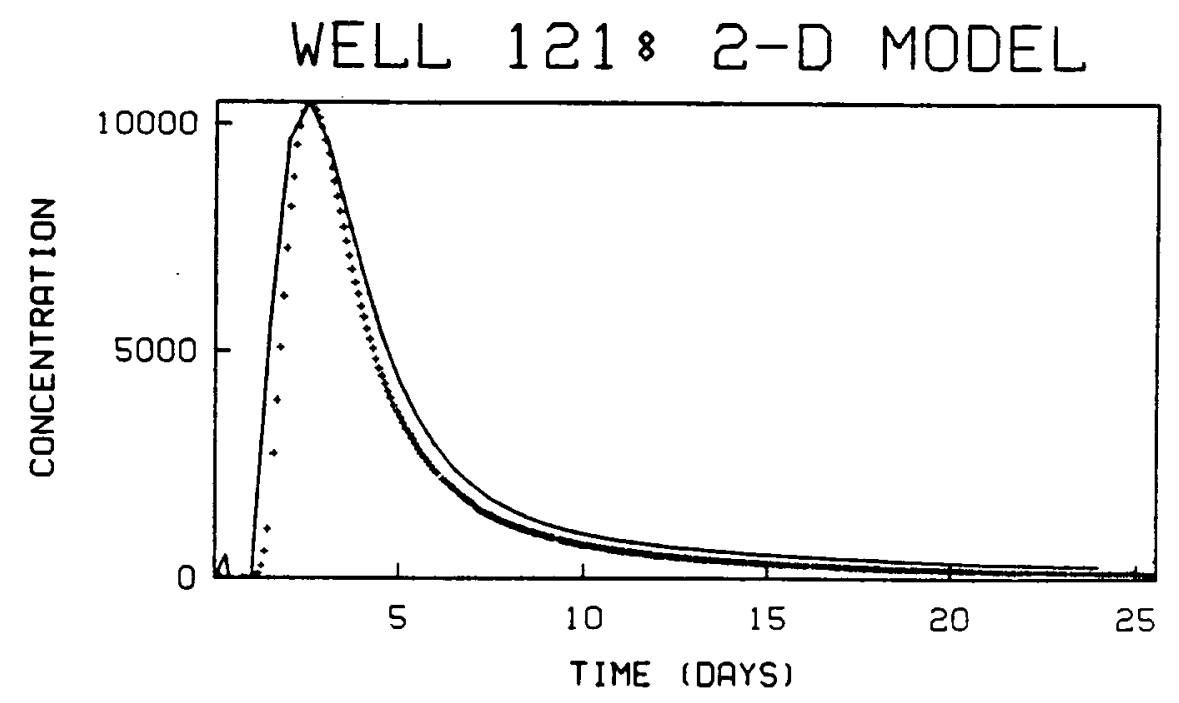

Figure 16 - WELL \#121 FIT WITH TWO-DIMENSIONAL MODEL

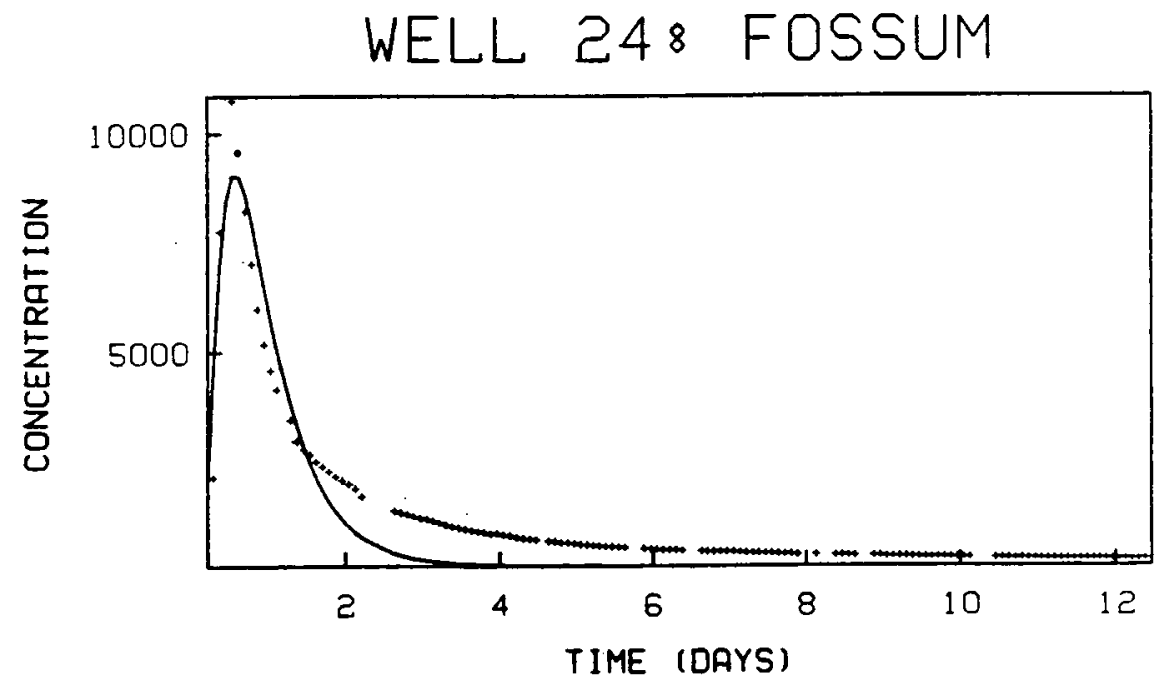

Figure 17 - WELL \#24 FIT WITH FOSSUM'S MODEL: 


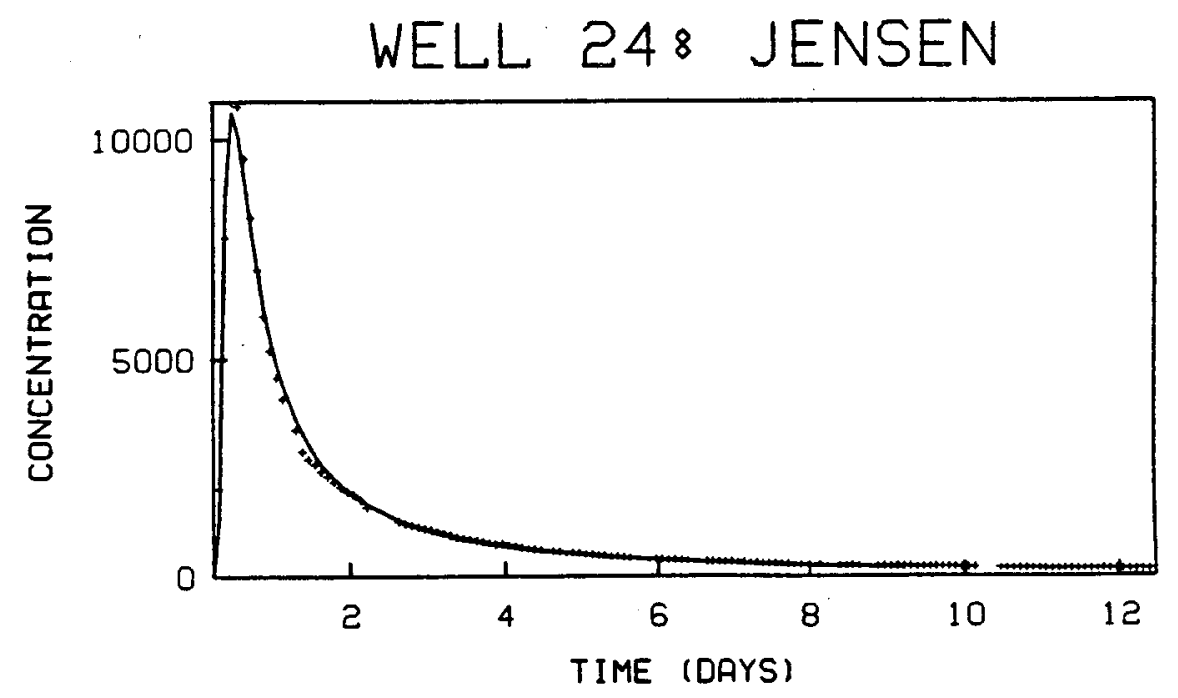

Figure 18 - WELL \#24 FIT WITH JENSEN'S MODEL

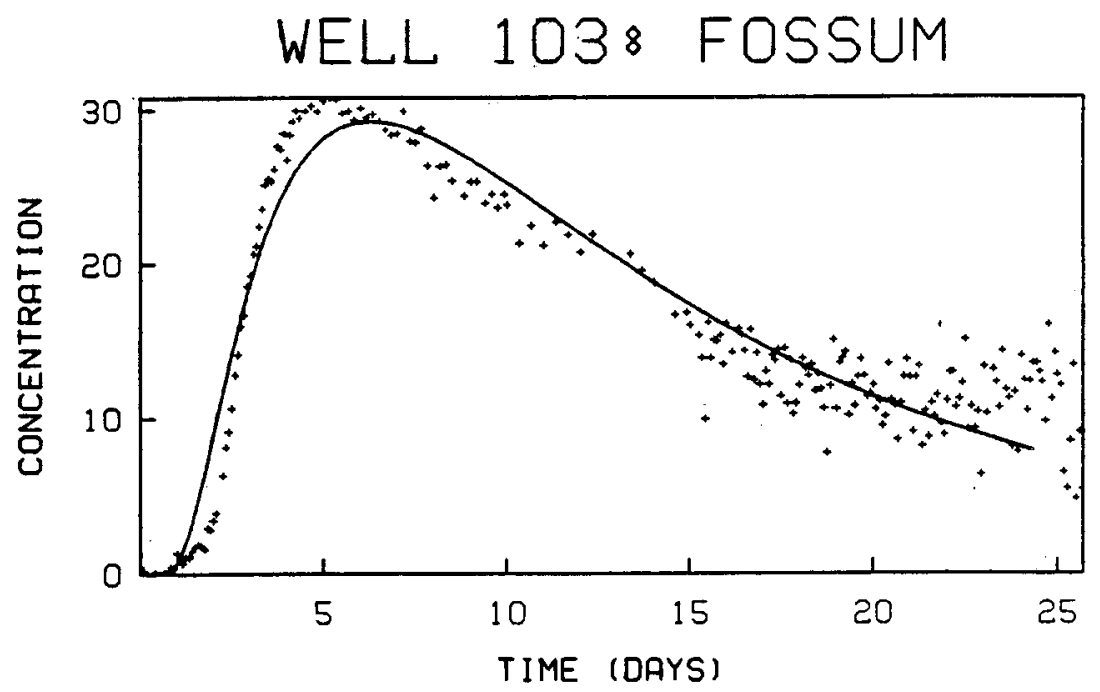

Figure 19 - WELL \#103 FIT WITH FOSSUM'S MODEL 


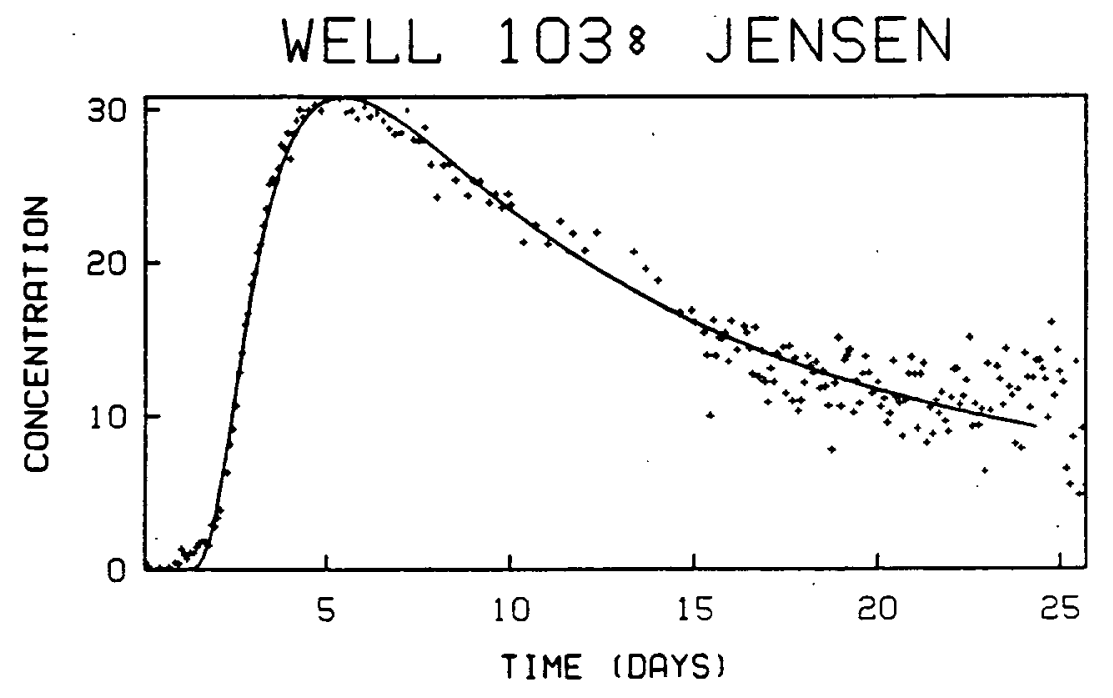

Figure 20 - WELL \#103 FIT WITH JENSEN'S MODEL

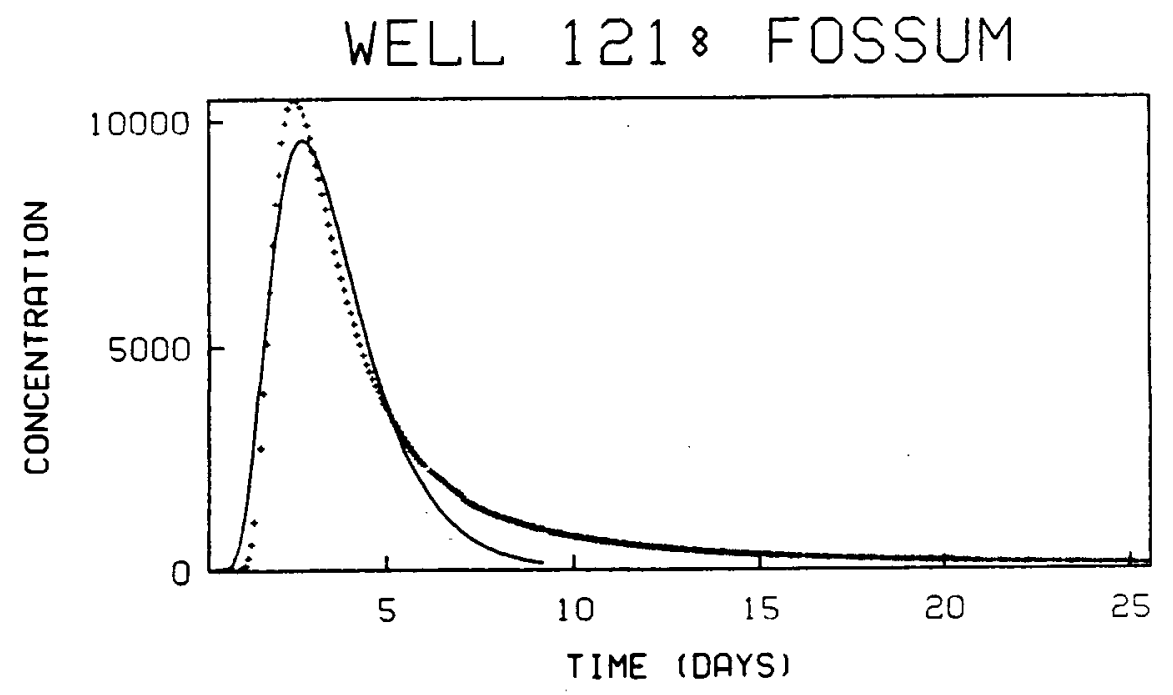

Figure 21 - WELL \#121 FIT WITH FOSSUM'S MODEL 


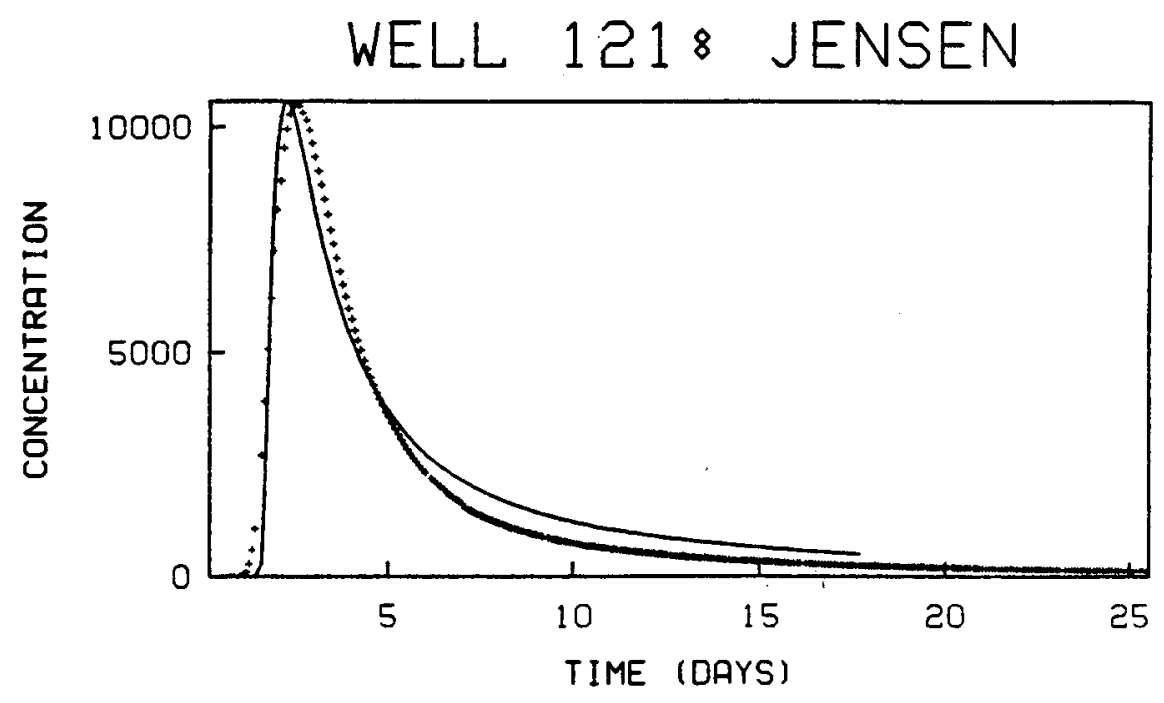

Figure 22 - WELL \#121 FIT WITH JENSEN'S MODEL

Table 5 - BEST FIT VALUES

\begin{tabular}{|c|c|c|c|c|c|}
\hline \hline WELL \# & $\boldsymbol{x}_{D}$ & $\mathrm{Pe}$ & $\boldsymbol{\beta}$ & $\mathrm{R}$ & $\alpha$ \\
\hline 24 & $1.55 \mathrm{E} 05$ & 0.201 & 0.502 & $2.01 \mathrm{E}-06$ & 0.0021 \\
103 & $5.01 \mathrm{E04}$ & 0.200 & 0.450 & $2.00 \mathrm{E}-05$ & 0.110 \\
121 & $9.71 \mathrm{E} 04$ & 0.170 & 0.500 & $3.44 \mathrm{E}-05$ & 0.004 \\
\hline
\end{tabular}


$-47-$

\begin{tabular}{|c|c|}
\hline TABLE 6 - CALCULATED FRACTURE NIDTHS \\
\hline \hline WELL \# & FRACTURE WIDTH (mm) \\
\hline 24 & 2.7 \\
103 & 6.6 \\
121 & 10.1 \\
\hline
\end{tabular}




\section{Section 11: CONCLUSIONS}

(1) Laboratory batch experiments run with Los Azufres, Mexico and Klamath Falls, Oregon reservoir rock are not sensitive enough to study the mass transfer processes active in tracer movement through a reservoir.

(2) A two-dimensional model that represents a fractured medium by a mobile region, in which convection, diffusion, and adsorption are allowed, and an immobile region, in which only diffusion and adsorption are allowed, can be used to represent tracer movement through a geothermal reservoir.

(3) The two-dimensional model that was derived in this study has demonstrated how each of the various mass-transfer processes included in the twodimensional model affect tracer return curves.

(4) It is possible to numerically fit real data to the two-dimensional model.

(5) The optimum values of the parameters determined from the curve fitting procedure provide a direct estimate of the fracture width and can be used to estimate other reservoir flow parameters if experimentally determinable values are known. 


\section{Section 12: SUGGESTIONS FOR FURTHER TORK}

An experimental study has been designed that would allow for experimental verification of the two-dimensional model developed in this study. This proposed study would use the same equipment as the experimental phase of the present study with only a few modifications.

The basic idea would be to separate the stainless steel core holder into a mobile and a immobile region by packing the center portion of core holder with larger grain material than the outer region. A large permeability difference between the two regions would effectively cause the center region to be mobile and the outer region to be immobile. Previous studies ${ }^{25}$ have shown that the difference in grain size required to achieve a 40:1 permeability ratio between center and outer region is not very large. Sand with a (8-12) mesh range, packed to approximately 35 percent porosity will give about a 1700 Darcy permeability while a (40-60) mesh range will only give about a 45 Darcy permeability.

Separation of the two sands would be maintained by a wire mesh tubular holder placed inside of the stainless steel core holder. Other necessary modiflcations to the present equipment would include:

(1) Using endplugs with a single port entrance to restrict flow to the center region.

(2) Rearranging the valves so that a instantaneous switch from water to tracer can be made.

By conducting flow tests in the apparatus described above it would be possible to verify that the two-dimensional model is correctly determining the "fracture" size by varying the diameter of the center region. Multiple tests (varying flow rates) could be used to determine other flow parameters such as the 
-50 -

diffusion coefficients. 
Section 13: REFERENCES

1. Horne, R.N., "Geothermal Reinjection Experience in Japan," Journal of Petroleum Technology, March 1982.

2. Fossum, M.P., Horne, R.N., "Interpretation of Tracer Return Profiles at Wairakei Geothermal Field Using Fracture Analysis," Geothermal Resources Council, Transactions, 6.

3. Strom, P.W., Johnson, W.E., "Field Experiments with Chemical Tracers in Flood Waters." Producers Monthly . Vol. 15, No. 2, 1951, 11-18.

4. Wagner, O.R., "The use of Tracers in Diagnosing Interwell Reservoir Heterogeneities - Field Results," Journal of Petroleum Technology , November, 1977.

5. Deans, H.A., "A Mathematical Model for Dispersion in the Direction of Flow in Porous Media," Trans. , AIME (1963), Vol. 228,49.

6. Carslaw, H.S., Jaeger, J.C., Conduction of Heat in Solids , Clarenden Press, Oxford, 1959.

7. Perkins, R.K., Johnson, O.C., "A Preview of Diffusion and Dispersion in Porous Media," Trans. AIME (1963), Vol. 228,70.

8. Coats, K.H., Smith, B.D., "Dead End Pore Volume and Dispersion in Porous Medial," SPE of AIME Trans. . March 1964, 73-84.

9. Brigham, W.E., "Mixing Equations in Short Laboratory Cores," SPE of AIME Trans. , Feburary, 1974, 91-99

10. van Genuchten, M. Th., Wierenga, P.J., "Mass Transfer Studies in Sorbing Porous Media; I, Analytical Solutions," Soil Science of America Journal . Vol.40, No.4, August, 1976, 473-480.

11. van Genuchten, M. Th., Cleary, R.W., "Movement of Solutes in Soil; Computer-Simulated and Laboratory Results," Soil Chemistry B. Physico -Chemical Models , Elsevier Scientific Publishing Company, New York, 1982.

12. Tester, J.N., Bivens, R.L. and Potter, R.M., "Interwell Tracer Analysis of a Hydraulically Fractured Granitic Geothermal Reservoir." Society of Petroleum Engineers Journal , vol.22, 537-545, 1982.

13. Breitenbach, K.A., Chemical Tracer Retention in Porous Media , Stanford Geothermal Program, SGP-TR-53, Stanford CA, May 1982.

14. Horne, R.N. and Rodriguez, F., "Dispersion in Tracer Flow in Fractured Geothermal Systems," Geophysical Research Letters . Vol.10. No. 4, 289292, 1983. 
15. Fossum, M.P., Tracer Analysis in a Fractured Geothermal Reservoir: Field Results from Wairakei, New Zealand , Stanford Geothermal Program, SGPTR-56, Stanford CA, June 1982.

16. Jensen, C.L., Matrix Diffusion and its Effect on the Modeling of Tracer Returns from the Fractured Geothermal Reservoir at Wairakei, New Zealand, Stanford Geothermal Program, SGP-TR-XX, Stanford CA, December 1983.

17. Sageev, A. Design and Construction of an Absolute Permeameter to Measure the Effect of Elevated Temperature on the Absolute Permeability to Distilled Water of Unconsolidated Sand Cores , Stanford Geothermal Program, SGP-TR-43, Stanford CA, December 1980.

18. Johnson, S.E., Doublet Tracer Testing at Klamath Falls Geothermal Resource: A Model Comparison, Stanford Geothermal Program, SGP-TR-XX, Stanford CA, June 1984.

19. Sufi, A.H., Ramey H.J., Brigham, W.E., Temperature Effects on Oil-Water Relative Permeabilities for Unconsolidated Sands . Stanford University Petroleum Research Institute, Stanford CA, October 1982.

20. Jackson, P.B., Method for the Collection and Analysis of Sample Fluids During a Tracer Test, Stanford Geothermal Program, SGP-TR-XX, Stanford CA, June 1984.

21. van Genuchten, M.Th., "Non-Equilibrium Transport Parameters from Miscible Displacement Experiments," United States Department of Agriculture Science and Education Adminstration, Report No. 119, U.S. Salinity Laboratory, Riverside CA, February 1981.

22. Stehfest, H., "Algorithm 368 Numerical Inversion of Laplace Transforms," Communications of the ACM , January 1970.

23. VARPRO, Computer Science Department, Stanford University, Stanford CA.

24. Golub, G.H., Pereya, V., "The Differentiation of Pseudo-Inverses and Nonlinear Least Squares Problems Whose Variables Separate," SIAM Journal of Numerical Analysis, Vol. 10. No. 2, 413-431, 1973.

25. van Poollen, H.K., Tinsley, J.M., and Saunders, C.D., "Hydraulic Fracturing Fracture Flow Capacity vs. Well Productivity," Trans. AIME (1958), Vol. 213,91. 
$-53-$

Appendix A: DERIVATION OF SOLUTION TO TWO DIMENSIONAL MODEL

The defining partial differential equations are

$$
\beta R \frac{\partial C_{1}}{\partial t}=\left(\frac{1}{P e}\right) \frac{\partial^{2} C_{1}}{\partial y^{2}}-\frac{\partial C_{1}}{\partial x_{D}}
$$

and

$$
(1-\beta) R \frac{\partial C_{2}}{\partial t}=\left(\frac{\alpha}{P e}\right) \frac{\partial^{2} C_{2}}{\partial y_{D}^{2}}
$$

where

$$
\begin{aligned}
& 1=\text { mobile region } \\
& 2=\text { immobile region }
\end{aligned}
$$

The initial and boundary conditions are

$$
\begin{gathered}
C_{1}\left(x_{D}, y_{D}, 0\right)=C_{2}\left(x_{D, y_{D}} 0\right)=0 \\
\left.\frac{\partial C_{1}}{\partial y_{D}}\right]_{y_{D}=1}=0 \\
\left.C_{1}\right|_{y_{D}=1}=\left.C_{2}\right|_{y_{D}=1} \\
\left.\frac{\partial C_{1}}{\partial y_{D}}\right|_{y_{D}=1}=\left.\alpha \frac{\partial C_{2}}{\partial y_{D}}\right|_{y_{D}=1} \\
\left.\frac{\partial C_{2}}{\partial y_{D}}\right]_{y_{D}=-}=0 \\
C_{1}\left(0, y_{D}, t_{D}\right)=1
\end{gathered}
$$

Transforming equation (A.1) with respect to $t$ (ie. $t$ goes to $s$ )

$$
\begin{gathered}
\left.\beta R\left[s \bar{C}_{1}-C_{1}\right]_{t=0}\right]=\left(\frac{1}{P_{e}}\right) \frac{\partial^{2} \bar{C}_{1}}{\partial y_{D}^{2}}-\frac{\partial C_{1}}{\partial x_{D}} \\
s \beta R \bar{C}_{1}=\left(\frac{1}{P_{e}}\right) \frac{\partial^{2} \bar{C}_{1}}{\partial y_{D}^{2}}-\frac{\partial C_{1}}{\partial x_{D}}
\end{gathered}
$$

Transforming equation (A.9) with respect to $\left(x_{D}\right)$ (ie. $x_{D}$ goes to $p$ )

$$
\left.s \beta R C P=\left(\frac{1}{P e}\right) \frac{\partial^{2} \bar{C}_{1}}{\partial y_{D}^{2}}-\left[p C P-\bar{C}_{1}\right]_{x=0}\right]
$$

Transforming boundary condition (A.5) and rearranging gives

$$
\left(\frac{1}{P e}\right) \frac{\partial^{2} \bar{C}_{1}}{\partial y_{D}^{2}}-(p+s \beta R) C_{1}^{p}=\frac{-C_{0}}{s}
$$


Equation (A.10) can be treated as an ordinary differential equation in $\left(y_{D}\right)$, and can be solved by method of undetermined coefficients. The solution to the corresponding homogeneous equation is

$$
(C P)_{H}=A e^{m y_{D}}+B e^{-m y_{D}}
$$

where

$$
m=\left(\frac{1}{P_{e}}\right)^{\frac{1}{2}}(p+s \beta R)^{\frac{1}{2}}
$$

The solution of the corresponding particular problem is

$$
\left(C_{P}\right)_{P}=\frac{C_{0}}{s(p+s \beta R)}
$$

The general solution is given by the sum of the homogeneous and particular solutions, thus the general solution is

$$
C P=A e^{m y_{D}}+B e^{-m y_{D}}+\frac{C_{0}}{s(p+s \beta R)}
$$

Transforming equation (A.2) with respect to (t) (ie. $t$ goes to $s$ )

$$
\left.(1-\beta) R\left[s \bar{C}_{2}-C_{2}\right]_{t=0}\right]=\left(\frac{\alpha}{P \varepsilon}\right) \frac{\partial^{2} \bar{C}_{2}}{\partial y_{D}^{2}}
$$

or

$$
\left(\frac{\alpha}{P e}\right) \frac{\partial^{2} \bar{C}_{2}}{\partial y_{D}^{2}}-s(1-\beta) R \bar{C}_{2}=0
$$

This is an ordinary differential equation whose solution is given by

$$
\bar{C}_{2}=M \mathrm{e}^{x y_{D}}+N \mathrm{e}^{-z_{D}}
$$

where

$$
\mathrm{z}=\left[\frac{P_{\mathrm{e}}(1-\beta) R s}{\alpha}\right]^{\frac{1}{2}}
$$

Boundary equation (A.4) determines that $(M)$ is equal to zero and boundary equation (A.2) gives

$$
\left.N=\left(\bar{C}_{1}\right]_{y_{D}=0}\right) e^{z\left(1-y_{D}\right)}
$$

Thus the solution for $\left(C_{2}\right)$ in $(x, y, s)$-space is 


$$
\left.\bar{C}_{2}=\left(\bar{C}_{1}\right]_{y_{D}=1}\right) e^{z\left(1-y_{D}\right)}
$$

Since in equation (A.12) only $\left(C_{1}\right)$ is a function of $\left(x_{D}\right)$ equation (A.12) can be transformed with respect to $\left(\mathrm{x}_{D}\right)$ (ie. $\mathrm{x}_{D}$ goes to $\mathrm{p}$ ) as

$$
\left.\left.C_{2}^{P}=\left(C_{P}\right]_{\nu_{D}=1}\right)\right] e^{z\left(1-y_{D}\right)}
$$

To determine the unknown parameters $A$ and $B$ in equation (A.11) both equations (A.11) and (A.13) must be solved simultaneously. Applying boundary equation (A.4) gives

$$
A=B
$$

Applying boundary equation (A.6) gives

$$
A=-\left[\frac{2 \alpha C_{0}}{s(p+s \beta R)}\right]\left[\frac{1}{(1-\alpha) M\left(e^{m}-e^{-m}\right)}+z \alpha\left(e^{m}+e^{-m}\right)\right]
$$

Using equation (A.14) in equation (A.11) gives the solution of the partial differential equation (A.1) and (A.2) for $\left(C_{1}\right)$ as

$$
C_{1}^{p}=\frac{C_{0}}{s(p+s \beta R)}-\left[\frac{z \alpha C_{0}}{s(p+s \beta R)}\right] \frac{e^{m y_{D}}+e^{-m y_{D}}}{(1-\alpha) M\left(e^{m}-e^{-m}\right)+z \alpha\left(e^{m}+e^{-m}\right)}
$$


Appendix 3: LISTING OF GEINERATE STEP ANO SAMPLE INPUT AND OUTPUT

L IS THF NUHEER OF LINEAR FARAMETEFS

$L=N L / 5$ WRITE (, 35$)$ IL

35 FORIMAT (NUMBER OF LINEAR PAFAMETERS $=$, IE)

c

IN IS THE NUMBER GF DESERVATIDHE

READ $(5, *)$ N

WRT TE $(0,40)$ iN

45 FORMAT: NUMEEF OF DESERWATIDHS $=1,14:$

I READ AND WRITE ESTIMATES DF WUWLIVEAR FARAIETEIS 


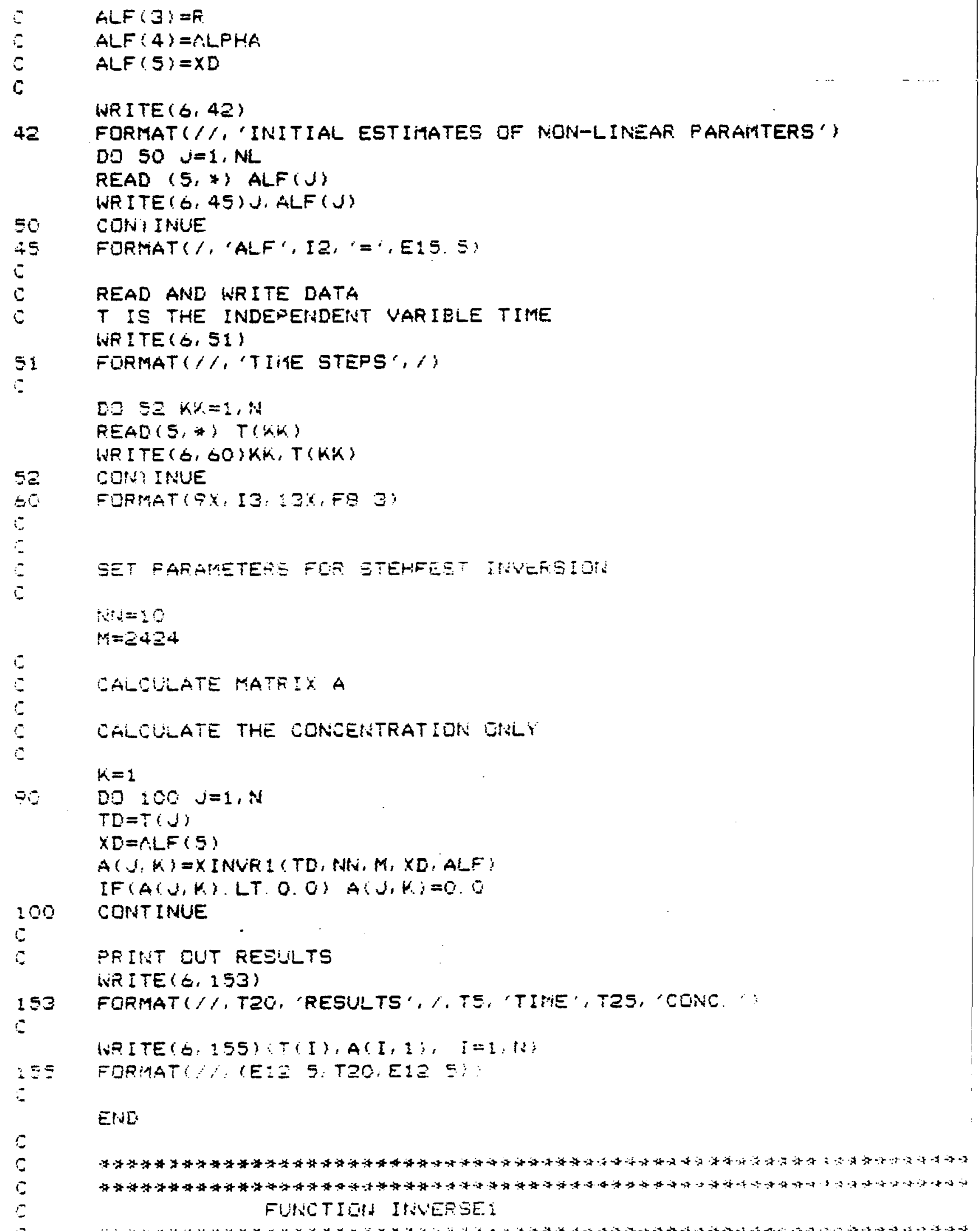


THE STEHFEST ALGORITHM

THIS IS THE FIRST INVERSION WHICH GOES FROM ( $X, Y, S)$-SPACE BACK TO REAL TIME. IT NEEDS THF EVALUATIOK OF THE FUNCTION IN S-SPACE ANU TO DO THIS IT CALLS SFUNCTION AS A FUNCTICN

FUNCTION XINVRI (TD,N, M, XD, ALF)

THIS FUNTION COMPUTES NUKERICALLY THE LAFLACE TRNSFORI INVERSE QF $F(S$ ?

IMPLICIT REAL*E (A-H. Q-Z)

DIMENSION G(50), V(SO), Hi(25)

WOW IF THE ARRAY UTI; WAS CDMPUTED BEFDRE THE PROGRAM GOES DIFECTLY TO THE EUS IF THE SUEPUTIRE TO CALCULATE F:S

IF (R. ED IS OD TO 17

$M=14$

DLEOTW $=0.531471805599$

$\mathrm{N} H \mathrm{H}=\mathrm{H}, \mathrm{N}=$

TERMS WITH W OWLY ARE GALCULATED IRTC ARFAY H $H(I:=2 . / G(N H-1)$

$D O=I=\Sigma_{1}, 14 H$

$F I=I$

IF (I-NH) $4,5, G$

$\div \quad H(I)=F I * N H * G(2 * I) ;(G(H H-I) * G(I) * G(I-I))$

Gi] T⿱

$5 \quad H(I)=F[* H H * G(2 * I) /(G(I) * G(I-1)$

$=$ COTIIINUE

5

THE TERHE $(-1 ; \# \# N H+1$ AFE CALCULATES

FIRST THF TERH FOR I $=1$

$5 H=2 *(N H-H H / 2 * 2:-1$

THE REST OF THE SN'S ARECALCULATED IH THE ":Ail: FUTINE. ,

$$
\text { DI THE ARRAY VII IS GALULATED }
$$

ViI $I=0$

FIRST SET VII $=0$

THE LIMITS FOF K ARE ESTABLISHED

THE LUWER LIMIT IS KI=IRTEQ: ITZ: $:$ : 


$$
H I=(I+1): \Omega
$$

E

$c$

$$
K e=I
$$

$$
\text { IF (KI-NH) B, 8, ? }
$$

9

$K 2=N H$

$c$

THE SUMMATION TERM IN V(I) IS CAI_CULATED.

DO $10 k=k 1, k \geq$

IF $(2 * k-I) 12,13,12$

$1 \cong \quad$ IF $\{I-H\} 11,14,11$

:1 V(I)=U(I)+H(K), (G(I-K)*G!2*H-I)

GD TO 10

$1 \Xi \quad V i I ;=U(I)+H(i), G(I-k)$

G. $10 \quad 20$

$14 \quad V(I)=U(I)+H(K), G(2 * K-I)$

:O COLITIMUE

c

c

8

$\div$

6

$$
\exists i=-E: ?
$$

THE VII ARRAY IS FINALLY CAICULATEE EY WEEGHTING ACCORDIKG TO SN

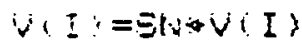

Y BOW!IHUE

$-$

$\Sigma$

THE WUMERICAL AFFFOKIMTTEOK IS GALCLLATEO

$X I P S R 1=0$.

$A=D L D G T ! N T$ TD

DO $15 \quad I=1, N$

$A R G-A-x I$

XINTR $I=X I N V R I+V I I\}+$ SFUNC $\{A R G, I, X D, A L F\}$

15 COHTINUE

XINVRI $1=X$ IPUVR $1 * A$

18 RETURN

ETSD

s

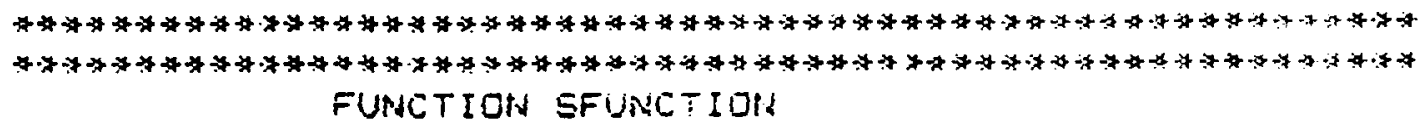

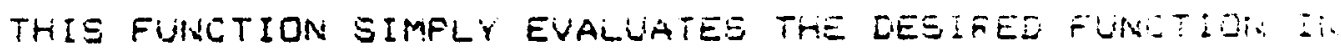
S-SPACE BY CALLING FOR A SECOND INVERSION USING THE STEHFAST ALGORITHW. IT SHOULD BE NOTEC THQT THE VAFIELE THAT IS TRANSFORMED FRDIA GOING FFOIT S-SFALE TO $=-E F A C$ IS XD THUS $S$ IS $A$ CONSTALT FROH THIS FDIH: OH: 
$c$

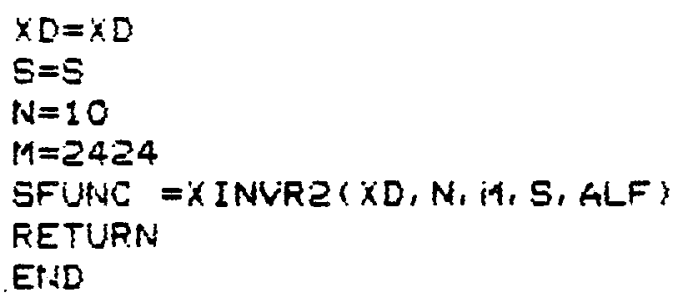

THIS FUNCTIOM WILL IHUERT FRDM (P, Y, S)-SPACE TO ( $X, Y, 5$ )SPACE HITH XU BEING THE VAFIELE OF INUERSIDN. THE FUNCTI NEEUS AH EXPRESSION FOR THE FUNCTION IIS F-BPACE AND THIS IS DONE BY CALLING PFUNC $(X D, 5$ ?

FUNCTIOH XINURE (XD,N,M, S, LLF)

THIS FUMTIOH COMPUTES HUMERICALLY THE LAFLACE TRMSFCRK INUERSE DF FIS:

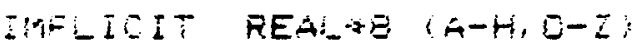

DIMENEION G(50), Viso!,Hi25)

NOW IF THE ARRAT VII: WAS COMFUTED DEFDRE THE FFDGRAM GOES DIRECTLY TO THE END GF THE SUEFUTINE TO GALGULATE Fi: :

IF (N.EQ.M) GO TD IT

$M=E N$

DLOGTH'=0. 6531471805599

$N H=N / 2$

THE FACTORIALS OF 1 TO $N$ GRE CALCULATED INTO AFAAY G. GiI $:=1$

Do $1 \quad I=2, i N$

Gi $I:=G(I-1) * I$

1

COHI INUE

TERMS WITH K ONLY ARE CALCULATED IIJTO GRRAY H $\mathrm{H}(1)=2, / \mathrm{G}(\mathrm{NH}-\mathrm{i})$

DD $6 I=2, N H$

$F I=I$

IFII-NH: $4,5,6$

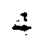

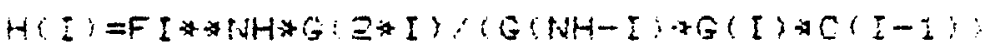

GT TO

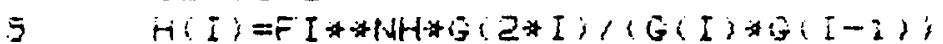

$\Leftrightarrow$ CONTINUE

THE TERMS $(-1) *$ *HHI: ARE CALCULATEL

FIRST THE TERIA FOR $i=i$

$S \cdot 4=2 *(H H-H H / 2 * 2)-1$ 
5

C

s

C

c

$E$

E

$C$

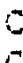

$c$

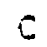

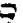

:

C

$\Xi$

$i=$

$\therefore$

$c$

C

7

5

5

17

15

$1:$

THE REST CF THE SN'S AREGALCULATED IN THE MAIN RUTINE.

THE ARRAY V(I) IS CALCULATED.

DO $7 I=1, N$

$V(I)=0$.

FIRST SET $V(I)=0$

THE LIMITS FOR \& ARE ESTABLISHED

THE LOWEF: LIMIT IS KI=INTEG $(I+1 / 2)$

$K I=\{i+i ; / 2$

$K e=I$

THE UPPER LIAIT IS KI=HIINUI, N/2)

IF (KZ-NH) $8, E, 9$

$M E=M H$

THE SUMMATICN TERM IN U(I) IS CAL_CULATED.

Do :O $k=k 1, k \geq$

IF $\{2+k-I\} 12,12,12$

IF $(I-k) 11, \pm 4,21$

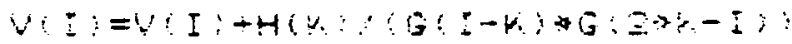

3.9 TO 10

VII!=V(I)+H(s)/G(I-H)

GQ TD 19

$V(I:=U(I)+H(H), G(\Xi * k-I)$

cot? INUE

THE UTI ARRAY IS FINAILY CALCULGTED BY WEIGHTING ACCEROING TO S?.

$U(I)=\sin (\mathrm{U})$

$2 n:=-E R$

THE TERM SN CHANGES ITS SIGN EACH ITERATION

CONTINUE

THE NUMEFICAL APPROXIMATICA IS CALCLLATED.

$X I N V R=0.0$

$A=D L D G T W / X D$.

DO $15 \quad I=1, N$

$\triangle R G=A+I$

$X$ INVRZ = XINVRE+V (I ; AFFUNC (ARG, I, S, ALF!

CONTINUE

XINURZ $=$ XINURZ*A

FET:RIS

ET:L. 
C

FUNCTIOT FFUNC

C

$* * * * * * * * * * * * * * * * * * * * * * * * *$

c

FUNCTION PFUNC (P, I, S, ALF?

IMPLICIT REAL

DIMEWSIDN F(4), ALF $(20\}$

$Y D=0.5$

r.

C INITIALLY SET ALL VALUES TO ZERD

CD $I I=1,4$

$F(I)=0.0$

1 EOWIIUUE

$F F=O . O$

$c$

C

CALCULATE THE COMPDHENTS OF THE CONGENTEATION FUNCTIOH

$$
\begin{aligned}
& I=(\{4 F\{1) *(1 .-A L F(2)) * A L F(3) * 5) / 4 L F(4) \div * * 0.5 \\
& X ! 1=(P+S * A L F(2) * A L F(3) ; / A L F(1 ;) * 0.5
\end{aligned}
$$$$
z P=Z, X X Y
$$

$F(1)=1 ;(S *(P+(S * A L F(2) * A L F(3)\})\}$

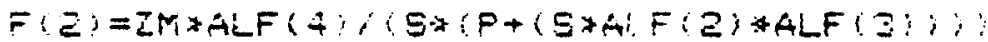

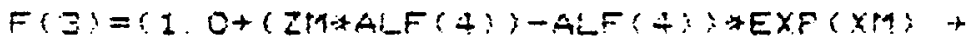

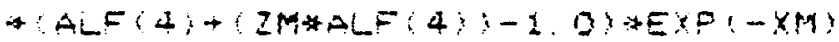

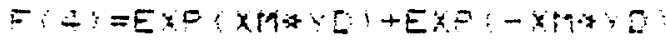

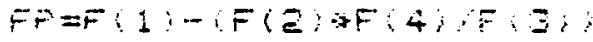

FFINTSEFF

FET:PR!s

ENT

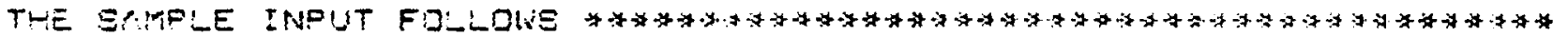

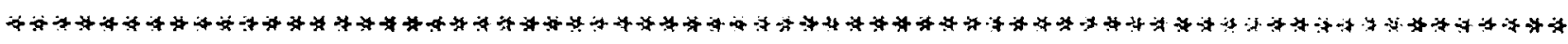
TEST: GENERATE A STEF

3

․ $19972 E-O 5$

0.0070049

o $16531 E 06$

i.

$\bar{c}$

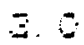

i. 0

5

7

9

13

13

15

17

19

$=:$

$=$

$2=$

국.

$=$

THE SAMPLE DUTPUT FDLLOWE*

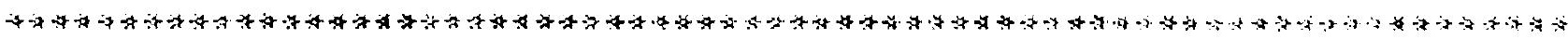




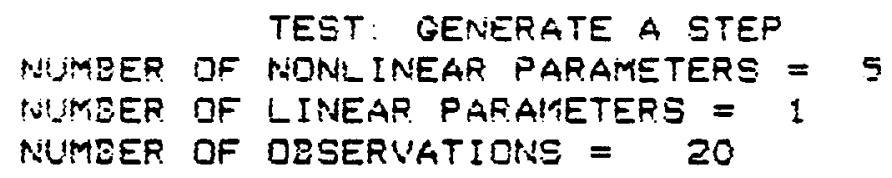

IUITIAL ESTIMATES UF NCN-LINEAR PARAMTERS
ALF $1=$
o. $201402: 00$
LLF $\Xi-$
0. $49742 e+00$
ALF $3=$
0. $19972 e-05$
ALF 4=
0. $70049=-02$
A.F $5=$
$0.16531 e+06$

\section{TIME STEPS}

$\begin{array}{lr}1 & 0.010 \\ 2 & 9.100 \\ 3 & 2.00 \\ 4 & 1.000 \\ 5 & 2.000 \\ 6 & 3.000 \\ 7 & 4.000 \\ 8 & 5.000 \\ 7 & 7.000 \\ 12 & 9.000 \\ 11 & 12.000 \\ 12 & 13.000 \\ 13 & 15.000 \\ 14 & 17.000 \\ 15 & 19000 \\ 16 & 21.000 \\ 17 & 23.000 \\ 18 & 25.000 \\ 19 & 27.000 \\ 20 & 29.000\end{array}$

TIVE

$$
\begin{aligned}
& \therefore: 00000-01 \\
& \text { 0. } 20000 e+00 \\
& \text { - 50000e+00 } \\
& \text { c. } 10000 e+01 \\
& \text { o. 20000a+01 } \\
& \text { o. } 30000 \mathrm{CO}+01 \\
& \text { c. } 40000 e+01
\end{aligned}
$$

\section{FESULTS}

cotse.

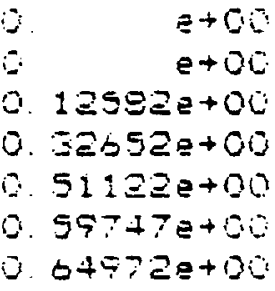

i. $\quad e+00$

o. $125922+00$

o. $32 b 52 e+00$

a. $51122 e+00$

0. $04972 e+00$ 
$-84-$
c. $50000 e+01$
$0 . \pm 857 \leqslant 2+00$
c. $70000 e+01$
o. $73350 e+00$
0 70000e+01
o $76453 e+00$
o. $11000 e+02$
o. $78677 e+00$
o. 13000e+02
o. $80371 e+00$
$0.15000 a+02$
o. $81716 e+00$
c. $17000 e+02$
o. $82818 \mathrm{e}+00$
c. $19000 \mathrm{e}+0 \mathrm{e}$
o. $83743 e+00$
o. $21000 e+02$
o. 845.33e+00
- 23000e+02
$0.85217 e+00$
C. 25000e+02
b. $27000 \mathrm{e}+02$
c. $29000 e+02$
o. $85818 e+00$
o. $86352 e+00$
C. EยE2 $29+C 0$ 
Appendix C: LISTING OF MAIN UF GERERATE. FINSTEP AND SAMPLE INPUT

$c$
$c$
$C$
$c$
6
6
6

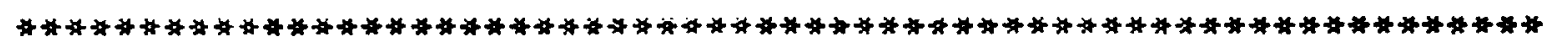

GENERATE. FINSTEP

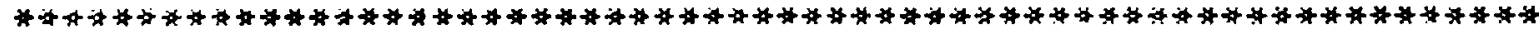

PROGRAIT EEGITSE

E

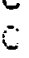

REAE ANE WRITE INITIAL DATA

REAE:S, IOCTITLE

$\therefore$ FOEIATEIEA4)

WRITE $(\dot{E}$, EO) GTITLE

$\because$ FIRMAT (1CX, ICA4)

5

NL IS THE NUMEEF DF NDNL INEAF PAFAIAETERS

SET NL $=S$ FCIR SING:E FRACTLIRE

$N L=5$

WRITE:6. 30) ML

30 FORMAT( NUMBER OF NONLINEAR PARAMETERS $=$ ', I $\equiv$ )

C.

5

L IS THE NUTBER GF LINEAR PARATIETERS

$L=N L i 5$

WFITECO, 35)L

35 FORIAAT: NUMBER OF LINEAR PARAMETERS $=$ : IZ;

5

$N$ IS THE NUMBER CF OBSERVATIOHS

READ (5, *; N

IVRITE $(6,40)$ N

5

DELT IS THE CURATION QF THE STEP ITVUT

4C FOEIAT: MUMBEF OF DESER:ATIONE = :I:

READ (S, * DELT

WRITE $(E, 41)$ DELT

4 FORMAT!'DURATION OF STEF INPUT = 'FG. 2 : 
READ AND WRITE ESTIMATES OF NONLINEAR PARAMETERS ALF $(1)=P E C L E T$ NUMBER = PE

C ALF $(2)=B E T A$

C ALF $(3)=R$

C ALF $(4)=A L P H A$

C ALF $(5)=\times D$

C

42 FORMAT(KI' 'INITIAL ESTIMATES OF NON-LINEAR PARAMTERS') DD $50 \mathrm{~J}=1, \mathrm{NL}$

REAL $(5, *)$ ALF (J)

ISRITE(6, 45) J, ALF (J)

5C. CORTINUE

45 FOFIAT $/$, 'ALF:, I2, '=', E15. 5!

$\mathrm{C}$

6 READ AIVI WRITE DATH

C T IS THE INDEFENDENT VARIELE TIME

WRITE $(6,51)$

5 S FORMATIII, 'TIME STEFS',

C

DO SE $K \mathcal{N}=1, N$

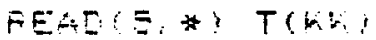

WFETE

5E COHTINUE

EC FDRIAT (9X.I3, 13X,FB. 3)

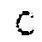

5

C

c

SET PARAMETERS FOR STEHFEST INVERSION

$N N=10$

$M=2424$

C

C

5

c

c

$-$

90

CALCULATE MATRIX A

CALCULATE THE CONICEHTRATION ONLY USE SUPERPCISITION

$K=1$

DO $100 \mathrm{~J}=1 \ldots \mathrm{N}$

$X D=4 L F(5)$

$T D=T(U)$

$A(J, H)=X$ INVRI $(T D, N H, M, X D, A L F$;

IF $(A(J, K) . L T . O . O) \quad A(J, K)=0.0$

IF(TD. LE DELT) GO TO 100

$T E=T(S)-D E L T$

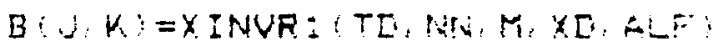

$A i j, K)=A(j, K:-B(J, K)$

IF $(A(J, K)$. LT. O. O) A J,K)=O. C

SG CONTINUE

$\mathrm{C}$

E PRINT QUT RESULTE 
WFITE (6: 153)

153 FORMAT!/, T2O, 'RESULTS', /,TS, 'TIME', T25, 'CONC. ')

c WRITE (6, 155) (T(I), A $(I, 1), I=1, W)$

155 FORMAT(/, (E12.5, T2O,E12.5))

C

END

A SAMFLE INPUT FOLLDISS $* * * * * * * * * * * * * * * * * * * * * * * * * * * * * * * * * * * * *$

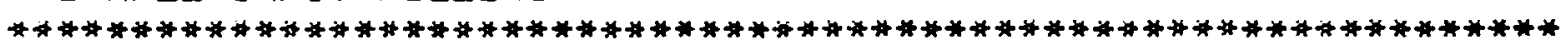
TEST: GENERATE A FINITE-STEP

27

16

0. $19972 E-05$

o. 0070049

o. $16531 E 0 E$

1.

2

3.

4. 0

5

0

7

E.

7.

$\therefore:$

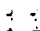

$\therefore$

$\because$

$i a$

$\because \because$

15

i?

19

15

20

22

$=$

20

$\because \Xi$. 
Appendix D: LISTING OF SFUNCTICN FOR GENERATE. SPIXE

$\mathrm{c}$

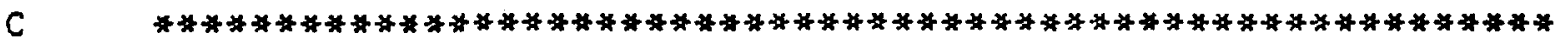

C $\quad * * * * * * * * * * * * * * * * * * * * * * * * * * * * * * * * * * * * * * * * * * * * * * * * * * * * * *$ C FUNCTION SFUNCTION

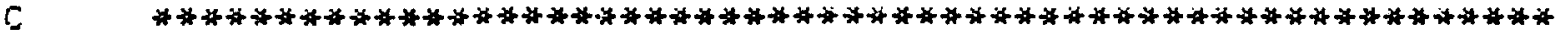

C

FUNCTION SFUNC (S, I, XD, ALF)

IMPLICIT REAL $\$ 8(A-H, 0-Z$;

C

C THIS FUNCTION SIMPLY EVALUATES THE DESIRED FUNCTION IN

C S-SPACE BY CALLING FOR A SECOND INUERSION USING THE

- STEHFAST ALGORITHA. IT SHOULD BE NOTED THAT THE VARIBLE

C THAT IS TRANSFORMED FROM GOING FROM S-SPACE TO P-SPACE

C IS KD THUS $S$ IS A CONETANT FROM THIS POINT ON.

c

$\mathrm{S}$

$c$

$c$

NDTE THE TIME DERIVATIVE NECESSARY FGR THE SPIKE INPUT IS ACHIEVED BY MUETIFLING THE FURETION EY 5

$\times D=\times D$

$\mathrm{S}=\mathrm{S}$

$N=10$

$M=2424$

SFUNC $=S * X$ INURZ $(X D, N, M, S, A L F)$

RETURN

END 


\section{Appendix E: CALCULATION OF THE DERIVATTVES OF THE TWO-DIMENSIONAL YODEI}

The calculation of the derivative of the solution equation (6.39) with respect to the five dimensionless variables was done in $(p, y, s)$-space. These values were then doubly inverted and entered to the curve fitting program as needed. The analytic expression for the solution is

$$
C p=\frac{C_{0}}{s(p+s \beta R)}-\left[\frac{z \alpha C_{0}}{s(p+s \beta R)}\right] \frac{e^{m y_{D}}+e^{-m y_{D}}}{(1-\alpha) M\left(e^{m}-e^{-m}\right)+z \alpha\left(e^{m}+e^{-m}\right)}
$$

To simplify the calculation of the derivatives, the solution has been separated into the following functions

$$
\begin{aligned}
f_{1} & =\frac{1}{s(p+s \beta R)} \\
f_{2} & =\frac{\left(\frac{z}{m}\right) \alpha}{s(p+s \beta R)} \\
f_{3}=\left\{\left[1+\left(\frac{z}{m}\right) \alpha-\alpha\right] e^{m}+\left[\alpha+\left(\frac{z}{m}\right) \alpha-1\right] e^{-m}\right\} & \\
f_{4} & =\left(e^{m y_{D}}+e^{-m y_{D}}\right)
\end{aligned}
$$

The derivative of the solution with respect to any of the dimensionless variables can be calculated from the derivative of the above simplified functions with respect to the variables. The following notation greatly simplifies the generalization of the calculations. Let

$$
\begin{aligned}
& P e=\alpha_{i} \\
& \beta=\alpha_{2} \\
& R=\alpha_{3} \\
& \alpha=\alpha_{4} \\
& x_{D}=\alpha_{5}
\end{aligned}
$$

In general the derivative of the solution with respect to any dimensionless 
variable $\left(\alpha_{j}\right)$ is given by

$$
\frac{\partial F}{\partial \alpha_{j}}=f_{2} f_{3} f_{4} \frac{\partial f_{1}}{\partial \alpha_{j}}+f_{1} f_{9} f_{4} \frac{\partial f_{2}}{\partial \alpha_{j}}+f_{1} f_{2} f_{4} \frac{\partial f_{3}}{\partial \alpha_{j}}+f_{1} f_{2} f_{3} \frac{\partial f_{4}}{\partial \alpha_{j}}
$$

All that is needed to complete equation (E.6) is an evaluation of $\left(\frac{\partial f_{i}}{\partial \alpha_{j}}\right)$. This partial derivative term is denoted by $\operatorname{PD}(i, j)$, where

$$
\begin{aligned}
& \mathrm{i}=\text { Function number } \\
& \mathrm{j}=\text { Variable number }
\end{aligned}
$$

For $\left(\alpha_{1}\right)$ the partial derivatives have been calculated as

$$
\begin{gathered}
P D(1,1)=0 \\
P D(2,1)=\frac{\alpha_{4} z}{m^{s} \alpha_{1} s} \\
P D(3,1)=\frac{m \alpha_{4}}{2 \alpha_{1}}\left[\left(\frac{2 z}{m^{2}}+1-\frac{z}{m}-\frac{1}{\alpha_{4}}\right) e^{m}\left(\frac{2 z}{m^{2}}+1+\frac{z}{m}-\frac{1}{\alpha_{4}}\right) e^{-m}\right] \\
P D(4,1)=\frac{m y_{D}}{2 \alpha_{1}}\left[e^{-m y_{D}}-e^{m y_{D}}\right]
\end{gathered}
$$

For $\left(\alpha_{2}\right)$ the partial derivatives are

$$
\begin{gathered}
P D(1,2)=-\frac{\alpha_{3}}{m^{4} \alpha_{1}^{2}} \\
P D(2,2)=-\frac{\alpha_{9}}{2 m^{3}}\left[\frac{1}{z}+\frac{z \alpha_{4}}{\alpha_{1}^{2} m^{2}}\right] \\
\left.P D(3,2)=\frac{s \alpha_{3}}{2 m \alpha_{1}}\left[1+\frac{z \alpha_{4}}{m}-\frac{\alpha_{1}^{2}}{z}-\frac{\alpha_{4} z}{m^{2}}-\alpha_{4}\right] e^{m}-\left[\alpha_{4}+\frac{z \alpha_{4}}{m}+\frac{\alpha_{1}^{2}}{z}+\frac{\alpha_{4} z}{m^{2}}-1\right] e^{-m}\right] \\
P D(4,2)=\frac{\alpha_{9} s y_{D}}{2 \alpha_{1} m}\left(e^{m y_{D}}-e^{-m y_{D}}\right)
\end{gathered}
$$

For $\left(\alpha_{3}\right)$ the partial derivatives are

$$
\begin{gathered}
P D(1,3)=-\frac{\alpha_{2}}{m^{4} \alpha_{1}^{2}} \\
P D(2,3)=\frac{1}{2 m^{3}}\left[\frac{\left(1-\alpha_{2}\right)}{2}-\frac{3 z \alpha_{4} \alpha_{2}}{\alpha_{1}^{2} m^{2}}\right] \\
P D(3,3)=\frac{s \alpha_{2}}{2 m \alpha_{1}}\left\{\left[1+\frac{z \alpha_{4}}{m}-\frac{\left(1-\alpha_{2}\right) \alpha_{1}^{2}}{\alpha_{2} z}-\frac{\alpha_{4} z}{m^{2}}-\alpha_{4}\right] e^{m}-\left[\alpha_{4}+\frac{z \alpha_{4}}{m}+\frac{\left(1-\alpha_{2}\right) \alpha_{1}^{2}}{\alpha_{2} z}+\frac{\alpha_{4} z}{m^{2}}-1\right] e^{-m}\right\}: \\
P D(4,3)=\frac{\alpha_{2} s y_{D}}{2 \alpha_{1} m}\left(e^{m y_{D}}-e^{-m y_{D}}\right)
\end{gathered}
$$


For $\left(\alpha_{4}\right)$ the partial derivatives are

$$
\begin{gathered}
P D(1,4)=0 \\
P D(2,4)=\frac{z}{\alpha_{1} m^{3}} \\
P D(3,4)=\left[\frac{1}{2}\left(\frac{z}{m}\right)-1\right] e^{m}+\left[1-\frac{1}{2}\left(\frac{z}{m}\right)\right] e^{-m} \\
P D(4,4)=0
\end{gathered}
$$

The above shows how the derivative of the solution can be calculated for all the dimensionless variables except $\left(x_{D}\right)$. This derivative was calculated using the following property of the Laplace transform

$$
\frac{\partial F}{\partial x_{D}}=\boldsymbol{p}\left(L^{-1} f^{p}\right)
$$

Thus the derivative with respect to $\left(x_{D}\right)$ was calculated by multilpying the solution by $p$ before it was numerically inverted from $(p, y, s)$-space to $(x, y, s)$-space. 
AppendiX F: LISTING OF CURVEFIT

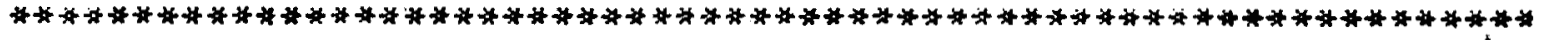

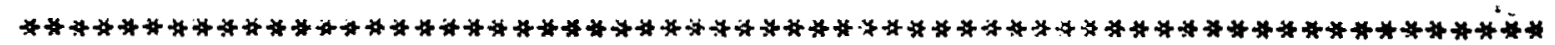
PROGRA!A EEGIRS

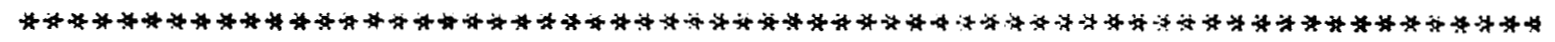
MAIN PROGFAM

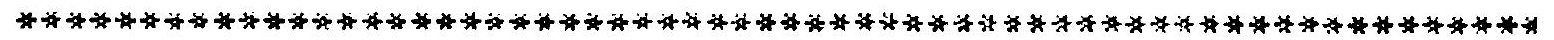

IMFLICIT REAL*Q(A-B,D-H, D-Z)

DIMENSION CTITLE (20), T(400), Y(400), ALF:?4: BETA:7;, W(400), IINC $(\{4, E), A(400,13), C(400)$

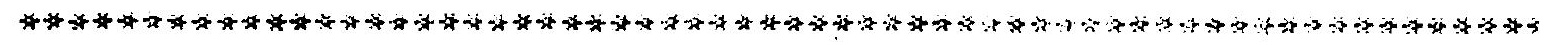

SET PARAKETERS FUR VARPRD

EYTEFHAL ADL

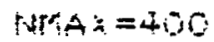

IPFINT $=1$

READ ATE WRITE INITIAL DATA

REAE(S, 10:CTITLE

1. FORMAT (2OA4)

WRITE (6,20) CTITLE

20 FORMAT (10X, 20A4)

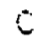

WL IS THE NUMEER OF NONLINEAR PARAMETERS

SET NLL=5 FCR A SINGLE FRACTURE $N N_{-}=5$

30 FORTAT ( NUMBEF OF NONILINEAR PARAMETERE = , IE:

e.

L IS THE NUMBER OF LINEAR PARAMETERS

$L=T+15$

WRITE $(6,35) L$

N IS THE NUMBER QF DESERVATIIONE

READ :5:*;N

WRITE $(5,40)$ iL

4O FORMAT ' NUMEER DF OBSERVATIDHS $=$ 'I I;

C

C IV IS THE NUMBER OF INDEPENDENT VARIBLEE 


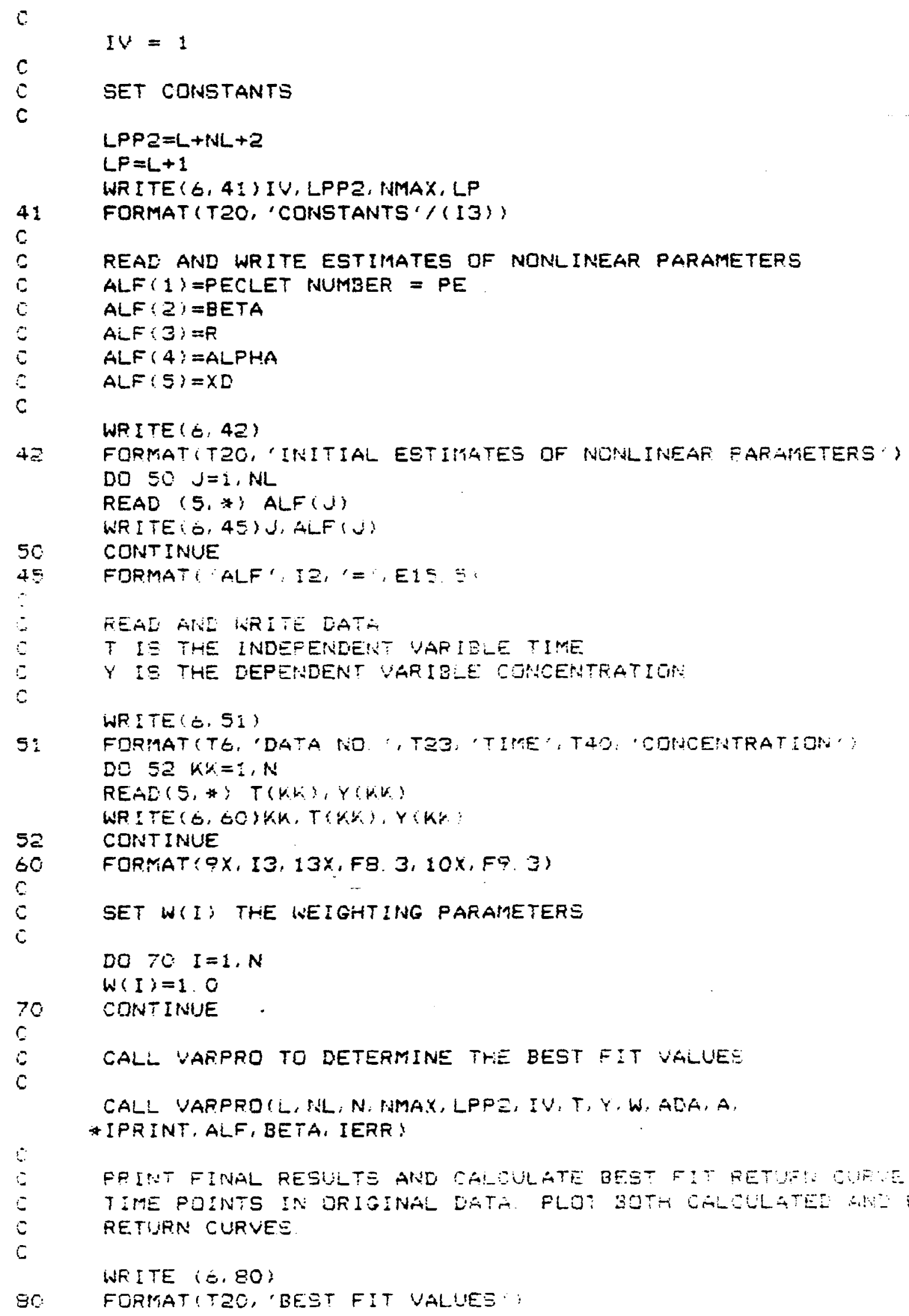


WRITE (E, 85) (I, ALF (I), I=1, ML)

25

FORIAAT ('ALF', I2, '= ',EI5. 5)

WR I TE $(6,70)$ (I, BETA(I), I=1,L)

90

FDRMAT('BETA', IZ, '= ',E15.5\}

$\mathrm{C}$

CALCULATE CONCENTRATION GY CALLING ADA

\section{ISEL $=1$}

$L P=L+1$

WR ITE (6, 130$)$

130 FORMAT 1 HO, 'CALCULATED CONCENTRATIONS', $\%, T 5$, 'TIME',

* 15. 'CONCENTRATIOA', /13

CALL ADA (LP, NL, N, NMFXX, LPPE, IV, A, IISC, T, ALF, ISEL)

DO $140 \quad I=1, N$

CII: $=$ BETA(1)*A(I, 1$)$

WRITE (6, 155; T(I), C II)

140

CONTINUE

155

100

FORIAAT (IX, ZF 1O. 4)

STOF

END

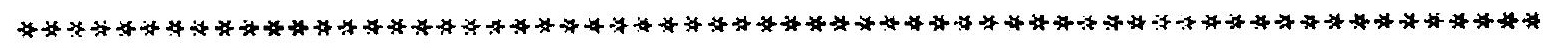

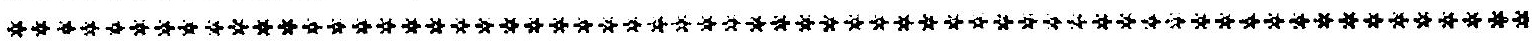

EUBROUTIRE AEA

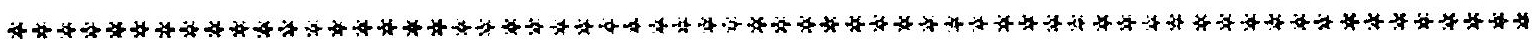

SUBFDUTINE ADA (LP, IH, N, NMAX, LFPQ, IV, A, INC, T, ALF, ISEL;

IMPLICIT REAL *B(A-H, D-Z)

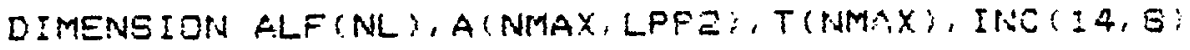

$N M !=10$

$L=L P-1$

$M=2424$

s.

C

SET INCIDENCE MATRIX; INC $(\%, \omega)=1$ IF ALPHA K: APPEARS IN PHI

SKIF UHLESS ISEL IS EQUAL TO 1

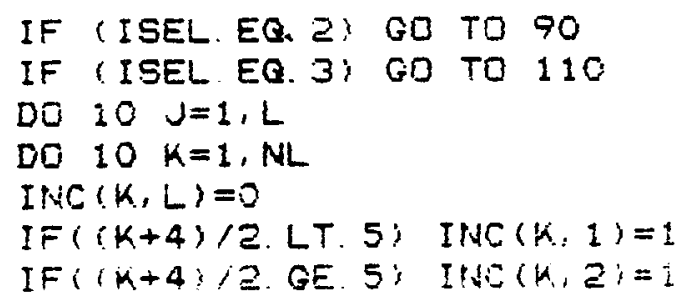

IF (ISEL. EQ. 2) GO TO 90

IF (ISEL EQ. 3) GO TO 110

DO $10 \quad J=1, L$

DO $10 \quad K=1, N L$

$\operatorname{INC}(K, L)=0$

IF $(i K+4) / 2$. LT. 5; $\operatorname{INC}(K, 1)=1$

IF $(K+4) ; \geq$ GE. $5 ; \operatorname{INS}(k, 2)=1$

1: COTITHE

calculate matfix a

CALCULATE COLUIAN EY COLUMAH

FIRET CALCLLATE THE CONCENTEATION GILLY 
C

90 DO 100$\}=1, N$

DO $99 \quad K=1, L$

$T D=T(J)$

ISET $=1$

$X E=A L F(5 * K)$

$K K=K$

$A(U, K)=X I N V R I(T D, P H, M, X D, A L F, I S E T, K K)$

IF $(A(J, K) . L T . O . O) A(J, K)=0.0$

99
100
$c$
$c$
$c$
0
6
0 CONTINUE

100 CONTINUE

C SKIF THE CALCULATION OF DERIVATIVES IF ISEL=E

IF (ISEL. EQ. $\supseteq$; GO TO 360

C CalCULATION GF THE DERIVATIVES

C FiRST CALCLLATE DERIVATIVE IVITH RESFECT TO ALF: 2 ; (PE)

110 DO $150, j=1, N$

EO $150 \quad \mu=1, L$

$T D=T(S)$

$X E=\{i L F(5 * \%)$

ISET $=$ ?

$I B=3$

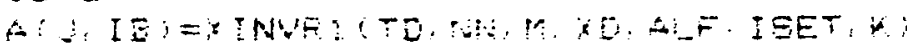

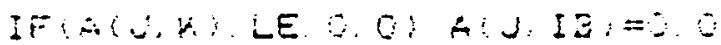

50 CORTIMLE:

c

$\Xi$

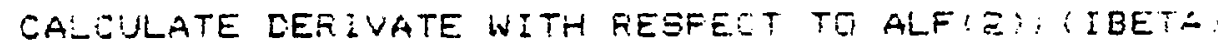

DC $200, i=1,1$

$D O \equiv 0 Q \quad r=1, L$

$T D=T ! U$

$X D=A L F(5 * 4)$

ISET $=3$

$I Z=4$

A I I IE : =XINUF: ITD. HN, M, XD. AIF, ISET, $;$ :

IF $(A(J, X)$. LE. C. O) A J I IE $)=0.0$

DOO CONTINUE

6

$c$

CALCULATE CERIVATIVE WITH RESFECT TO ALF $3: ;$ :

$i$

250

DO $250 . j=1, i$

DO $250 \quad k=1, L$

$T E=T(J)$

$X D=A L F: S * L$ :

ISE $T=4$

I $B=5$

ACJ,IE) = XINUFI (TD, PWN, M, XE, ALF, IEET, W

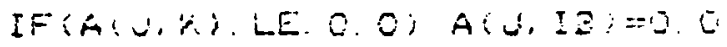

CONTINUE

6

6

CALCULATE DERIVATIUE WITH RESPECT TO ALFI:I, IALPHE: 
DO $300 \quad J=1, N$

DO $300 \quad K=1, L$

$T D=T(J)$

$X D=A L F(S * 4)$

ISET $=5$

$I B=t$

$A(J, I E)=X I N V R I(T D, N N, M, X D, A L F, I S E T, K)$

$\operatorname{IF}(A(J, K)$. LE. O. O) $A(J, I E)=0.0$

300 CONTINUE

(

CALCULATE DERIVATIVE WITH RESPECT TO ALF(5); (XD)

DD $350 \quad j=1, N$

DO $350 \quad x=1, L$

$T D=T(U)$

$X[=A L F(5 * K)$

ISET $=6$

I $\mathrm{E}=$ ?

$A(J, I Q)=X I N V R I\{T E, N N, M, X D, A L F, I S E T, W\}$

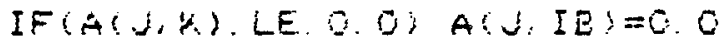

350 CONTINUE

300 CONT INUE

500 RETURN

El.D

a

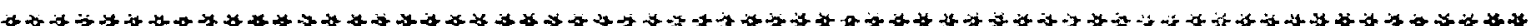
FUNCTILU! IRWEPSE:

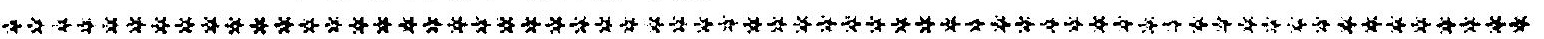
THE STEHFEST ALGDPITHMM

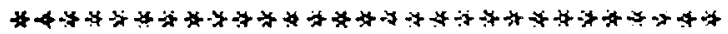

THIS IS THE FIFST INUERSIOH WHICH GOEE FROM : $X: Y: S$ : SPACE BACK TO REAL TIME. IT NEEDS THE EYALLLATION CF THE

FUNCTIOH IN S-SPACE ARE TO DO THIS IT CALLE SFUPCTIOH

AE A FUHCTID:

FUNCTIDIA XINUEI (TD, N, M, XD)

THIS FUNTIDN COMPUTES WUMERICALLY THE LAFLACE TFNGFOFH INUERSE OF FIS:

IMPLICIT REAL*B (A-H, D-Z)

DIMENSION G(5O), V(SO):H(25)

NOW IF THE ARRAY VII; WAE CEMPUTED BEFORE THE FROGRAM GOES DIRECTLY TO THE END GF THE SUBRUTINE TO CALGULATE : $F(S$ )

IF (N.EG M) GO TO 17

$M==1$.

DLDGTW=0. 6932472805597

$N H=H / Z$

C.

THE FACTDFIALS OF I TO N GRE CALCULATEL IIAT AFFAY $G(1)=1$ 


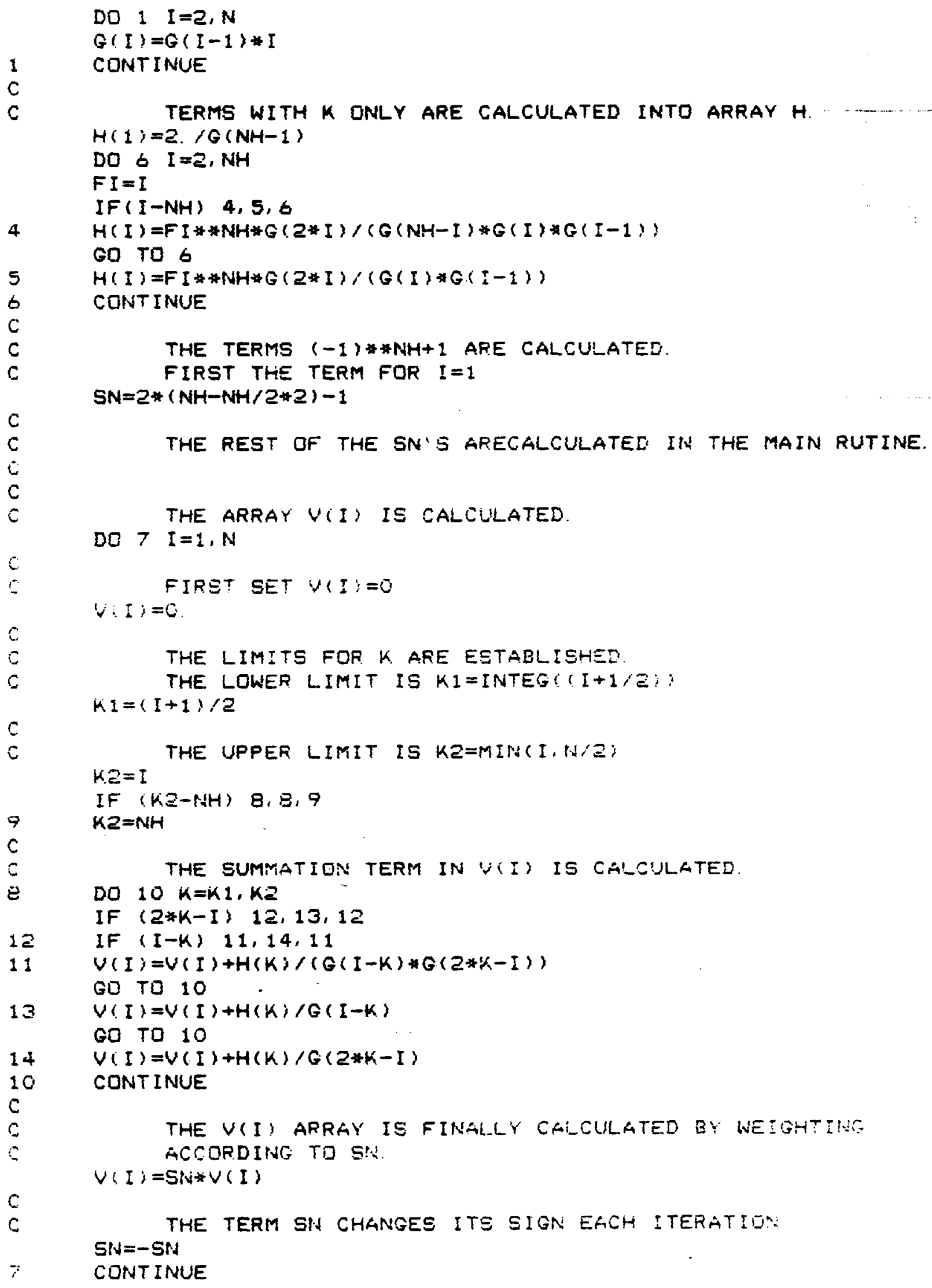


S

$c$

i) XINURI $=0$

$A=D L O G T H: T D$

DO $\$ 5 I=1, N$

$A R G=A * I$

XINURI = XINVR $1+V(I) * S F U N C$ (ARG, I, XD)

15 CONTINUE

$X$ INUR $1=X \operatorname{INVR} I * A$

18

RETURN

END
C

c

$c$

c

c

$c$

$c$

c

5

$-$

6

$\therefore$

$c$

$c$

c

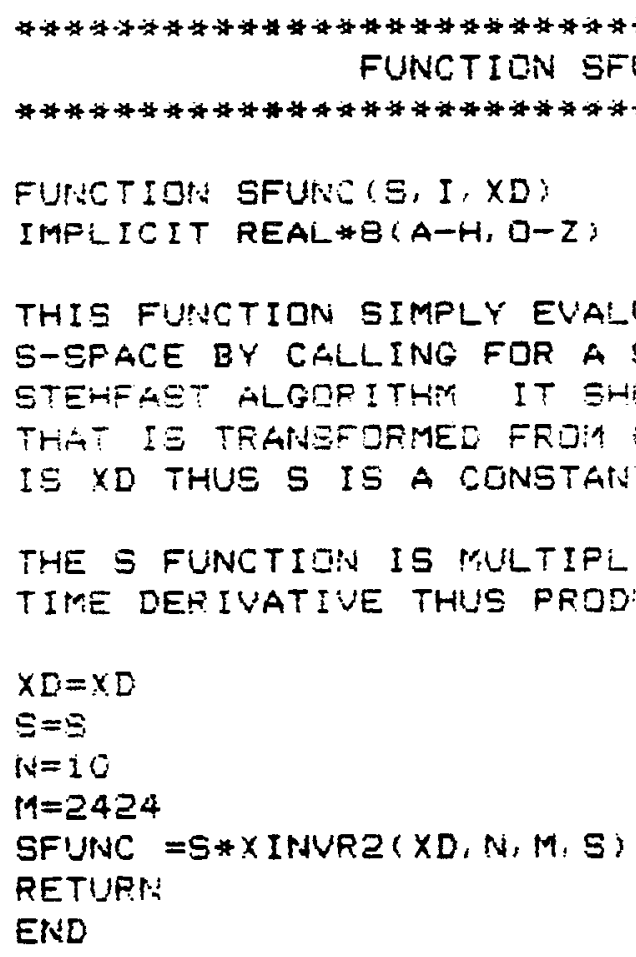

THIS FUNCTION WILL IWVEAT FFOM F-SFACE TO E-SF-OE: WITH XD EEING THE VAFIELE OF ITVEAEIOI THE FUT TII

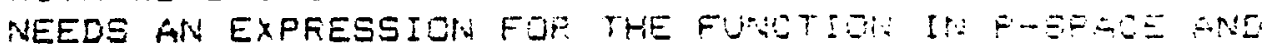
THIS IS DONE BY CALLING FFURC $X O X, S$

FURVTION XINURE (XO, M. M. Si THIS FUNTION COMPUTES WUMERICALLV THE LAFSACE TRHSFIFM 


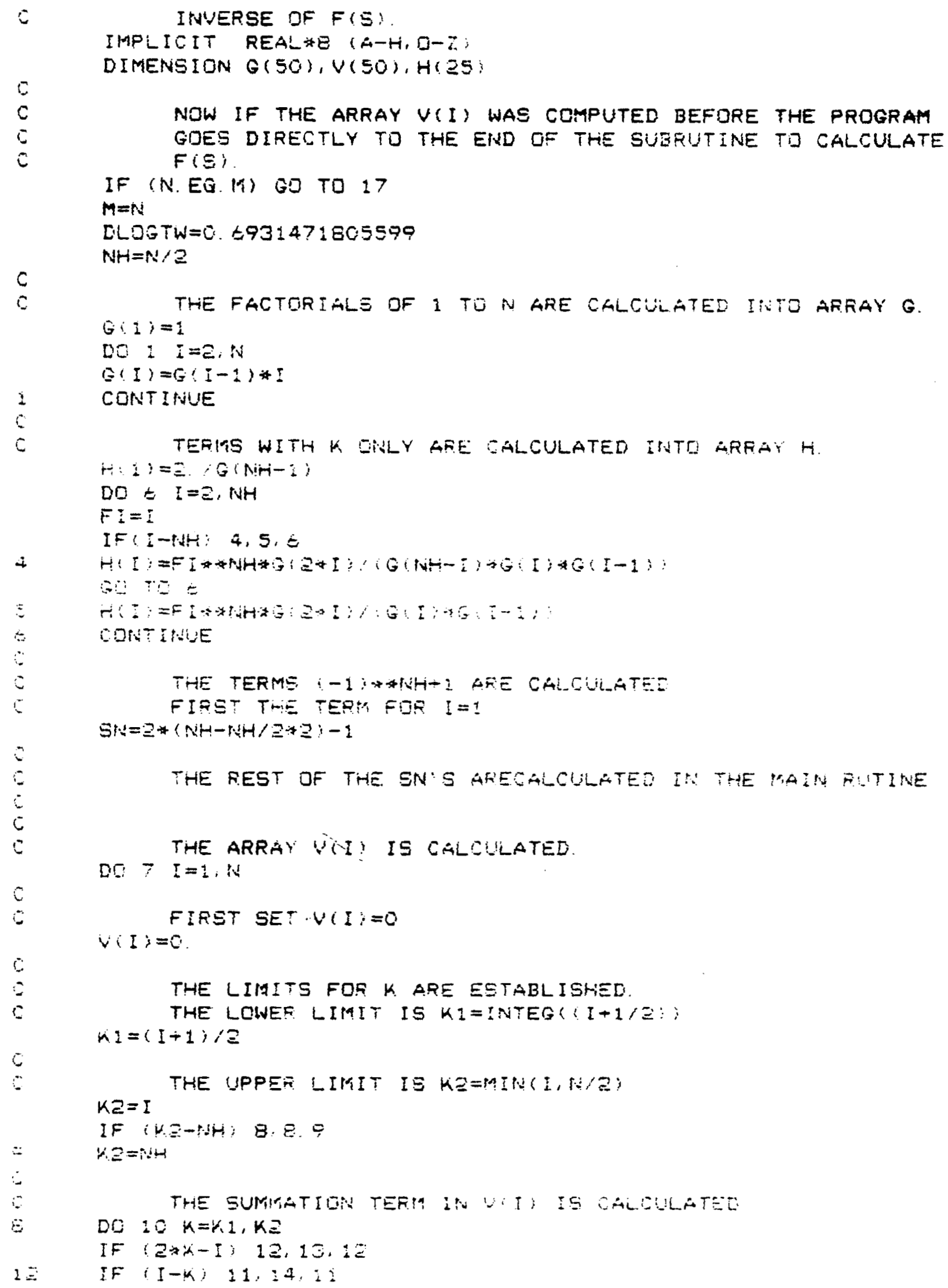

THE SUMMTIEN TERIA IN YITI ES GALGULATEL 
$F(1)=1 /(S *(P+(S * A L F(2) * A L F(3))))$

$F(2)=Z M * A L F(4) ;(S *(P+(S * A L F(2) * A L F(3)))$

$F(3)=(1.0+i Z M * A L F(4))-A L F(4)) * E X F(X M)+$

* (ALF $(4)+(Z M * A L F(4))-1.0) * E X P(-X M)$

$F(4)=\operatorname{EXP}(X M * Y D)+E X P(-X M * Y D)$

$F F=F(1)-(F(2) * F(4) / F(3))$

IF (ISET. EQ. 1 )GO TO 15

$c$

c

\section{CALCULATE THE PARTIAL DERIVATIVES AND STURE IN PDF}

\section{FIRST CALCULATE WITH RESPECT TO. ALF(1)}

$P E F(1,1)=0.0$

$\operatorname{PDF}(2,1)=(A L F(4) * Z /(\{X M * 3) ;(A L F(1 ; * * 2) ;) *(1,5)$

$P I=(2 . * Z /(X \mid M * Z Z))+1 .-Z M-(1 . / A L F(4 ;)) * E X P(X M)$

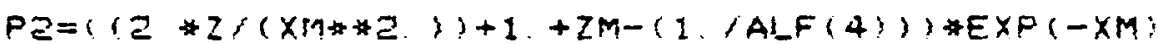

$P D F\{3,1 ;=\{X M * A L F(4),(2 * A L F(1))\} *(F)+P Z)$

PDF $(4,1)=(X M * Y D i(2 \Rightarrow A L F(1 ;)) *(E X P(-X)\} \times Y D)-E X F(X M * Y D))$

CALCULATE WITH FESPECT TO ALFIZ:

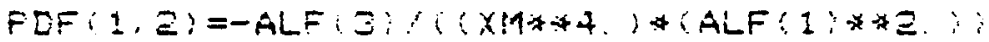

$P 1=(3 . * A L F(4) * 2) ;(, X M * A L F(1 ;) * 2$. )

PEF $(2,2)=-A L F i 3) /(2 *(X M+3 ;: *(1) / Z ;+F 1)$

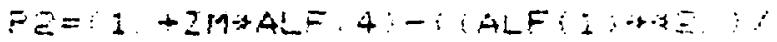

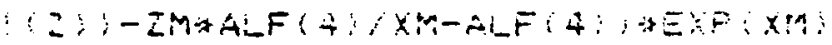

$F 3=(A L F: 4)+Z \eta * A L F(4)+($ ALF:I)**2) $:$

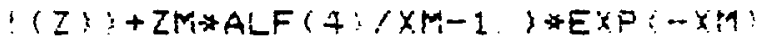

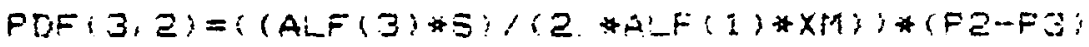

$P D F(4,2:=(A L F(3) * S * V D)(2, * A ; F(1) * X M)) *(E X F(X) * Y D:-E X F(-X M * Y D) ;$

CALCULATE WITH RESPECT TO ALFi3)

$P D F(1,3)=-A L F(2 ;)((x M * * 4 . ; *$ ALF $(1 ; * * Z) ;$

$P 1=(3 . * 2 * A L F(\Omega) * A L F(4) /:(X M * A L F(1)) * * 2) ;$

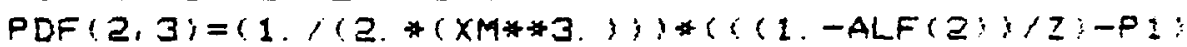

$P E=i$. +ZM*ALF $(4)+($ IALF $(1) * 2: ; *(1-A L F(2): \because$

$!(Z * A L F(2) ;)-Z M * A L F(4) ; X M-A L F(4)$

$P 3=A L F(4)+Z M * A L F(4)-((A)+F(1) * 2$. $) *(1-A L F(z):)$

! $(Z * A L F(Z)))+Z$ IA $* A L F(4)(X M-\dot{P}$.

$P D F(3,3)=(S * A L F(2) /(2 * A L F(1) * X M)) *(P 2 * E X P(X M)-F 3 * E X P(-X M)\}$

$P D F(4,3)=(S * A L F(2) * Y D /(2$. AIF $(1\} * X M)) *(E X P(X) * Y D)-E X P ;-X P * Y Q))$

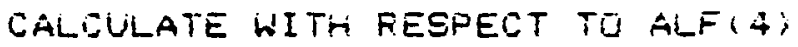

$P D F(1,4)=0.0$

$\operatorname{PDF}(2,4)=Z /(A !-F(1) *(X M * * 3))$

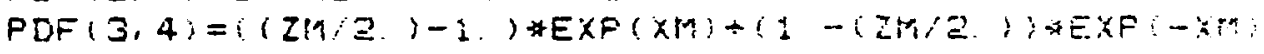

FDF $(4,4)=0.0$

NOW Calculate the DERIVATEE

$X=F(1 ; \# F(2) * F(3) ; F ; 4)$

$0010 \quad I=1,4$ 


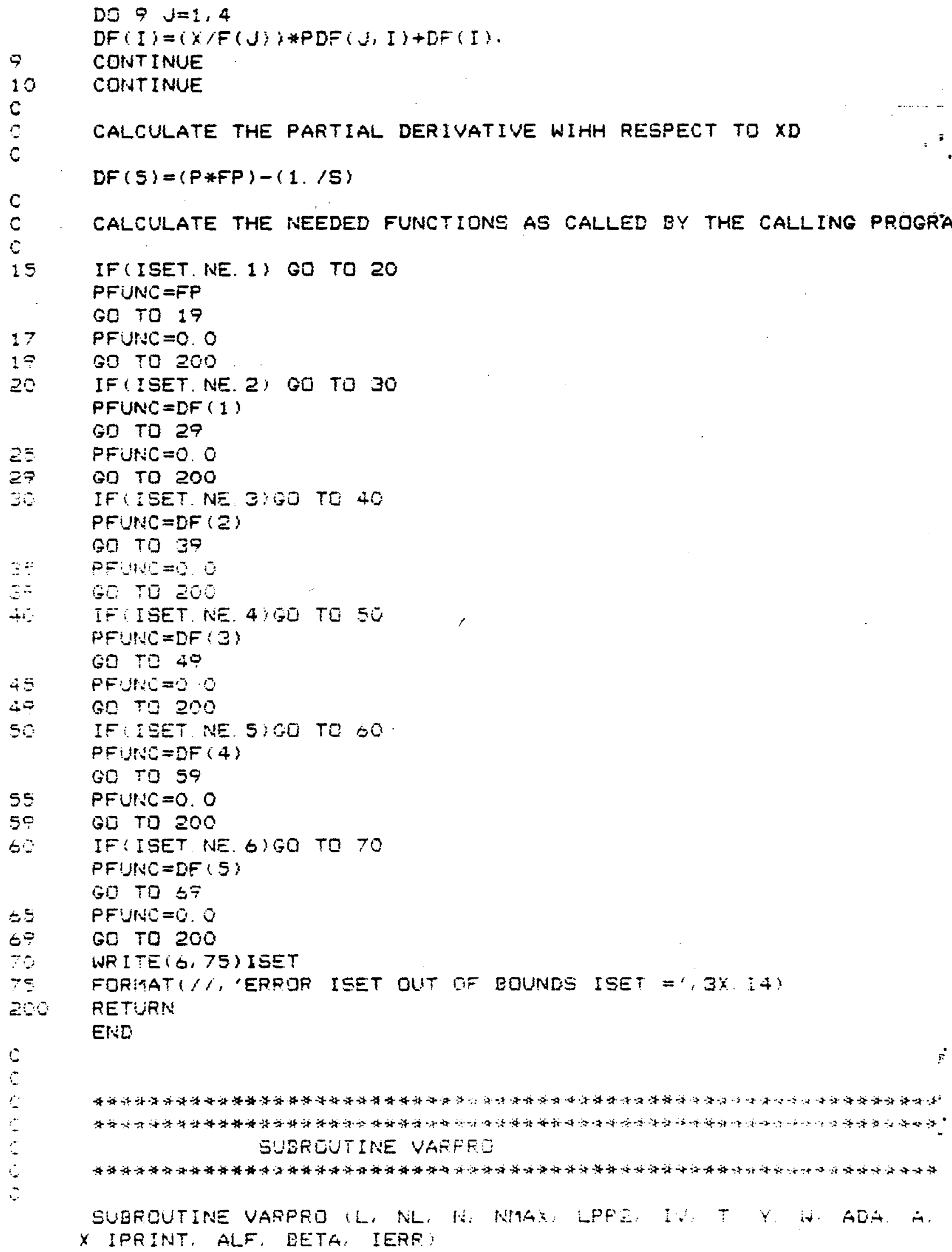


GIVEN A SET DF N OBSERVATIONS, CONSISTING OF VALUES $Y(1)$. $Y(Z) ; . . ., Y(N)$ DF A DEPENDENT VARIABLE $Y$. WHERE $Y(I)$ CORRESPONDS TO THE IV INDEPENDENT VARIABLE(S; $T(I, 1), T(I, 2)$ .... T(I, IV), VARPRO ATTEMPTS TO COMPUTE A WEIGHTED LEAST SQUARES FIT TO A FUNCTION ETA (THE 'MODEL') WHICH IS A LINEAR COMBINATION

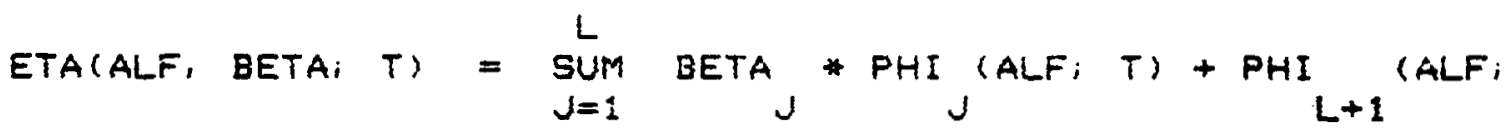

OF NDNLINEAR FUNCTICNS FHI (J) (E. G, A SUM DF EXPONENTIALS ANU OR. GAUSSIANS?. THAT IS, DETERIIIHE THE LINEAF PARAMETERS BETA $U$ '; ANO THE VECTOF OF NONLITNEAR PARAMETERS ALF BY MINIMIZ: ING

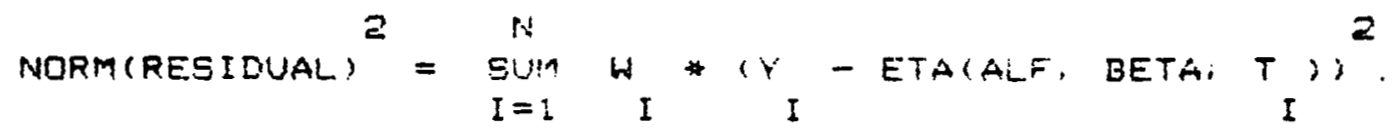

THE (L+1)-ST TERM IS CPTIONAL, AND IS USED WHEN IT IS DESIRED TO FIX ONE OR MORE GF THE EETA'S IRATHER THAT LET THEM BE DETERMINED: VARPRO REQUIRES FIRST DERIVATIVES OF THE PHI'S.

$$
\text { :DE: }
$$

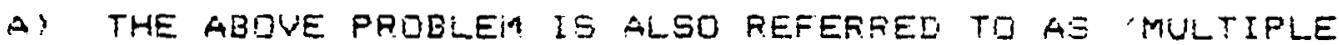
WONLINEAR FEGRESSION, FOR USE IRS STATISTIOAL ESTIMATIOH. VARPRO RETURNS THE RESIDUALS, THE CONAFIANCE MATRIX OF THE LIMEAR AND NONLINEAR PARAMETERS: AND THE ESTIMATED VARIAHCE THE DBSERVATILNS.

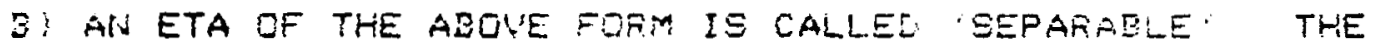
CASE DF A NONSEPARABLE ETA CAR bE HAINDLED BY SETTIMG L = 0 AND USING PHI (L+I).

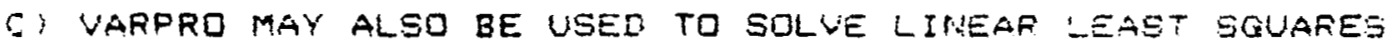
PROBLEMS IIN THAT CASE NO ITERATIONS ARE FERFORMED: SET $N L=0$.

D) THE MAIN aEVANTAGE OF VARPRD DVEF OTHER LEAST SQUARES PROGRAMS IS THAT NO INITIAL GUESSES ARE NEEEED FOF. THE LINEAR PARAMETERS NOT ONLY DOES THIS KAKE IT EASIER TO USE. BUT IT DFTEN LEACS TO FASTER CONVERGENCE.

\section{DESCRIPTION OF PARAMETERE}

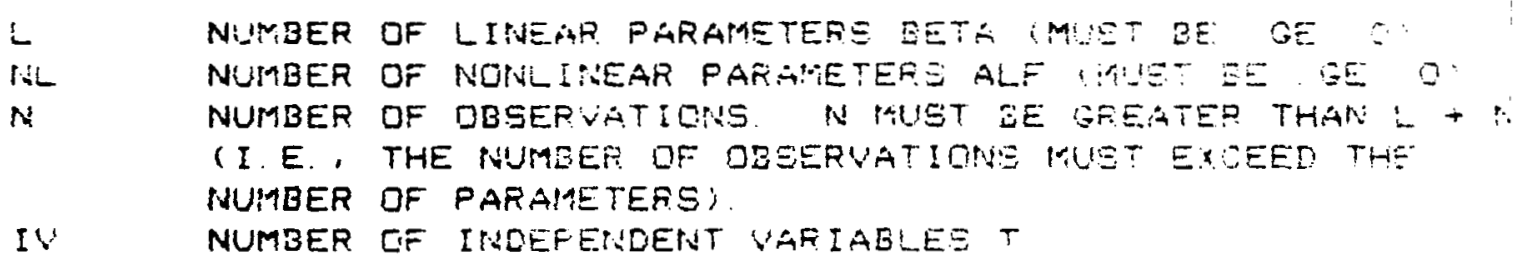


$T$

$Y$

is

INC

A

IFR IRT

ALF

BETA

IEFF

REAL $N$ BY IV MATRIX OF INDEPENDENT VARIABLES. T(I, COMTAINS THE VALUE OF THE I-TH OBSERVATION OF THE $J$ INDEPENDENT VARIABLE. N-VECTOR OF OBSERVATICNS, ONE FOR EACH ROW OF T. N-VECTOR DF NONNEGATIVE WEIGHTS. SHOULD BE SET TO IF WEIGHTS ARE NOT DESIRED. IF UARIANCES OF THE : INDIVIDUAL OESERVATIONS ARE KNOWN, WII SHOULD BE SE TO 1. NARIANCE II?

NL $X(L+1)$ INTEGER INCIDENCE MATRIX. NON-LINEAR PARAMETER ALF(K) APPEARS IN THE J-TH

FUNCTIOI PHI (J). (THE PROGRAM SETS ALL OTHER INC (K, TO ZERO.'; IF PHILL+1; IS IHCLUDED IN THE MODEL.

THE APPROPFIATE ELEMENTS GF THE (L+i)-ST COLUMA SHOU BE SET TO 1.5 . INC IS WOT NEEDED WHEN $L=0$ OR $\mathrm{NL}=$ CAUTION: THE DECLARED FOW DIMENSION OF INC (IN ADA) MUST CURAENTLY BE SET TO 12 . SEE 'RESTRICTIONS' BEL NMAX THE DECLARED ROIN DIMENSION DF THE MATRICES A AND $T$. IT MUST BE AT LEAST MAXYTi, 2*1NL+3)

LPF? L+F+2, WHERE $P$ IS THE MUMEER GF ONES IN THE MATRIX I THE DECLARED COLUMT DIMEHSION OF A MUST ZE AT LEAST LPP $2 . \quad$ IIF L $=0$, SET LPPZ $=N L+2$. IF $N L=0$, SET LP $L+\Xi:$

REAL MATFIX DF SIZE MAX (N, $Z+M L+Z) E Y L+P+2$. ON INF IT CONTAINS THE PHI $(U) ' S$ AND THEIR DERIUATIVES (SEE BELOW OW OLTPUT THE FIRET LTHL FOINE ANE COLUNANE

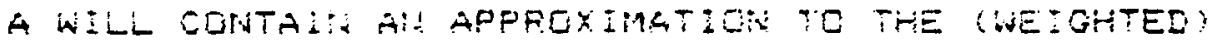
COUARIAISE MATFI: AT THE SULUTION TTHE FIRET L ROWS COFRESPOHE TO THE LINEAR PARAMETERS THE LAST HL TO NOHLINEAR ONES; COLUMR L+NL+1 WILL CONTAIN THE.

WEIGHTES RESIDUALS (Y - ETA), AII, L+NL+Z; WILL. CORT THE (EUCLIDEAN) WORM GF THE INEIGHTED FESIDUAL. AIVD

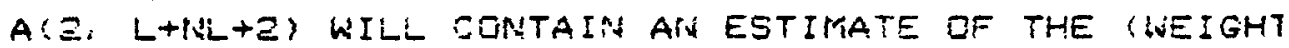
VAFIANCE OF THE OBSERVATIONS, NORMIRESIOUAL:

(W $-L-N L$ :

INPUT INTEGER CONTROLLING PRINTED DUTPUT. IF IPRINT POSITIVE, THE NORLINEAR PARAMETERS, THE NOFM OF THE REEIDUAL, AIND THE MARQUARDT PARAMETEP WILL BE DUTPUT EVERY IPRINT-TH ITERATIDN IAND INITIALLY, AND AT THE FINAL ITERATION: THE LINEAE FAFAMETERS WILL $3 E$ PFINTED AT THE FITUAL ITERATION. ANT ERRDA MESSAOES WILL ALSO BE PRINTED. (IPRIIIT = 1 IS RECOMIMERDED A) F.IRST. Y IF IPRINT $=0$, GNLY THE FINAL QUANTITIES WIL BE PFINTED, AS INELL AS ANY ERRDR MESSAGES IF IPRIF -1. ND PRINTING INILL BE DENE. THE USEF IS THEN RESPONSIBLE FOR CHECKING THE PARAMETER IERF FJR ERRC NL-VECTOR OF ESTIMATES CF NONLINEAR FAFAMETERS (INPUT: ON OUTPUT IT WILL CENTAIN OPTIIAAL VALUES [ THE MONLINEAR PATAMMETERS L-WECTOR OF LIMEAS FARAMETERE IOUTF!T DTH: INTEGER ERROR FLAG COUTPUT:

. GT. O - SUCCESGFU CONVERGEINCE, IEAT: TE THE INIIAEF ITERATICHS TAKEW

-1 TERIIINATED FOR TOO MATY ITERATIDSS

-2 TERMINATED FOP ILL-CONEITIONING MAOOUARET 


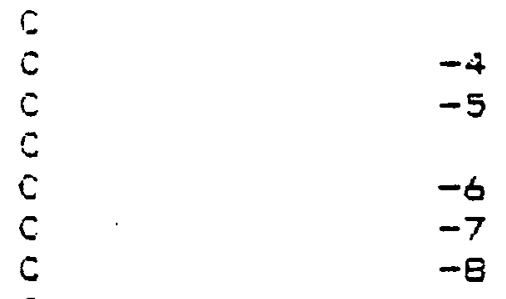

PARAMETER TDO LARGE. ALSO SEE IERR = -B BELCW -4 INPUT ERROF IN PARAMETER N, L, NL, LPPZ, DR NMAX. -5 INC MATRIX IMPROPERLY SPECIFIED, OR P DISAGREES WITH LPPZ.

-b A WEIGHT WAS NEGATIVE.

-7 'CORSTANT' COLUMNN WAS COMPUTED MORE THAN ONCE.

- $B$ CATASTROPHIC FAILURE - A COLUMP OF THE A MATRIX HA BECOIAE ZERD. SEE 'CONUERGENCE FAILURES' BELOW.

(IF IERR. LE. -4, THE LIMEAR PARAMETERS, COVARIANCE MATRIX, ETC. AFE NOT RETURIVED. ;

\section{SUBROUTINES REQUIREU}

NINE SUBROUTINES, DPA, DRFACI, DRFACE, BACSUB, POSTPR, CQV, XNDRI1. IIIIT. AND VARERR ARE PRDUIDED. IN ADIITION, THE USER MUST PROVIDE A SUBROUTINE (CORFESPONUING TO THE ARGUMENT ADA: WHICH: GIVEN ALF, WILL EVALUATE THE FUNCTIONS PHI(U) AND THEIF FARTIAL DERIVATIVES D PHI (U)/D ALFiK:, AT THE SAMPLE POINTS TSI: THIS RQUTINE MUET BE DECLAPED 'EXTERISAL' IN THE CALLINE PROGRAM. ITS CALLING SEGUENCE IS

SUBROUTINE ADA (L+1, NL, N. NMAX, LPF2, IV, A, INC, T, ALF, ISEL;

THE LISEF EHOULO MOE:F' THE ERAMFLE EUEROUTISE ADA (GIVEN

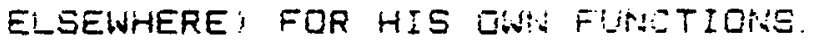

THE VECTOR SA!APLED FUHCTIONS PHIUU SHOULO EE STCRED IN THE FIRST $N$ RDINS AND FIRST $L+I$ CDLUMNS GF THE MATEIX A I E., A(I, J) SHOULD CONTAIN PHISJ, ALF; T(I, I), TII, 2 :

T(I,IVi), I $=1, \ldots$, Ni $J=1, \ldots, L$ LOR L+Ii. THE $(L+1)-S$ COLUMN IF A CONTAINS PHI(L+1) IF PHI:L+1: IS IN THE MODEL,

DTHERWISE IT IS RESERVED FOR WORYSPACE. THE 'CONSTANT' FUHCTIONS (THESE ARE FUNCTIONS PHI $U$ ) WHICH DO NOT DEFEND UPON AN NONLINEAR PARAMETERS AIF, E.G., T(I) $*$ U) (IF ANY) MUST APPEAR FIRST. STAFTING IN CDLUTAN i. THE COLUMN N-VECTORE DF WONZERO PARTIAL DERIVATIVES D PHI $(J) ;$ I ALF(K) SHOULD BE STORED SEQUENTIALLY IN THE MATRIX A IN CCLUMNS L+Z THROUGH L+F $+I$. THE DRDER IS

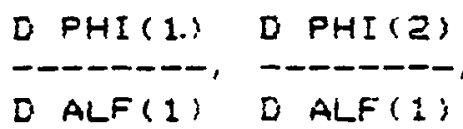

D PHI( 2 )

-D-D-D,

D ALF ( 2$)$

$$
\begin{aligned}
& \text { D PHISL+1; } \\
& \text { D ALF }
\end{aligned}
$$

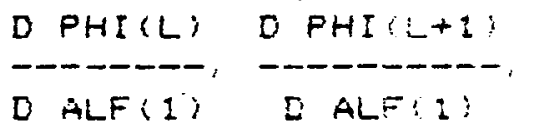

$$
\begin{aligned}
& \text { D PHICI) } \\
& \text { D ALFOHL: }
\end{aligned}
$$

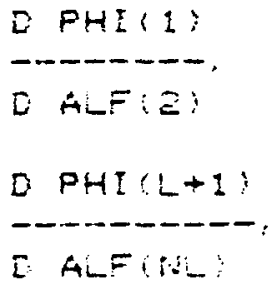

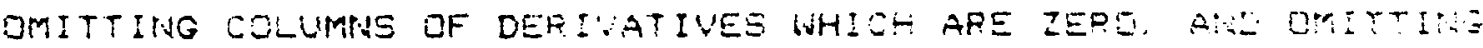
PHI (L+I) COLUMTHS IF PHIIL+I) IE NOT IH THE MDDE W WOTE THAT THE LINEAR PARAIAETERS EETA ARE ROT UEEI IN THE MATFIX 1. COLUMR L+F+Z IS RESERVEE FCR WORHSPACE 
THE CODING OF ADA. SHOULD BE ARRARGED SO THAT:

ISEL $=1$ (WHICH OCCURS THE FIRST TIME ADA IS CALLED) MEANS:

A. FILL IN THE INCIDENCE MATRIX INC

B. STORE ANY CONSTANT PHI'S IN A.

C. COMPUTE NONCONSTAITT PHI'S AND FARTIAL DERIVA-; TIVES.

$=2$ MEANS COMPUTE ONLY THE NONCOHSTANT FUNCTIONS PHI

$=3$ MEANS COMPUTE ONLY THE DERIVATIVES

(WHEN THE PROBLEM IS LINEAR (NL $=0$ ) ONLY ISEL $=1$ IS USED, DERIVATIVES ARE WOT NEEDED, )

\section{RESTRICTIONS}

THE SUBROUTINES DFA, INIT IANO ADA) CONTAIN THE LDCALLY DIMENSIONED MATFIX INC, WHOSE DIMENSIDNS ARE CURRENTLY SET F MAXIMA CIF $L+1=B$, $N L=12$. THEY MUST BE CHANGED FOA LARGER PROBLEMS. DATA PLACED IN AFFAYY A IS DVEFWRITTEN ('DESTROYED DATA FLACED IN ARRAYE T, Y A:AD ITC IS LEFT INTACT. THE PRDG RUNS IN WATFIV. EXCEPT WHEN $L=0$ OR NL $=0$

IT IS ASSUMED THAT THE MATPIX PHILJ ALF: TII: HAE FULL COLUMN RANH. THIS MEAHE THAT THE FIRST L CDLUMINS OF THE MAT A MIET BE LINEAEIY INDEPEWREHT

DFTICNAL NDTE AE WILL BE NOTED FRDM THE SAMPLE SUEPROGR ADA, THE DERIVATEUES D PHIUMI ALF : ISE: = $3:$ MUET BE COMPUTED INDEPENDEMTL, DF THE FUNCTIOHE FHI U ISEL = 2 : SIMCE THE FUACTIDN VALUES ARE OVERINRITTEM AFTEF ADA IS CALLE WITH ISEL = 2 . THIS IE DONE TO MINIMIZE STORAGE, AT THE POS SIELE EXPENSE OF SOME RECOMPUTATION CEINSE THE FUHCTIOHS AND DERIVATIVES FREQUENTLY HOVE SOHE CDIMON SUEEXPRESSIDNS: REDUCE THE AMOUNT OF COMPUTATION AT THE EXFEISE DF SOME STORAGE, CREATE A MATRIX B OF DIMENSIOM HMAX EY L+I IN ADA, AFTER THE COMPUTATION DF THE PHI'S (ISEL = $\equiv$, COP INTO 2 . THESE WALUES CAL THEN BE USED TO CALOULATE THE DEFI ATIVES (ISEL $=3$;. (THIS MAKES USE OF THE FACT THAT WHER A CALL TD ADA WITH ISEL $=3$ FOLLOWS A CALL WITH IEE: = 2 , THE ALFS ARE THE SAIAT.

TO CONVERT TO OTHER MACHINES. CHARGE THE OUTFUT USIT IN T DATA STATEMENTS IN VARFRO, DPA, PIETPR, IND VARERR THE PROGRAM HAS BEEIN CHECKED FOR PORTABILITY BY THE BELL LABE PF VERIFIER. FOR MACHINES WITHOUT DCUBLE FRECISION HARDWARE, I MAY BE DESIRABLE TO COMUERT TO SINGLE PRECISIOR. THIS CANGB DONE BY CHANGING (A) THE DECLARATIONS 'DDURLE PRE: ISIOI: TO 'REAL', (B' THE PATTERIN' $D$ ' TO 'E' IN THE 'DATA STATEMERIT VARPRD, IC: OSIGH, DSQRT AIND DABE TO SIGU, GOFT ANE AES

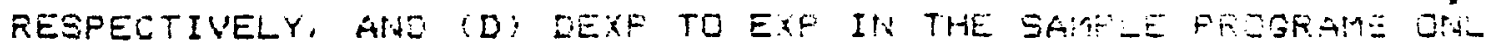
NOTE ON INTERFRETATION OF COVARIANCE MATRIX. 
REGRESSION) VARPRO RETURHS THE COVARIANCE MIATRIX OF THE LINEAR AND NONLINEAR PARAMETERS. THIS MATRIX WILL BE USEFUL ONLY IF THE USUAL STATISTICAL ASSUMPTIONS HDLD: AFTER WEIGHTING, THE ERRORS IN THE OBSERVATIONS ARE INDEFENDENT AND NORMALLY DISTRI BUTED, WITH MEAN ZERO AND THE SAIYE VARIANCE. IF THE ERRDRS DE NOT HAVE MEAN ZERO (OR ARE UNKNOWN), THE PROGRAM WILL ISSUE A WARNING MESSAGE (UNLESS IPRINT. LT. O) AND THE COVARIANCE MATRIX WILL NOT BE VALID. IN THAT CASE, THE MODEL SHOULD BE ALTERED TO INCLUDE A CONSTANT TERM (SET PHI $(1)=1$.).

NOTE ALSO THAT, IN ORDER FOR THE USUAL ASSUMPTIONS TO HOLD, THE OBSERVATICNS MUST ALL BE OF APFROXIMATELY THE SAME IKAGNITUDE IIN THE ABSENCE OF INFORIMATIOLN ABOUT THE ERROR OF EACH OBSERUATICW:, OTHERI:ISE THE VARIANCES WILL NOT BE THE SAME. IF THE DBSERVATIORS ARE NOT THE SAME SIZE. THIS CAN BE CURED BY WEIGHTIHG.

IF THE USUAL ASSUTATIONS HOLD. THE SGUARE ROOTS OF THE DIAGONALS OF THE COVARIANCE MATRIX A GIVE THE STANDARD ERROR

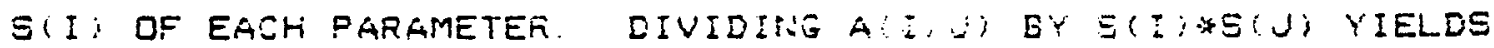
THE CORRELATION MATRIX DF THE PAFIAISETERS PFINCIFAL AXES AND CONFIDENCE ELLIPSOIDE CATS BE DETAIMEE EY PEFFOFMING AN EIGENVALUE, EIGENVECTOP. ANALYSIS OH A ONE SHDULE CALL THE EISPACK FROGRAM TREDE. FOLLUWEE EY TQLE IOF USE THE EISPAE CONTROL FRDQEA: ?

COWUEFGENGE FAILURES

IF CONNERGENCE FAILURES OCCUR, FIFGT SHEQW FDR INCORRECT CODING UF THE SUEROUTINE ADA. CHECK ESFECIALLY THE ACTION DF ISEL, AND THE CDIAUTATIQV DF THE PAFTILL DEPIVATIUES IF THE ARE CORRECT, TRY SEVERAL STARTING GUESEES FDF ALF IF ADA IS CODED CDRRECTIY, ATO IF ERRDF RETURTSS IERT $=-2$ GR -9 PEFSISTENTLY OCCUR, THIS IS A SIGN DF ILL-CONEZTIOHING, WHICH TiAY be CAUSED BY SEVERAL THINGS. ONE IS PDOF BLALING of THE PARAMETERS: ANOTHER IS AN UNFORTUNATE INITIAL GUESE FDR THE PAR̃AMETERS, STILL ANDTHEF IS A POOF CHOICE OF THE MDOEL

\section{ALGORITHM}

THE RESIDUAL $R$ IS MDDIFIED TO IMCORPORATE FOR ANY FIXED ALF, THE DPTIMAL LINEAR FARAMETERS FQR THAT ALF. IT IS THENA POSSIBLE TO MINIMIZE ONLY DN THE NONLINEAR PAFATMETERS AFTER

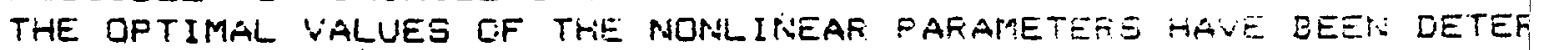
MINED. THE LINEAR PARAMETERS CAN BE RECQYERED EY LINEAF LEAST SQUARES TECHNIQUES (SEE REF. 1;

THE MINIMIZATIOH IS BY A MOLIFIOATIOUN DF DEDOFNE'S LREF 3 : MODIFICATION OF THE LEVENEERG-MAFQUAFET ALGOFITHM INETEAE TF SOLVING THE NORIMAL EGUATIOUSS WITH MATE:

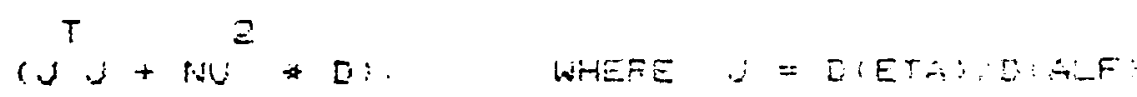


STABLE ORTHOGONAL (HOUSEHOLDER! REFLECTIONS ARE USED ON A MODIFICATION OF THE MATRIX

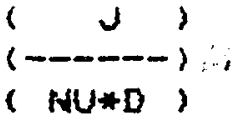

WHERE D IS A DIAGONAL MATRIX CONSISTING OF THE LENGTHS OF THE COLUMNS OF $J$. THIS MARQUARDT STAEILIZATION ALLOWS THE ROUTI TO RECOVER FROM SOME RANK DEFICIEINSIES IN THE JACOBIAN.

DSEORNE'S EMPIAICAL STRATEGY FOR CHOOSING THE MARQUARDT PARAI ETER HAS PROUEN REASONABLY SUCCESSFUL IN PRACTICE. (GAUSSNEWTON WITH STEP CONTROL CAN BE OBTAINED BY MAKING THE CHANGI INDICATED BEFORE THE INSTRUCTION LABELED S\%. A DESCRIPTION BE FOUND IN REF. ( $(3)$, AND A FLOW CHART IN $(Z ;, P .22$.

FOR REFERENSE, SEE

1. GEIUE H. GOLUE AND $V$. PEREYRA, 'THE DIFFERENTIATION OF PSEUDO-INVERSES ANO NONLINEAR LEAST SQUARES PROBLEMS WHOS VARIABLES SEPARATE,' SIAMT 4 . RUMEF:. ANAL 10, 413-432 (1973).

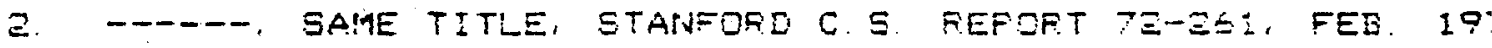

3. DSBORNE, MICHAEL R., 'SOME ASFECTS DF NON-LINEAR LEAST SQUARES CALCULATIOHS, IN LOOTSIMA; ED, 'NUMERICAL METHOI

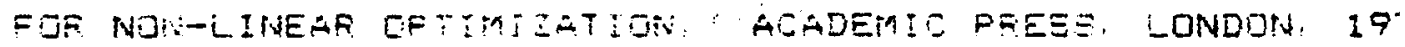

4. HROGH. FRED, 'EFF: IENT IMPLEMEHTATION OF A YAEIAELE PRO. JECTION ALGUSITHM FOF MONLIVEAR LEAST SQIJARES FROBLEITS. COMII. ACM 17: PP ITY-160 IMLRCH: 1974:

5. KAUFMAM, LINOA, 'A VARIAELE PROJEOTIOM METHDO FOA SOLVINH SEPARAELE NOHLINEAP LEAST SOUAFES PRIJLEYS. B I. T. 15 , $49-57$ (1975)

6. DRAPER, N., AND SHITH, H., APPLIES REGREESIOH AMALYSIS, WILEY, $N Y$ Y 1960 IFOF STATISTICAL INFOFPATION CNIY:

7. C. LAWEON ANO R. HANSOM SOLVING LEAST SQUARES PFOELEMS. PRENTICE-HALL, ENGLEWDOD CLIFFS, N. $\because .1974$

JUHN BOLSTAD COIMPUTER SCIEHCE DEPT. ; SERRA HOUSE STANFCRD UNIVERSITY JANUARY, 1977

DOUELE FRECISION AUNMAX, LPFZ:, BETACL), OLF(NL: TUMAR, IV), $2 W(N), Y(N)$, ACUM, EPS1, GNSTEP, NU, PRJRES: F, RNEIV XHORIA

INTEGER B1, DUTPUT

LOGICAL SKIP

EXTERNAL ADA

DATA EPSI /1. LUEI, ITMAX IEO: DUTPUT :O

THE FOLLOWING TWO PAFAMETERS ARE USED IN THE GQYVESGEHCE.

TEST: EPSI IS AIN ABSOLUTE AINO FELATIVE TOLERANCE FDE THE NORM OF THE PROJECTION DF THE RESIDUAL ORTO THE RANGE OF JACOBIALS OF THE VARIAE!EE PROJECTION FUNCTIOHA- 


$$
\begin{aligned}
& 6 \\
& c \\
& c
\end{aligned}
$$

ITMAX IS THE MAXIMUM NUMBER OF FUNCTION AND CERIVATIVE EVALUATIONS ALLDWED. CAUTION: EPSI IAUST NOT BE SET SMALLER THAN 10 TIMES THE UNIT ROUND-OFF OF THE MACHIM

5
$c$
6
$c$
$c$
$c$
6
6

$$
\begin{aligned}
& \text { IERR }=1 \\
& \text { ITER }=0 \\
& \text { LPI }=L+1 \\
& B I=L+2 \\
& \text { LNLE }=L+N L+2 \\
& \text { NLPI }=\text { NL }+1 \\
& \text { SKIP }=\text {. FALSE. } \\
& \text { MODIT = IPRINT }
\end{aligned}
$$$$
\text { IF IIPRINT. LE O) MODIT = ITHAX + } 2
$$$$
\text { NU }=0 \text {. }
$$

IF GAUSS-NEWTCH IS DESIRED REMOVE THE NEXT STATEMENT. $H L=1$

BEGIN DUTER ITERATION LOOP TO UPDATE ALF. CALCULATE THE NORIM OF THE RESIDUAL AND THE DERIVATIVE THE MODIFIED RESIDUAL THE FIRST TIME, BUT OIULY THE DERIVATIVE IN SURSEQUENT ITERATIONS.

5 CALL DFA $L$, NL, N, NTÁX, LPFE, IV, T, $Y$, W, ALF, ADA, IERR,

X IPRINT, A, BETA, AI1, LFI;, F;

GUSTEP $=1.0$

ITERIN $=0$

IF (ITEF GT O) GO TO 10

IF INL. EQ O) GO TO

IF (IERR IUE 1 ) GO TO 59

IF (IPRINT LE O) GO TO 10

ISRITE IOUTPUT, ZOT: ITERIR, R

WRITE (CUTPUT, DOO) NU

BEGIN TWD-STAGE DRTHOGOMAL FACTDRIZATIE

10 CALL ORFACI (NLPI, NMAX, N, L, IPRINT, A(1, $21 \%$, PFJFES, IERF) IF IIERR . LT. O) GO TO 99 IERF $=\mathrm{e}$

IF (NU. EQ. O.) GO TO 30

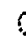

E

C

C

ES CALL DRFACZ(NLP1; NMAX, NU: AI1, B1):

SOLVE A NL X NL UPPER TRIANGULAR SYSTEM FOF DELTA-GLF THE TRANSFORMED RESIDUAL IIN CQL LNLE DF $A:$ IS DVEFWRITTEN BY THE RESULT CIELTA-A!F'

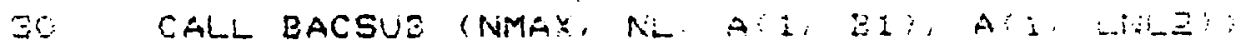


$c$

NORM OF RESIDUAL. NEW ALF IS STORED IN COLUMN B 1 OF

40 CALL DPA (L, NL, N, NMAX, LPP2, IV, T, Y, W, A(I, B1), ADA,

$X$ IEFR, IPRINT, $A$, BETA, A(1, LPI), RINEW;

IF (IERR. NE. 2) GO TO $9 \%$

$I T E R=I T E R+1$

ITERIN $=$ ITERIN + 1

SKIP $=$ MOD IITER. MODIT). NE. O

IF (SKIP) 60 TO 45

WRITE (DUTPUT, 203) ITER

WRITE (OUTPUT, 21E) (A(K, B1), $K=1, N L$ )

WRITE (OUTPUT, 207) ITERIN, RNEW

$c$

45 IF (ITER . LT. ITMAX) GO TO 50

IERR $=-1$

CALL VARERR (IPRINT, IERR, 1)

GO TO 95

SO IF (RNEW - R. LT, EPSI* $(R+1 . D O)$, GO TD 75

C

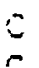

RETRACT THE STEP VUST TAKEH

IF INU NE O. GO TO 00

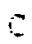

55

5

$=0 \quad+4 !=1.5 * 4 U$

GNSTEP $=0.5 *$ GNSTEP

IF IGNETEF L. EPEZ: GO TO OE

$D=55 \%=i, H$

G.HUSS-INEWTON DPTION DN

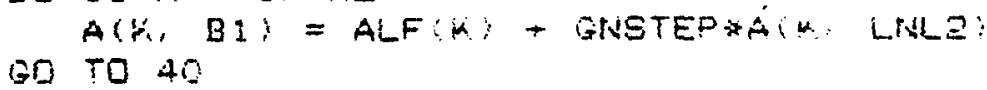

IF (. WOT. SKIP) WRITE (OUTPUT, EQE) NU

IF (NU) LE IOO ) GJ TJ 65

IERT $=-2$

CALL VAREFR IIPRINT, IERF, 1 ;

GD TO 95

6

s.

$\pm 5 \quad 5070 K=1, N L$

$K S \cup B=L P_{1}+K$.

DO $70 J=K$, NLPI

JSUB $=$ LPI $+J$

ISUB $=$ NLPI +1

79

A (F: JSUE) = A ISUE, KSUE:

GD TO 25

$\mathrm{C}$

6

RETRIEVE UPPER TFIATGULAF F AWO RESICUALI DF FIRST ETAGE

ENLARGE THE IMARQUARDT FARAM

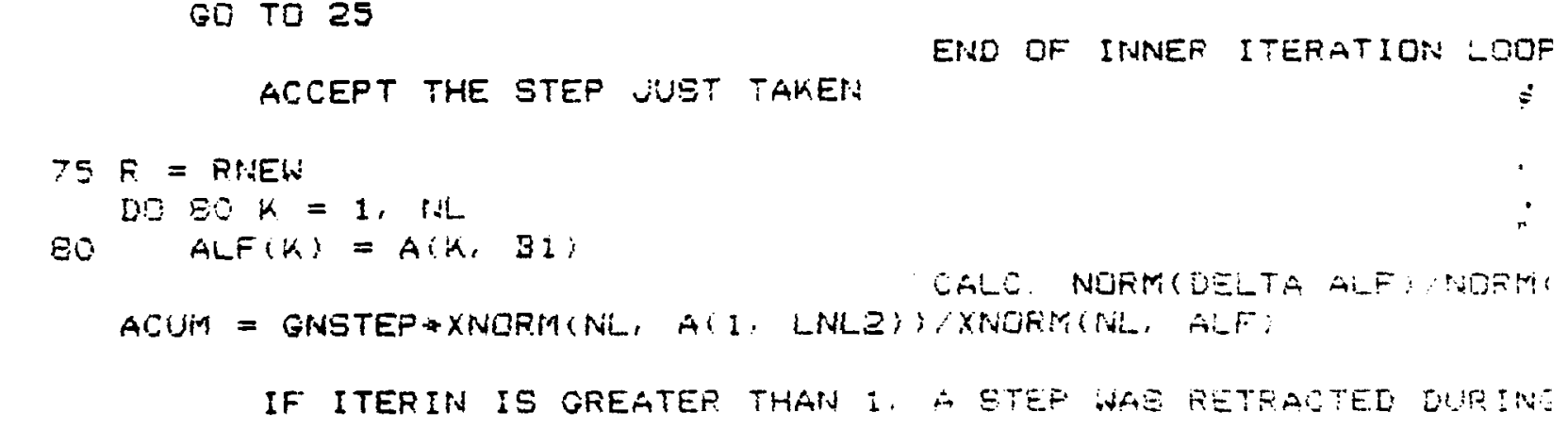

ACCEPT THE STEP VUST TAKEH

IF ITERIN IS GREATEP THATN $i$, SETEF WAE RETRACTED DUR EN: 


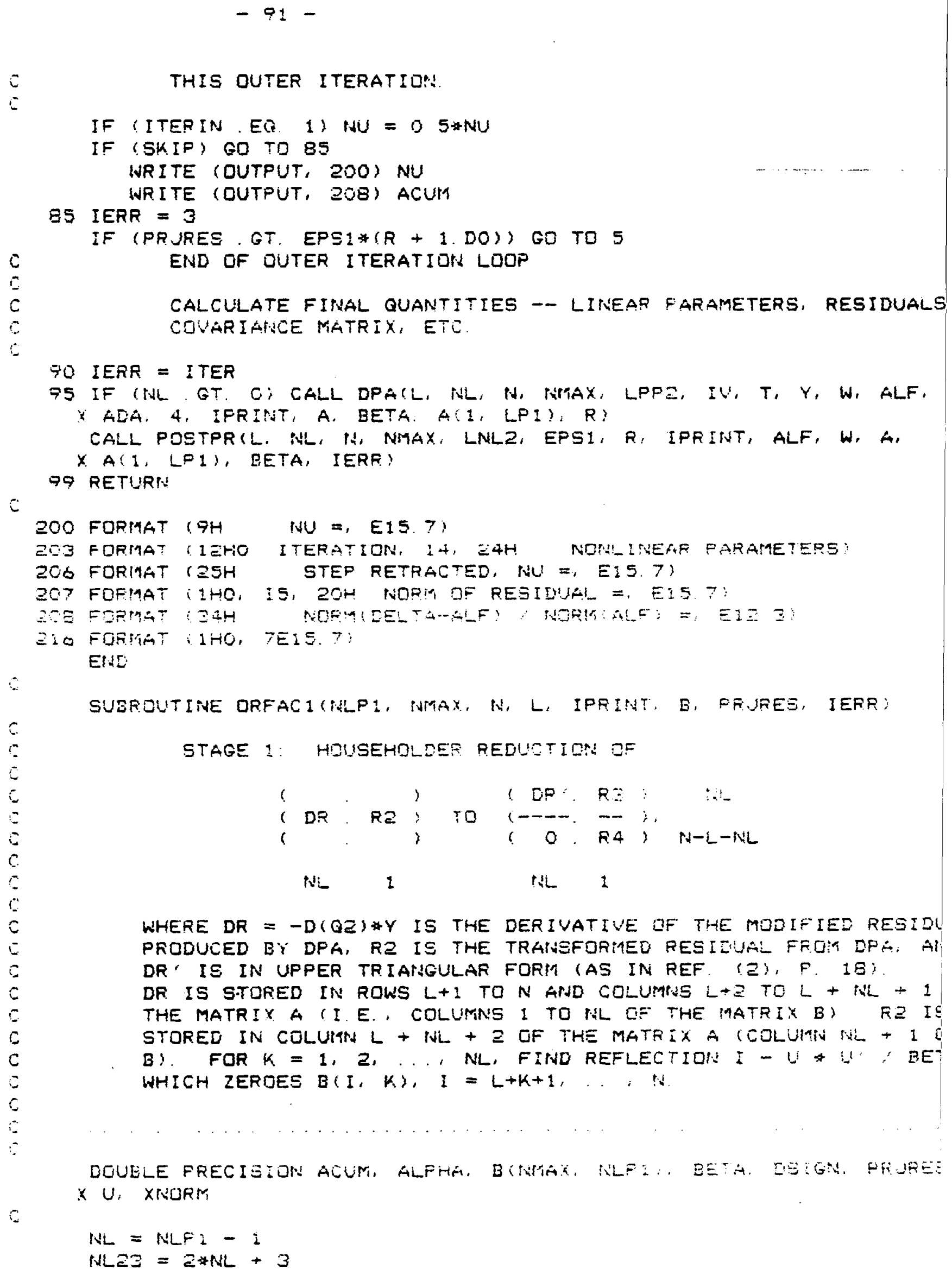

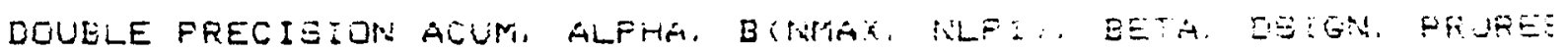
$\times U$, XNORM

$N L=N L F i-i$

$N L a \Xi=2 * N L+3$ 


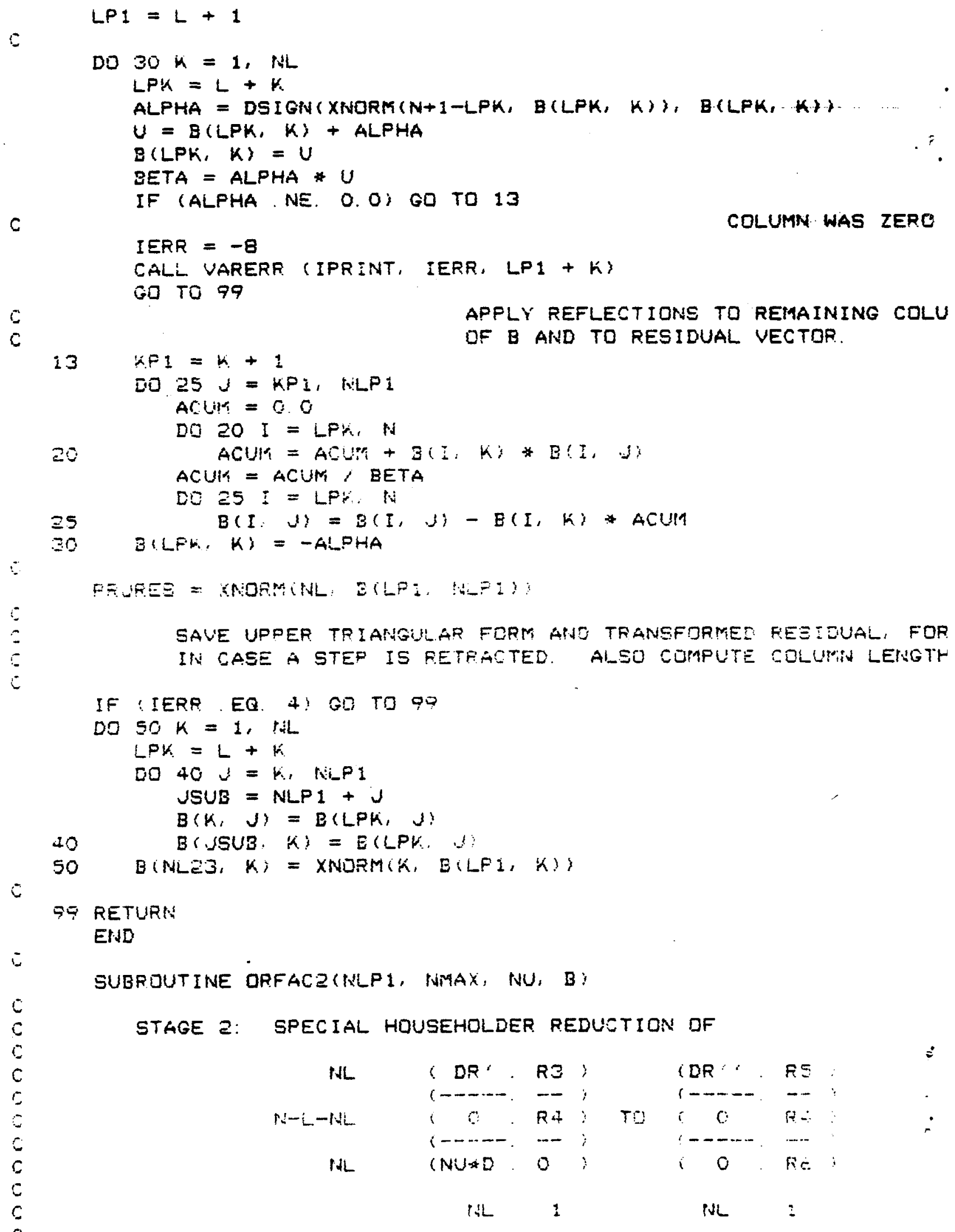

\begin{tabular}{|c|c|c|c|c|c|c|}
\hline \multirow[t]{2}{*}{ NL } & \& DR' & R3 & 3 & & I DR: & F5 \\
\hline & $(-\cdots$ & -- & ; & & $1-\infty--$ & -- \\
\hline \multirow[t]{2}{*}{$r-L-N L$} & $6 \%$ & 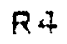 & $\vdots$ & $T S$ & $6 \quad 0$ & fi: \\
\hline & $i--\cdots--$ & -- & $\dot{i}$ & & :- - . & $\cdots$ \\
\hline \multirow[t]{2}{*}{ INL } & $(N U * D$ & 0 & 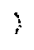 & & $i 0$ & Fe \\
\hline & ISL & 1 & & & NL & 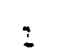 \\
\hline
\end{tabular}


5
$c$
$c$
$c$
$c$
5
5
$c$

WHERE DR', R3, AND R4 ARE AS IN DRFACI, NU IS THE MARQUARDT PARAIAETER, D IS A DIAGOINAL MATRIX CONSISTING OF THE LENGTHS D THE COLUMNS OF DR', AND OR'" IS IN UPPER TRIANGULAR FORM. DETAILS IN (1), PP. 423-424. NOTE THAT THE (N-L-NL) BAND OF ZEROES, AND R4, ARE OMITTED IN STORAGE.

DOUBLE PRECISION ACUM, ALPHA, B(NMAX, NLP1), BETA, DSIGN, NU, U, $c$ $\times$ XNORM

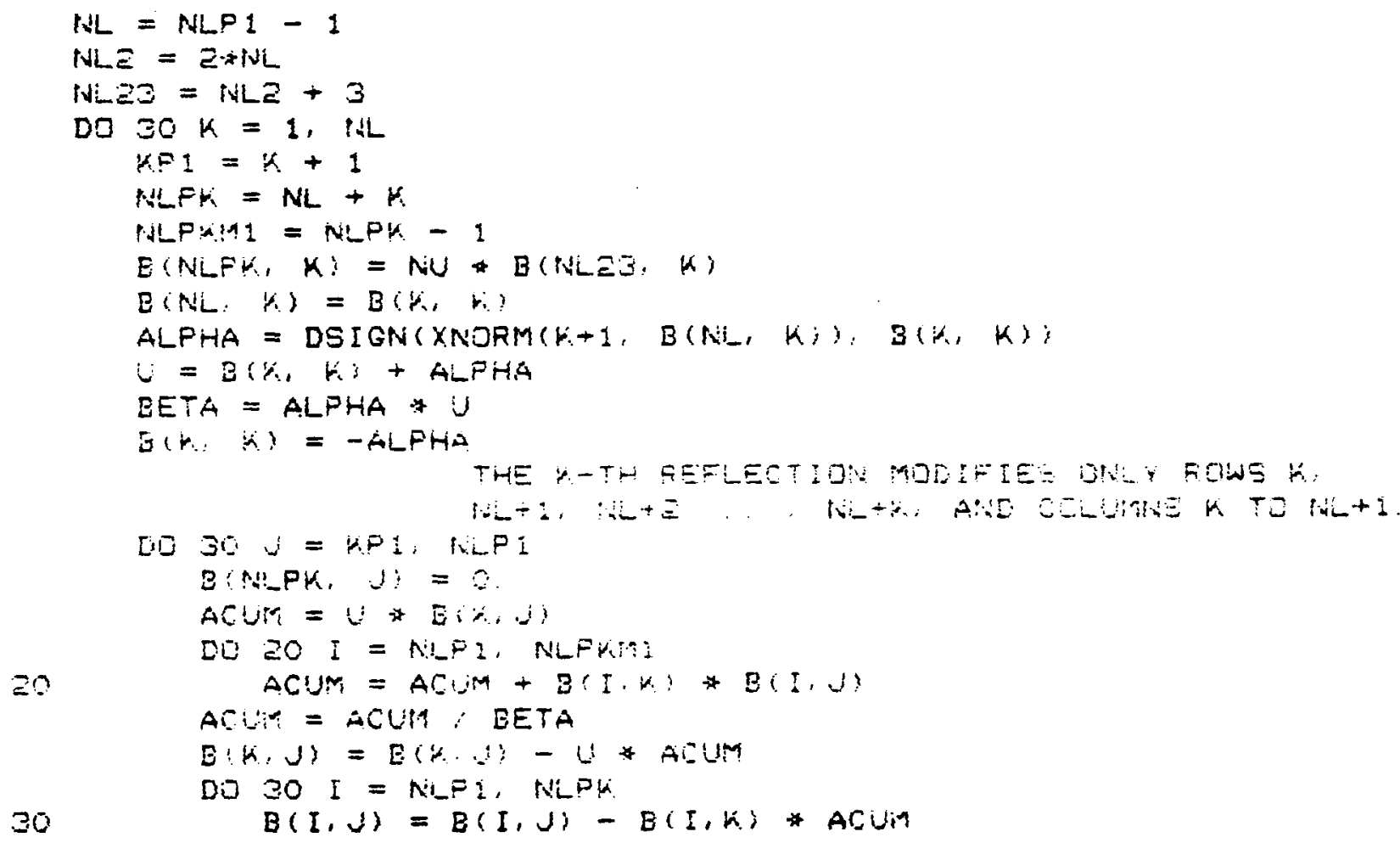

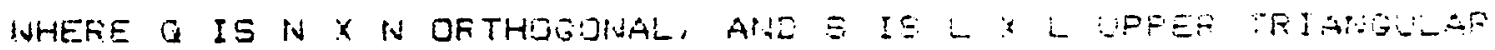

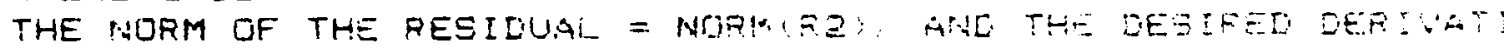




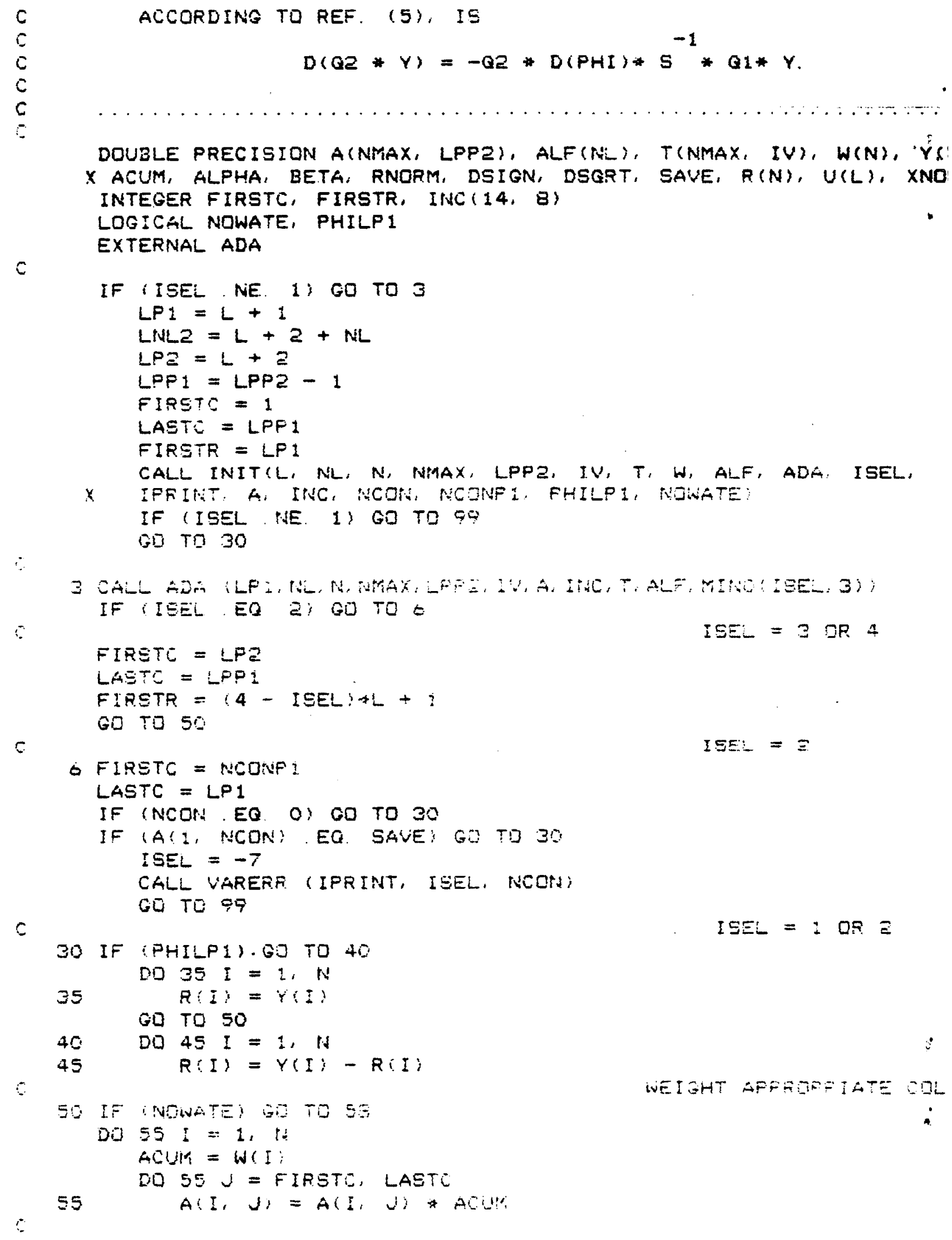


COMPUTE ORTHOGONAL FACTDRIZATIONS BY HOUSEHOLDEE

REFLECTIONS. IF ISEL $=1$ OR 2 , REDUCE PHI CSTORED IN THE FIRST L COLUM:NS OF THE MATRIX A) TO UPFER TRIANGULAR FORM, ( $Q * P H I=S$ ), AND TRANSFORM Y (STOREE IN CDLUMN L+ 1 ), GETTING $Q * Y=R$. IF ISEL $=1$. ALSO TRANSFORM $J=D$ PHI ISTORED IN COLUMNS $L+2$ THROUGH $L+P+1$ OF THE MATRIX AI, GETTING $Q * J=F$. IF ISEL $=3$ QR 4, PHI HAS ALREADY BEEI\& REDUCED, TRANSFDRM OIVY $Y$ J. $S$, $R$, AND F OVERIVRITE PHI, $Y$, AND $J$, RESPECTIVELY, AIND A FACTORED FORM DF $Q$ IS SAVED IN $U$ AIND THE LOWER TRIANGLE OF PHI.

SB IF (L.EQ. O) GO TO 75

DO $70 K=1$, L

$K P_{1}=K+1$

IF (ISEL GE. 3 . OR. (ISEL . EQ. 2 . ARD. K. LT. NCONP 1) GO TO GE

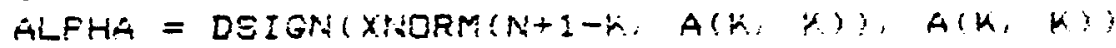

$U(K)=A(K, K)+A L P H A$

$A(K, K)=-A L P H A$

FIRSTC $=K P 1$

IF SALPHA NE. O. O; GO TO DE

ISEL $=-B$

CALL VAREFF IIFFINT, ISEL. K:

GI TO 99

S

\section{$=0$}

BET = -A R R

ED $\because G U=$ FIFETS: LASTS

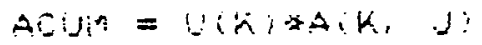

DO $6 B I=K F 1, N$

EE ACUR = ACUH + AII, HAOH, Xi

APPLY FEFLEOTIONS TO COLUMHS FIFETE TE :-DET:

ACUI = ACUH : EETA

$A(k, J)=A(A, i)-U(B) * A C U M$

70

DI $70 I=K F_{i} ; \quad$ P

$c$

TS IF (ISEL . GE 3) GO TO ES

RHORM $=$ XNORTIN-L, R(LPI):

IF (ISEL .EQ Z) GO TO 99

IF (NCDN . GT. O) SAVE = A 1 , NCOT:

6
6
6

Fe IS NOW CONTAINED IN RONE LT1 TO MA ANO GOLUMIE L+E TO

$L+P+1$ OF THE MATRIX A NOW SOLVE THE $L X L$ UPPER FFIANGULA SYSTEM $S * B E T A=R I$ FOR THE LIMEAR FAFAMETERS BETA. BETA OVEFWRITES R:.

ES IF (L GT. Q) CALL 3ACSUE (HMAX, L, A, R)

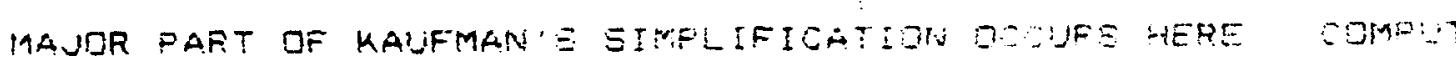

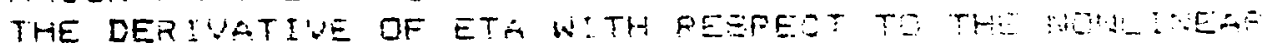
PARAMETERS

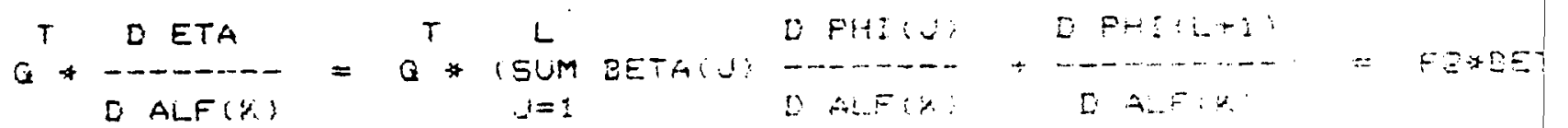


$c$
$c$
$c$
$c$
$c$

AND STORE THE RESULT IN COLUMNS $L+2$ TO $L+N L+1$. IF ISEL NC $=4$, THE FIRST L ROWS ARE OMITTED. THIS IS -D(GR)*Y. IF ISEL NOT $=4$ THE RESIDUAL RZ = QZ*Y (IN COL. L+I) IS COPIE TO COLUMN L+NL+2. OTHERWISE ALL OF COLUMN L+1 IS COPIED.

DO 95 I = FIRSTR, $N$

IF (L. EQ. NCON) GO TO 93

$M=L P 1$

$D O 90 K=1, N L$

$A C U M=0$.

DO $8 B J=$ NCONP 1, L

IF (INCKK, Ji EQ. O; GO TO BB

$M=M+1$

$A C U M=A C U M+A(I, 14) *$ Ri J)

88 CONTIRUE

$K S U B=L P I+K$

IF (INEIK, LPI) . EO. O) GO TO 90

$M=M+1$

ACUIT $=$ ACUM + ACI, IS

$90 \quad A(I, K S U B)=A C U / 1$

$c$

95 AII, LPLE) = RII:

9T RETURN

E!d:

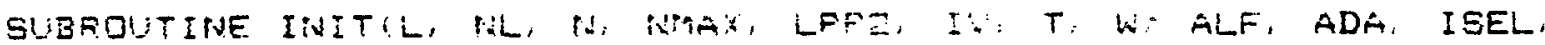

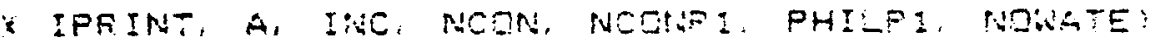

8

GHECK VALIDITY OF INPUT FARAMETEFS: ANE DETERMINE WUMEER OF CONSTANT FUNCTIONS

DOUBLE PRECISION AINMAX, LPPZ:, ALF(NL: TINMAX, IV), W(N):

\section{$\times$ DSQRT}

INTEGES OUTPIST, P, INCI:4, OY

LOGICAL NOWATE, PHILFI

DATA DUTPUT IÉ

6

$L P 1=L+1$

LNLE $=L+2 \cdot+N L$

5

CHECH. FOR JALID INRUT

IF IL GE $O$. AND. NL GE $O$ arSD LOML LT M. AND LNEE LE.

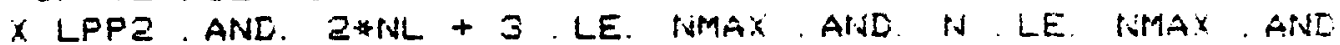

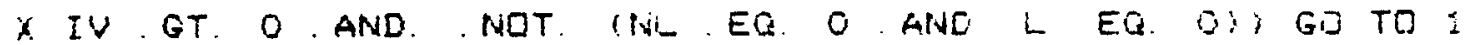

ISEL $=-4$

CALL VARERE IIPRINT, ISEL, I;

GO TO 99

1 IF IL. EQ. O. DR. NL EQ. O, GO TO

LO $2 J=1$. LPI

2

LO $2 k=1, k L$

a $\operatorname{INC}(k, J)=0$ 


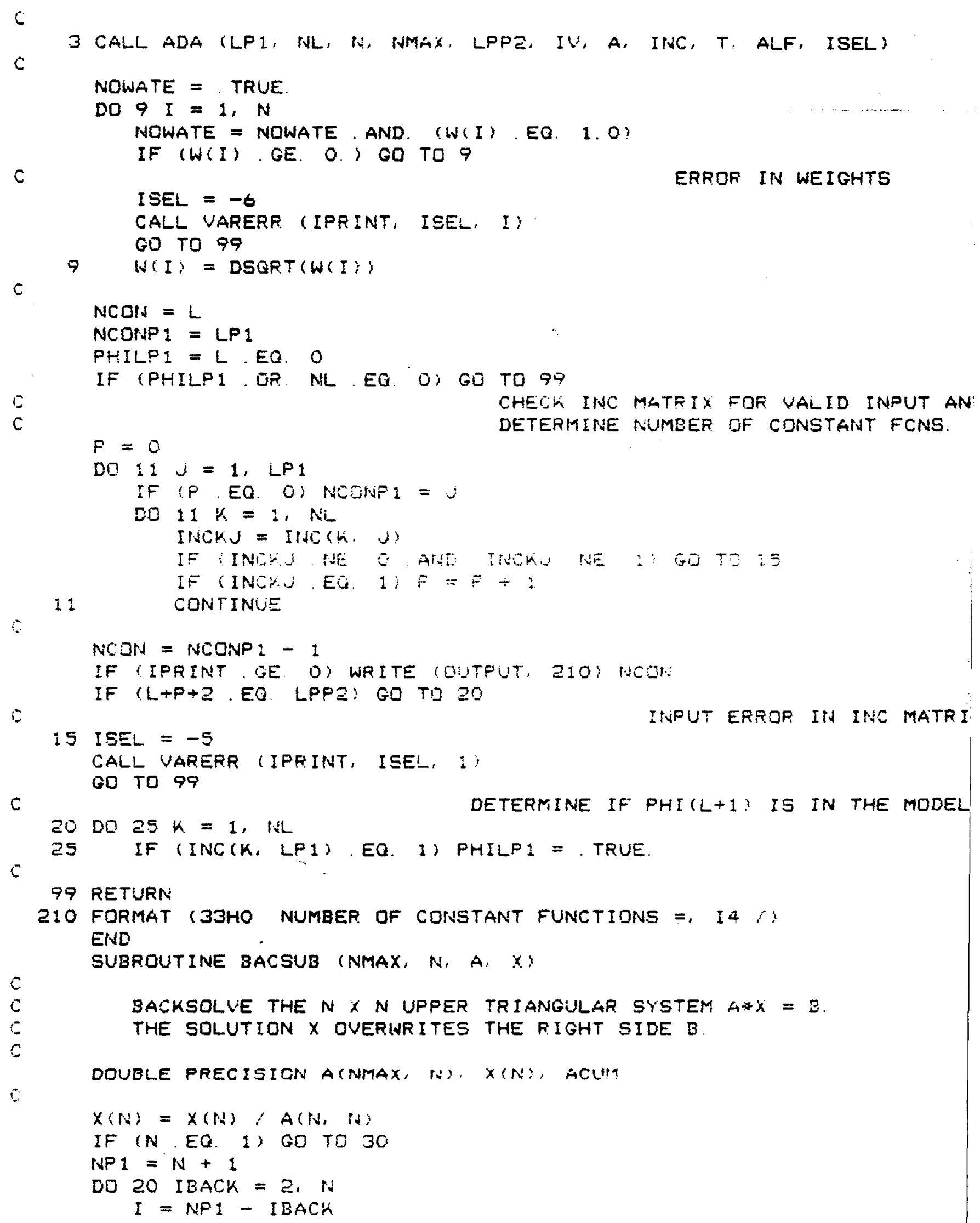




$$
\begin{aligned}
& I=N-1, N-2, \ldots, 2,1 \\
& I P I=I+1 \\
& \text { ACUH }=X(I) \\
& \text { DO } 10 J=I P 1, N \\
& \text { ACUM }=\text { ACUH }-A(I, J) * X(J)
\end{aligned}
$$

10

C

20

30 RETURN

END

SUBROUTINE POSTPRCL, NL, N, NMAX, LNL2, EPS, RNDRM, IPRINT, ALF,

c

C

c

C

$c$

C

$X W ， A ， R, U$, IERR )

CALCULATE RESIDUALS, SAMPLE VARIANCE, AND COVARIANCE MATRIX. ON INPUT, U CONTAINS INFORMATION ABOUT HOUSEHOLEER REFLECTION FROM DPA. ON OUTPUT, IT CONTAINS THE LINEAR PARAMETERS.

DOUBLE PRECISION ACNMAX, LNL2), ALF(NL), R(N), U(L), W(N), ACUM, $X$ EPS, PRJAES, RNORM, SAVE, DAES

INTEGER DUTPUT

DATA DUTPUT IGI

$L P I=L+1$

LPNL $=$ LNLE - 2

LNLS = LPHL + 1

Di] is $I=1, i \alpha$

$10 \quad, 4(I)=W(I) * 2$

5

C

25

IF IL EQ. O) GO TO 30 .

DO $25 \mathrm{KBACK}:=1, L$

$K=L P 1-K B A C K$

$K P 1=K+1$

$A C U M=0$.

DO $20 I=K P 1, N$

20

$$
A C U M=A C U M+A(I, K) * R(I)
$$

SAVE $=R(K)$

$R(K)=A C U M / A(K, K)$

$A C U M=-A C U M,(U(K) * A(K, K))$

$U(K)=$ SAVE

$0025 I=. K P 1, N$

30 ACUM $=0$.

$D O 35 I=1, N$

35

$A C U M=A C U M+R(I)$

SAVE $=$ ACUM $/ \mathrm{N}$

THE FIRST L COLUMTS JF THE MATFIX HAVE EEEN SEDUEEE TS UPPEF TRIANGULAR FORM IN DPA. FINISH EY REDUCING ROWS $L+1$ TO $N$ AND COLUIINS L+2 THPOUGH L+NL+1 TO TF. IANGULAR FERM. THEIN SHIFT COLUMNE OF DERIVATIVE MATFIX OVER GTHE TO THE LEFT TO BE AOJACENT TO THE FIEST L COLUMNS 
$c$

IF (NL. EQ. O) GD TO 45

CALL ORFACI $I N L+1$, NMAX, $N, L$, IPRINT, $A(1, L+2)$, PRJRES, 4)

DO $40 I=1$. $N$

$A(I, L N L 2)=R(I)$

DO $40 K=$ LP1, LNLI

C

40

$$
A(I, K)=A(I, K+1)
$$

$45 A(1, L N L 2)=R N O R M$

ACUM = RNORM*RNORM/(N - L. - NL)

$A(2, L N L 2)=A C U M$

CALL COVINMAX, LPNL, ACUM, A)

C

IF (IPRINT. LT. O) GO TO 99

WRITE (DUTPUT, 209)

IF (L. GT. O) WRITE (OUTPUT, 210$)(U S U), J=1, L$ )

IF (NL . GT. O) WRITE (OUTPUT, 211 ) (ALF $K$ ), $K=1$, $\mathrm{HL}$ )

WFITE (DUTPUT, 214) RNORM, SAVE, ACUM

IF (DABS (SAVE) GT, EPS) WRITE (GUTPUT, 215:

WRITE (QUTPUT, 209)

C

97 RETURN

COMPUTE COVARIANCE MATRI

209 FCRMAT (1HO, 5O(1H')

210 FORMAT (ZOHO . LINEAF PARAMETERS // (7E:5. 7);

EI FUTHAT IZ3HO MONLINEAR PARAMETERS $/ \%$ IVEIS.7;:

2:4 FORIAAT (2IHO NORM OF RESIDUAL $=1$ E15.7, 33H EXFECTED ERRDR OF DI XERUATIONS $=$, E15.7, $39 H$ ESTIMATED VIAFIANCE OF OESERVATIONS $=$, $\times$ E15.7

2:5 FORMAT (95H WARNING - EXPECTED ERFER OF ORSEFVATIONS IS WOT ZEF

$x$. COUARIANCE MATRIX MAY bE MEANINGLESS.;) ENSD

SUBROUTINE COUINMAX, N, SIGMAE, A?

$c$
$c$
$c$
$c$
$b$
$c$
$c$
$c$
$c$
$c$
$c$
$C$
$c$
$C$

COMPUTE THE SCALEd COVARIANCE MatriX af THE L - Ki PARAMETERS. THIS INVOLVES COMPUTING

$$
\operatorname{SIGMA} * T^{-1} * T^{-T}
$$

WHERE THE (L+NL) X (L+TL) UPPER TRIARGULAR MATRIX I IS DESCRIBED IN SUBROUTINE POSTPR. THE RESULT OVERWRITES THE FIRST L+NL ROWS AND COLUMNS OF THE MRTRIX A. THE RESULTING MATRIX IS SYMMETRIC. SEE REF. 7, PF. 67-70, כE 1

DOUBLE PRECISION AINMAX, N, SUM, SIGTIAE

$c$

$\mathrm{C}$

10

DO $10,1=1,1$

$A(J, J)=1 \cdot \operatorname{ta}(J, J)$

INVERT T UPON ITSELF

IF (N EQ. 1) GO TO 70 


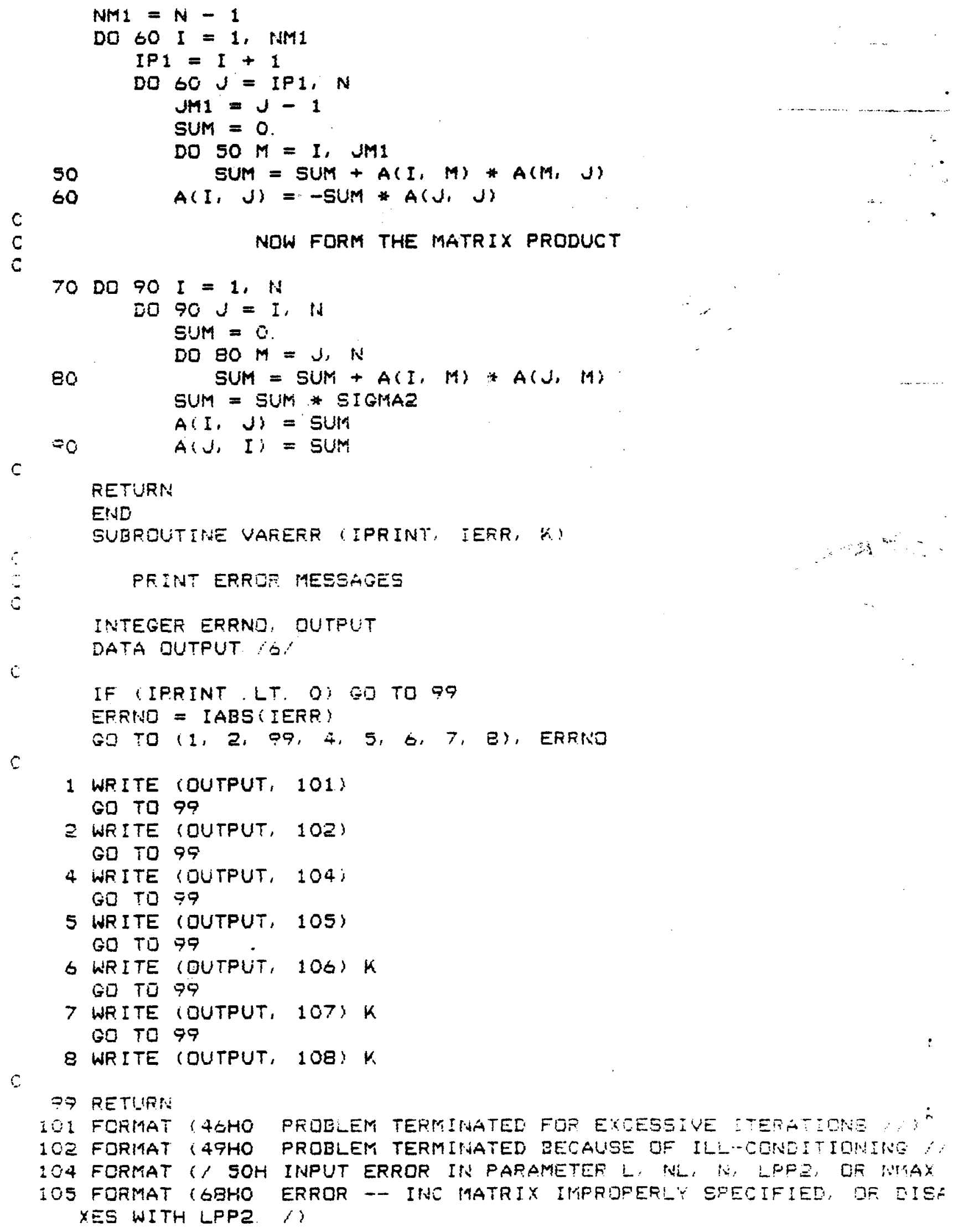




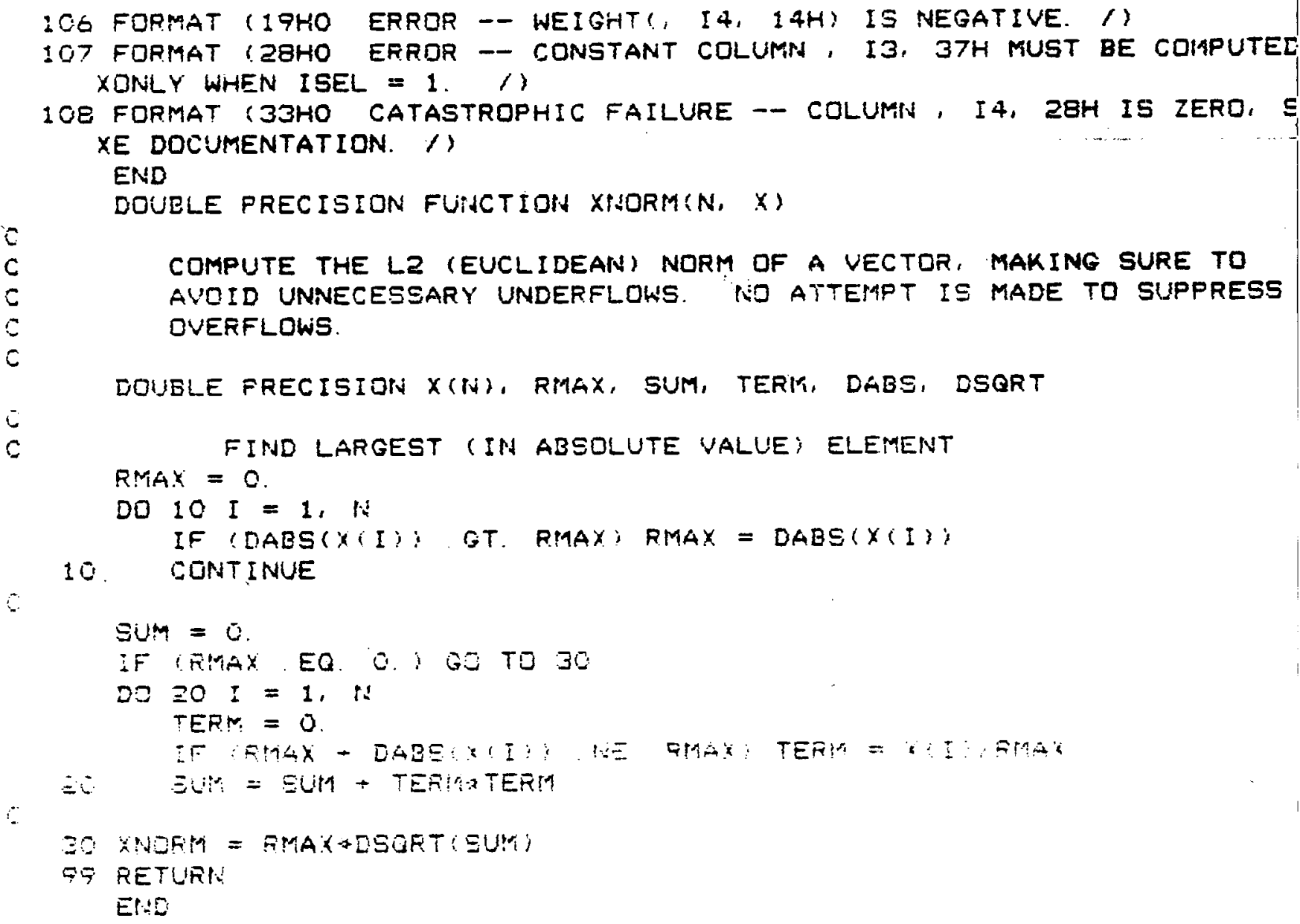

